\title{
بحثبنوان
}

دورالمراجيج الخارجيقفتلنيةفجوةالثقةفىييئة

التجارة|الاكترونية- معدراسة|إسكشافية

\author{
مقلمم من

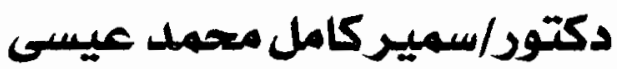 \\ كلية التجـارة - جامعة الإسكندرية
}




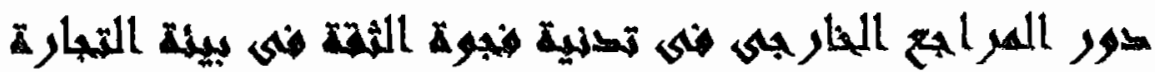

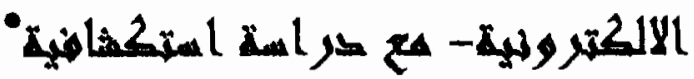

جاءت شبكة المعلومنت الدولية ولثدة لتمنية الحاسبات والآتصال غن بعد، وجاعت التجارة

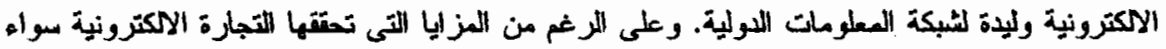

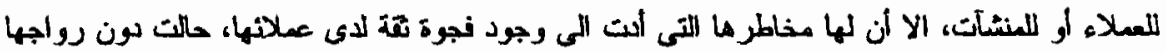
بالقعر الأى تستحقه. وأدراكا من معهدى المحامبين القانونيين الأمريكى والكندى (AICPA/CICA)

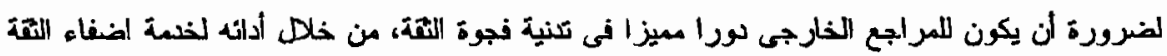

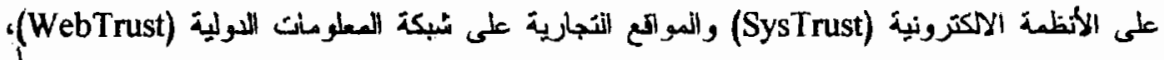
الصدر مجموعة من المباديه والمهايير التى ينبغى على المراجع الالتزام بها عند أداثه لهذه الخماتك.

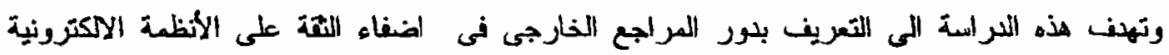

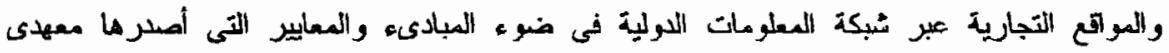
السحاسيين التانونيين الأمريكى والكندى، ونلك كمساهمة منه فى تلنية فجوة التقة فى بيئة التجارة

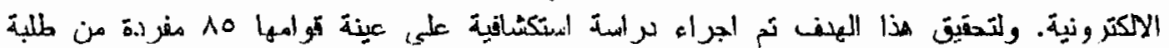

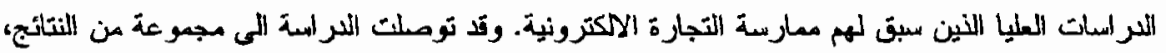

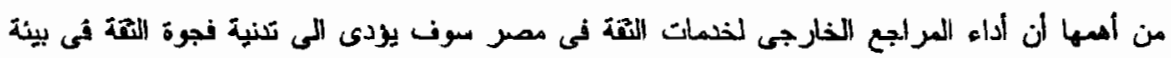

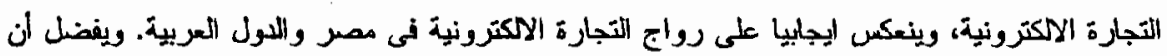

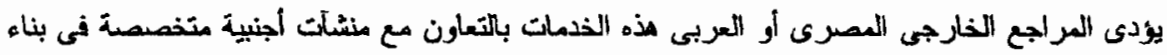

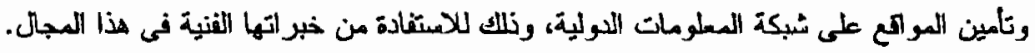

\section{1- مقدمة}

أدى التطور الهائل فى تقنية المعلومات والاتصال عن بعد إلى

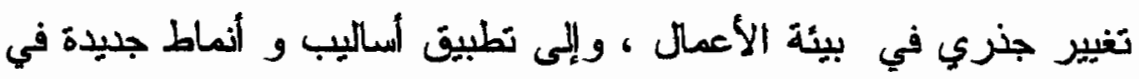

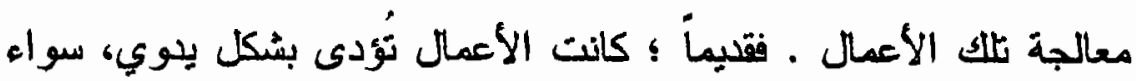

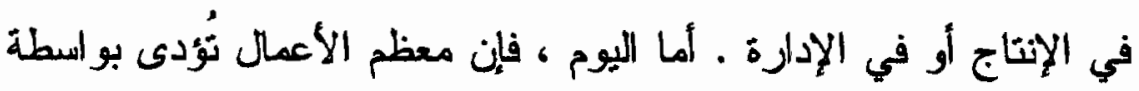

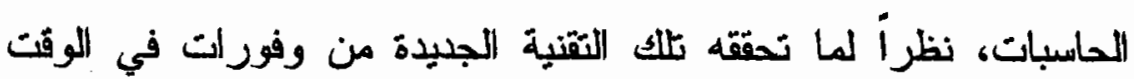

• ككتر / سمير كامل محمد عيعى، استاذ المحاسبة و المر اجعة المساعد، كلية التجارة -- جامعة الاسكندرية. 
والجهد والتكلفة، ولأهمبتها وتقها في إنجاز الأعمال. أضف الى نلك أن

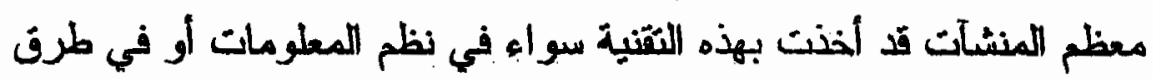

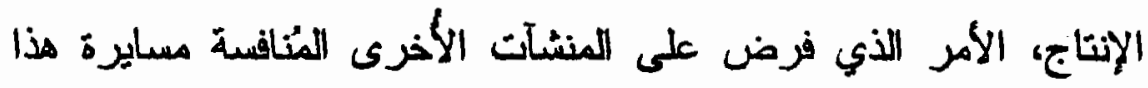

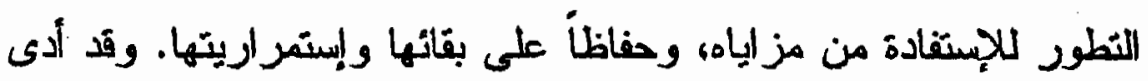

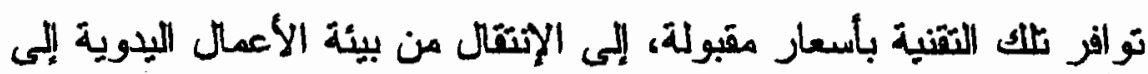
بيئة الأعمال الإكترونية.

وتختف بيئة الأعمل الإكترونية عن بيئة الأعمال الينوية فيما

يلي: Conviser 2004)

1- فهل المهام.

r- إختاء المر اجعة المستثدية .

r- العد من الأخطاء الكتابية ، وإحتمال زيادة الأخطاء المنطقية

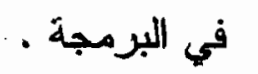

ع- تتفيذ ومتابعة العمليات بواسطة الحاسب الآلي ، ودون أي

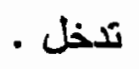

0- إحتمال زيادة المخاطر الناتجة عن الإختراقلت، وزيادة الأعمال الغير شرعية.

7-وجود اجراءات رقابية مبرمجة بالاضافة الى الاجراءات

الرقابية اليدوبة.

ע- إختلاف أدوات الرقابة المستخدمة فى البيئتين.

وقد ازداست فعالية بيئة الأعمال الإكترونية وأهميتها ، خاصةً بعد

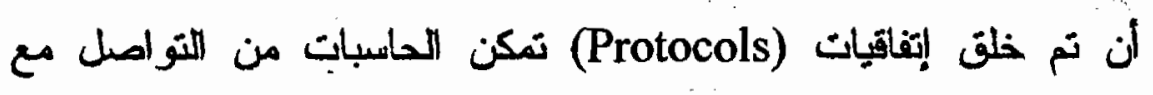

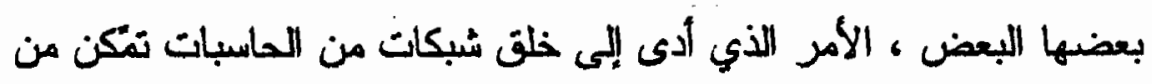
تبانل البيانات فيما بيذها بسر عة ورقة ضمن الأشبكة الوالحدة ـ و وأدى إتصلال 
الشبكات ببعضها البعض عن طريف مقّوي (Repeater) أو مقَوي

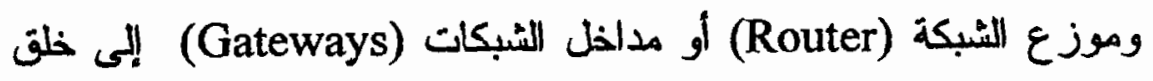

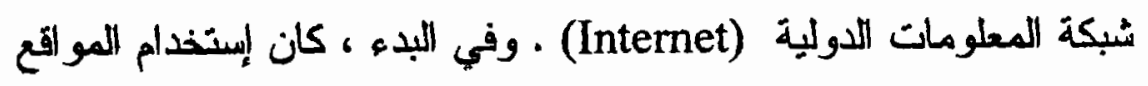

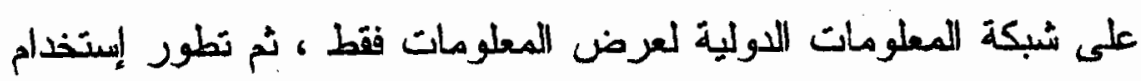
تلاك المواقع إلى أن أمبحت ومنذ بداية السبعينات تثوم بكامل الأعمال التجارية ، بدء' من عرض العلع والخدات وروصو لاً إلى بيعها وتحصيل

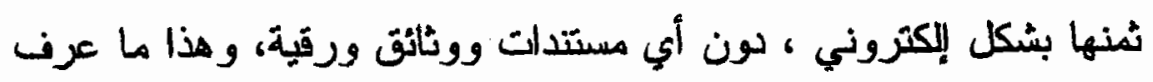
بالتجارة الإلكترونية.

وبعنى ما سبق حرث أمرين هامين : أولأ تطور الأعمال من يدوية إلى إلكترونية، كنيجة لاستخدام الأنظمة الالكترونية. وثئليا نطور

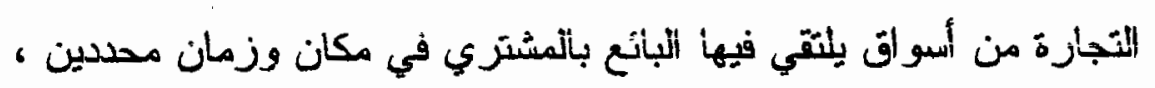

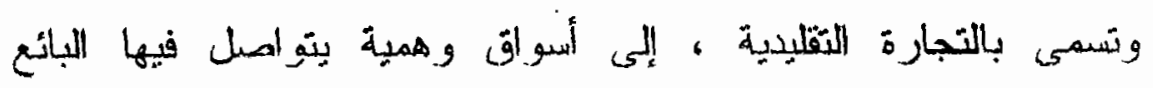

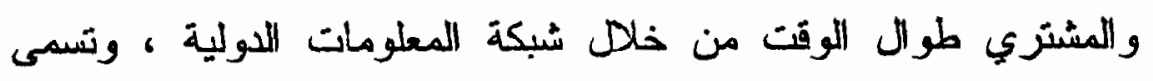
بالتجارة الإكترونية .

\section{مغهوم الأنطمة الإكترونية}

لا تختلف هذه الأنظمة عن الأنظمة اليدوية ، إلا من خله آلية

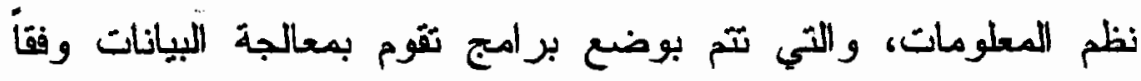

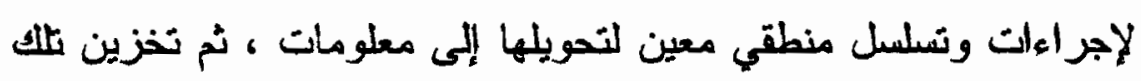

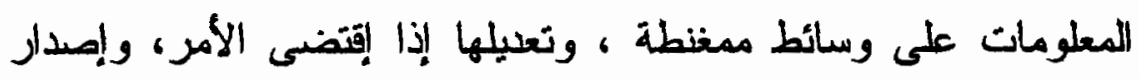

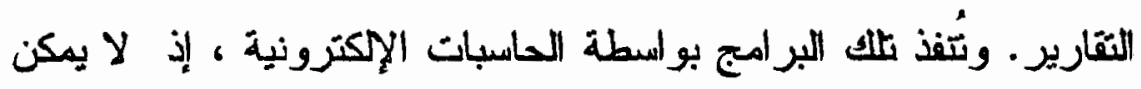

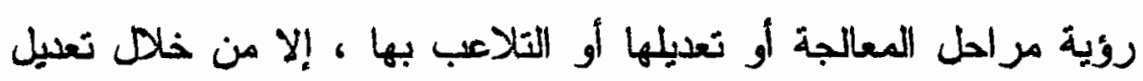

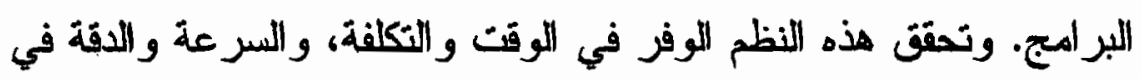


معالجة وتخزين واستدعاء البيانات، إضافةً إلى إختقاء الأخطاء الروتينية .

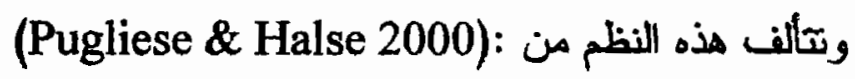

- البنية التحتية: مثل الأجهزة (Hardware) والتسهيلات اللازمة.

- البرامج: وتتضمن نظم التشيغيل ، برامج المنفعة، البرامج

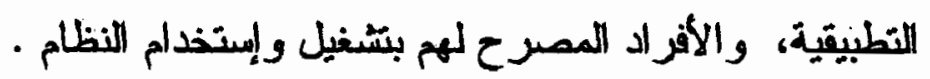

- الإجراءات: وتتضمن اجراءات ادخال وتشغيل البيانات، تخزينها، استذعاتها، تحسئها، وصيانة نظام المعلومات. - البيانات التي يستخهما النظام في انتاج المخرجات. مفهوم التجارة الإكترونية

يعتبـر ممارســة الأعــال التجارية من خلال شبكة المعلومات الدولـية من الظواهر الحيثة فى عالم الإقتصاد والتجارة، حيث مكنت هذه

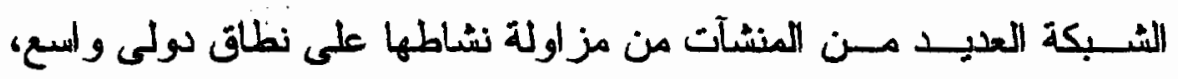

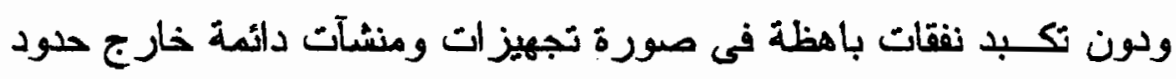

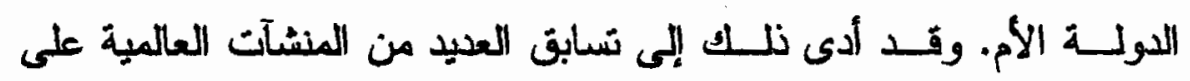

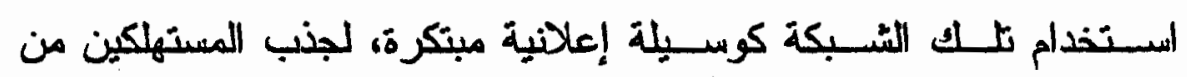
مستخدميها فى جميع أنحاء العالم لترويج التجارة الإكترونية.

وقد تعدنت تعريفات التجارة الإكترونية، ولعل من أهمها نعريف

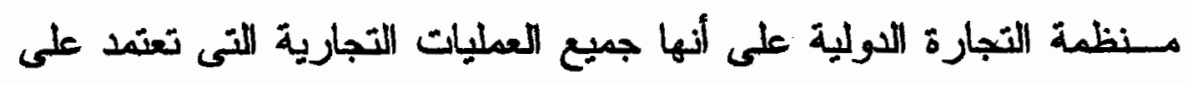

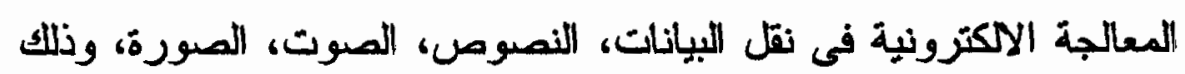


باستخدام العديد من التقنيات منل التبادل الاككترونى للبيانات (EDI)، اجهزة

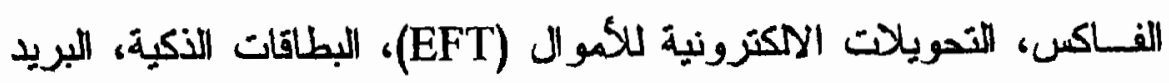

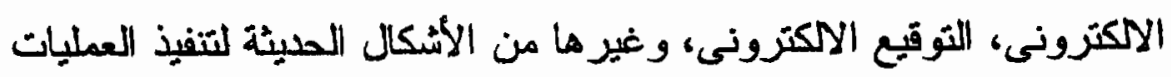
التجارية (Primoff 1998).

ويتضح من هذا التعريف مدى إتساع وأهمية التجارة الإكترونية،

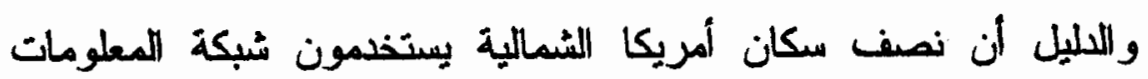

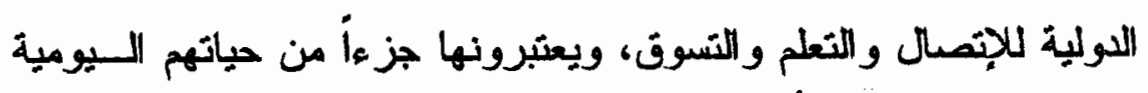

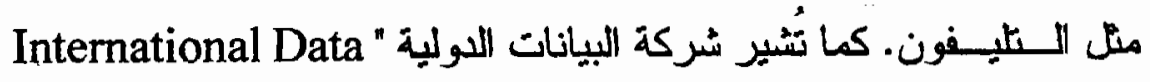
Corporation

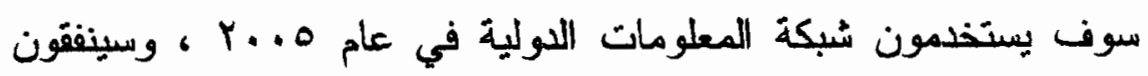

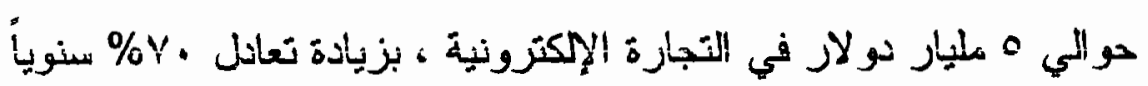

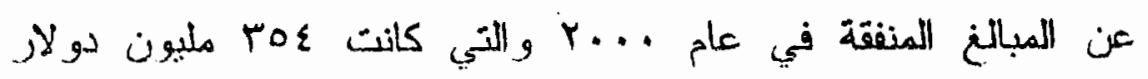
.(Sivasailam et al 2002)

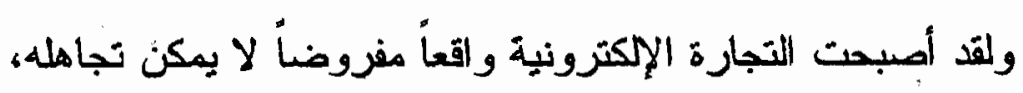

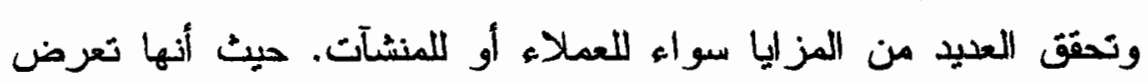

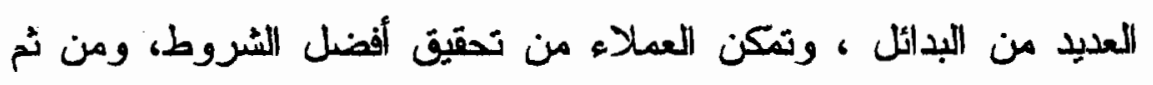
فانها تحقن ميزة تتافسية لا بمكن إغفالها بل يجب الاستفادة منها.

إن المميزات والتشهيلات التي تقدمها الأنظمة الالكترونية بصفة

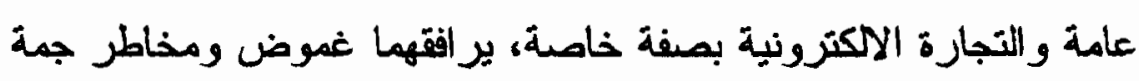
مثل الأمن، الخصوصية ، ومدى قرة تالك الأنظمة على تلبية الحتياجات

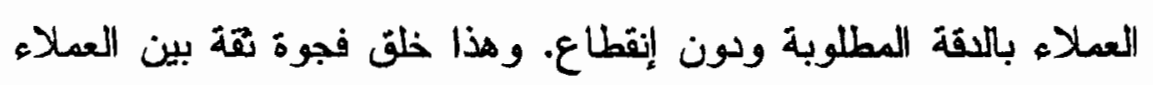

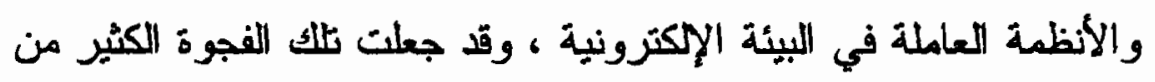

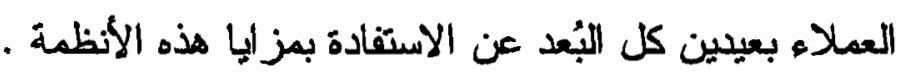




\section{فجوة الثقة}

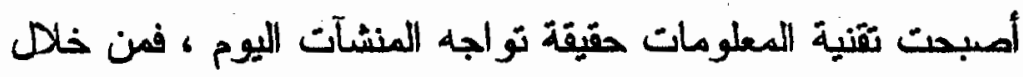

نظم المعلومات الالكترونية بتم تشغيل العديد من التطبيقات المحاسيية

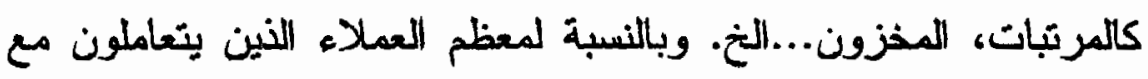

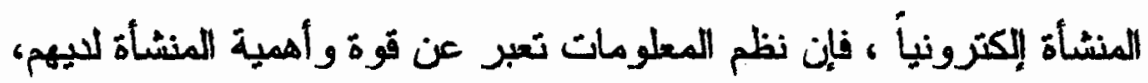

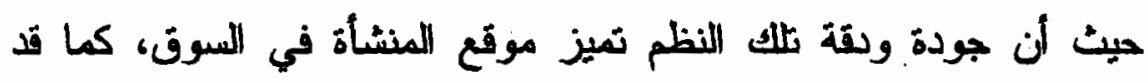

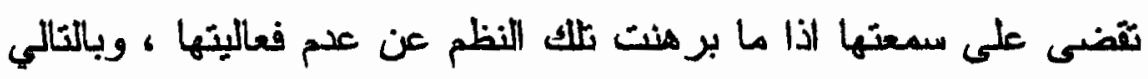
ضعف إمكانية الإعثماد عليها .

ولقد أصبح كل من المنشآت والأفراد بدرك تماماً مدى أهمية

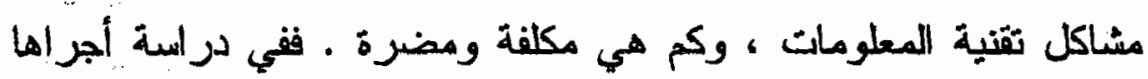

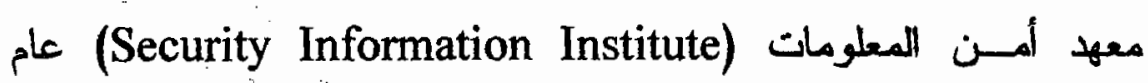

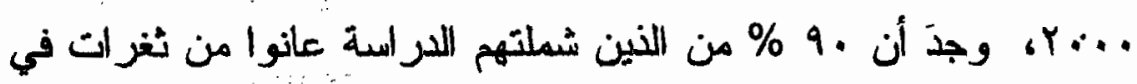

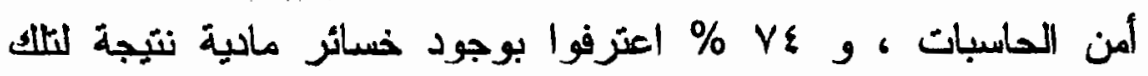

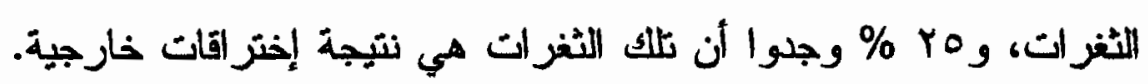

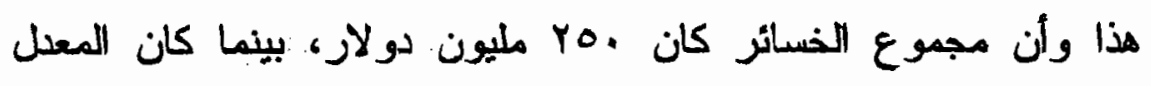

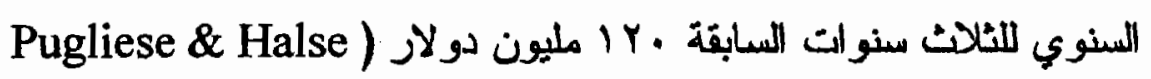

. 2000

وقد خلقت مشاكل تقنية المعلومات فجوة نقة بين العملاء وبيئة

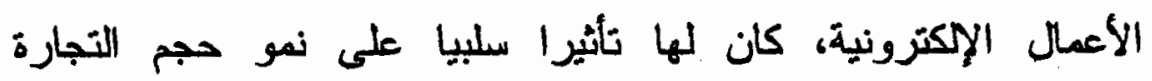

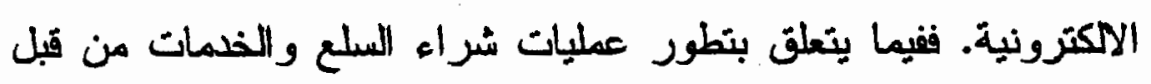

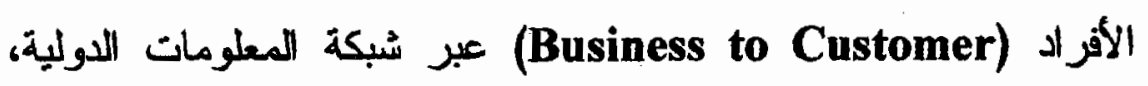
على مستوى العالم فإن هناك زيادة فى تلك العمليات ولكن بنسب منففضة

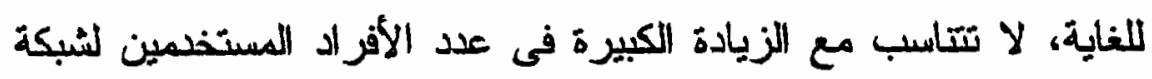


المعلومات الدولية (Primoff 1998). حيث تشير العليد من الدراسات

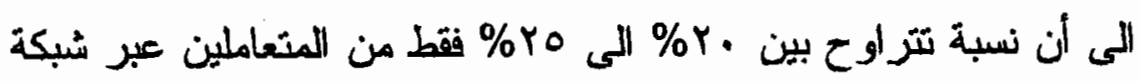

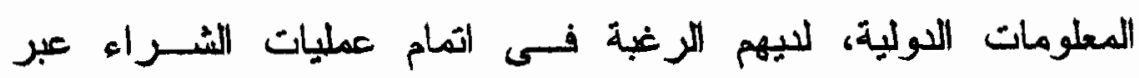
الثـبكة (Anderson 1999).

ويرجع السبب في نلك إلى أن غالبية الأفراد يمارسون التجارة

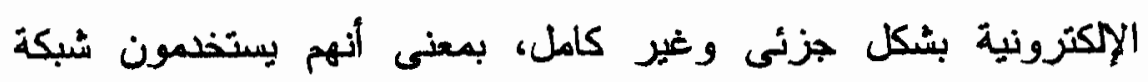

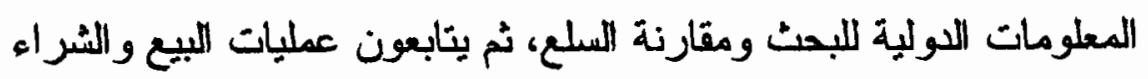

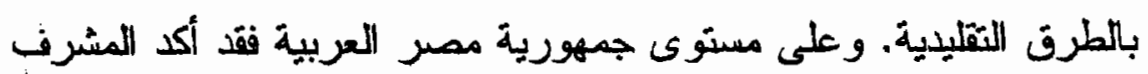

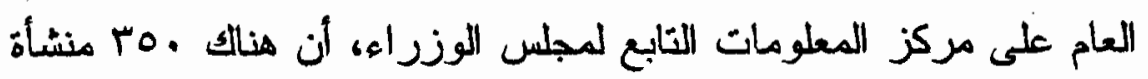

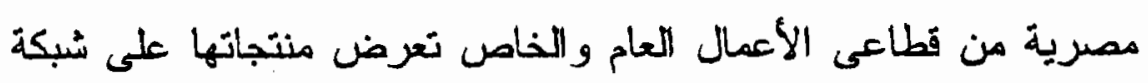

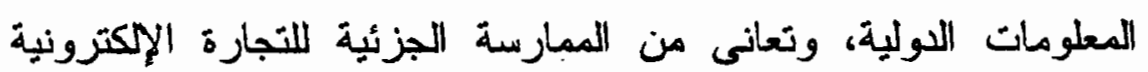
(رحنوان (1999).

هذا ويرجع السبب الحقيقى للممارسة الجزئية للتجارة الإلكترونية،

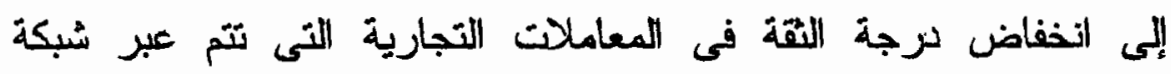

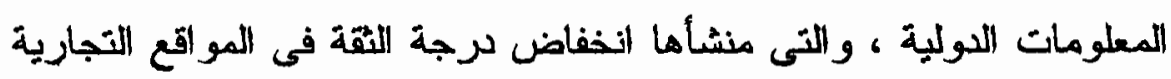

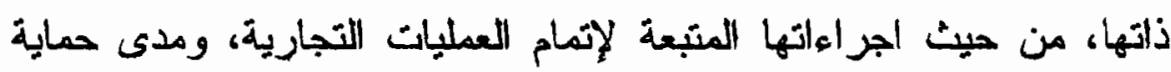
المعلومات الخاصة بالعملاء واحترام خصوصيتها (Cohn 2001).

وحتى عام 1999 أصبح 9r9\% من المنازل فى اللولايات المتحدة

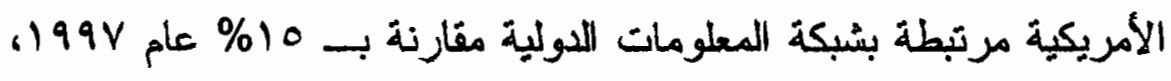

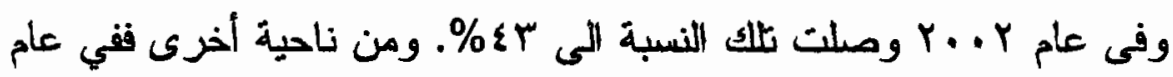

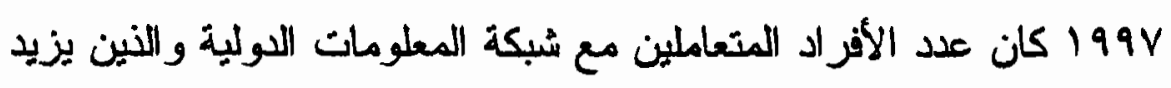

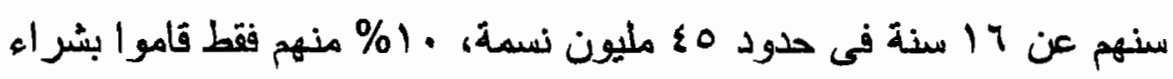

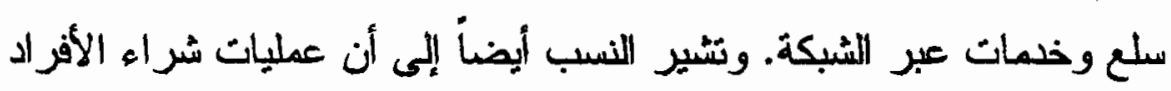


للسلع والخدمات عبر شبكة المعلومات اللدولية قد زادت فى حدود بv مليار

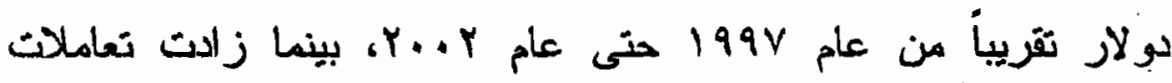
المنثآت التجارية مع بعضها البعض عبر شئر شيكة المعلومات الدولية بمقدار واب مليار دولار تقريباً خلالم نفس الفترة (Sivasailam et al 2002).

وقد أوضحت براسة أجر اها معهد المداسبين القانونيين الأمريكى

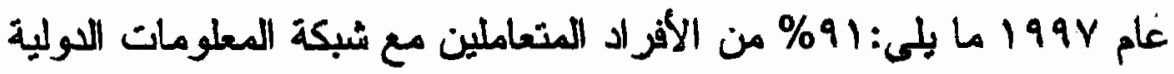

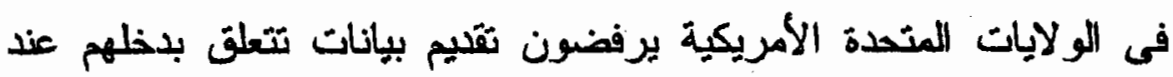

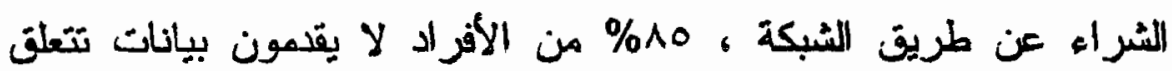

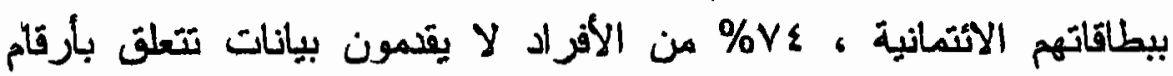

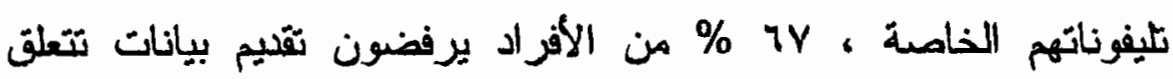
بعناوينهم المنزلية أو الخاصة بالعمل (Anderson 1999).

وفى احصائية منشورة لجمعية حماية المستهلك فى الولايات

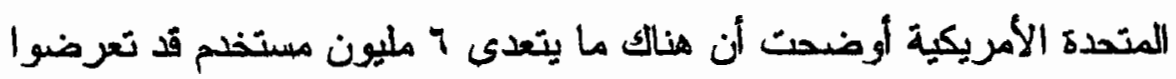

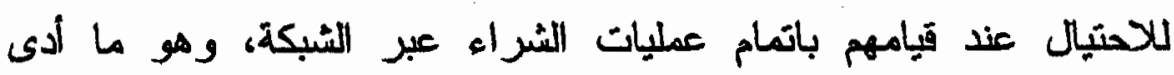

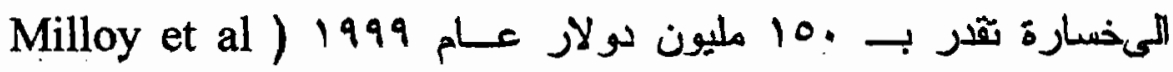
. (2002

ورفقا لدر اسة "Dialogue 2001" فان و\% من مستخدمى الشبكة

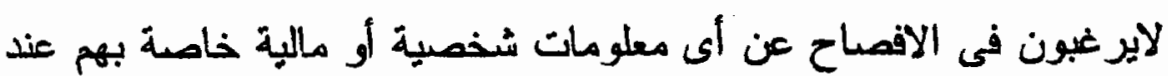
الشر اء عبر الشبكة.

وفى استقصاء أجر اه "Pitkow \& Kehoe 1997" لأراء عينة من مستخدى شبكة المعلومات الدولية، تم التوصل الىى النتائج التالية: 
- - . - من المنعاملين مع الشبكة يرون أنه يجب أن يكون

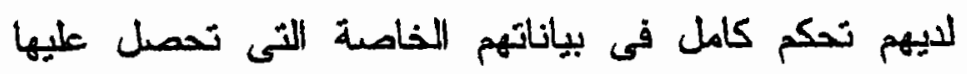

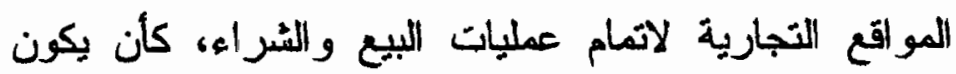

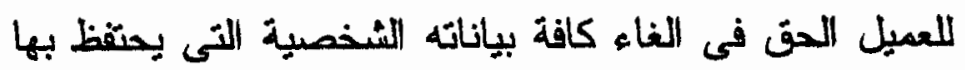
الموقع بعد اتعام العملية.

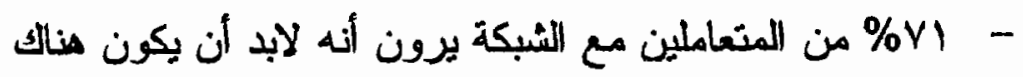
قانون ملزم بعطل على حماية خصوصية بياناتهم الثخصية.

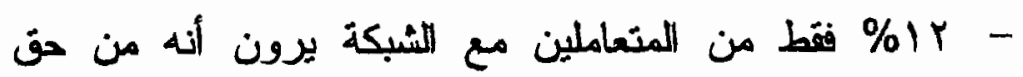

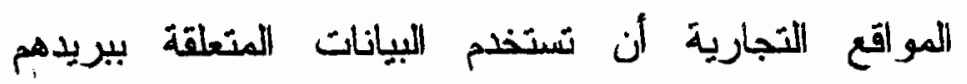

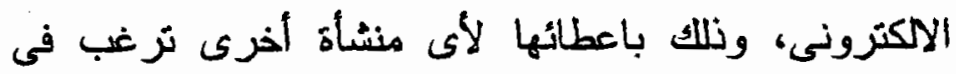
تسويق وترويج منتجاتها.

وفيى در اسة أجر اها "Meridian Research" عالم 1999 وجد أن

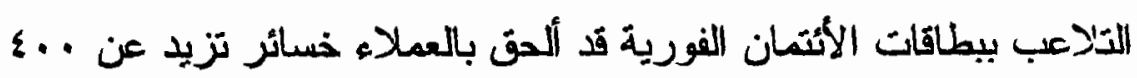

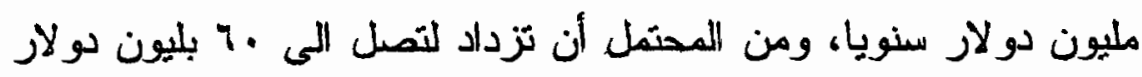

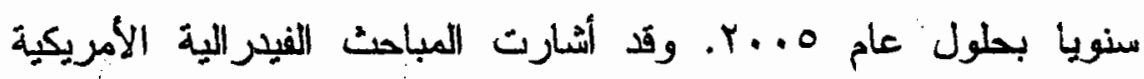
المى أنه بيتم سرقة أرقام مليون بطاقة ائنمان سنويا من المنشآت الفورية (2000 (Pugliese \& Halse).

وقد أوضحت الدراسات أن نقص الأمان و الثقة فى المو اقع التجارية

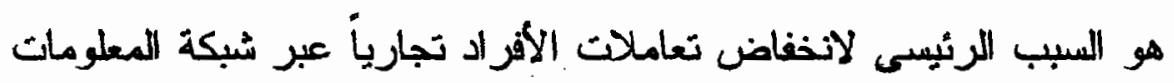

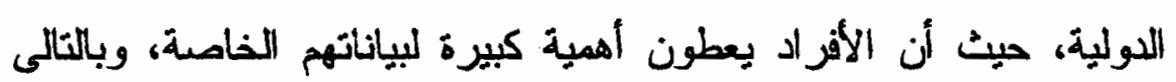

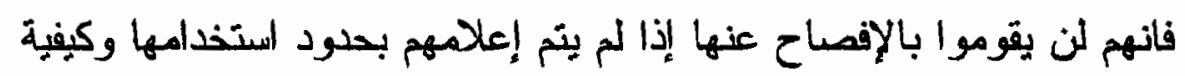

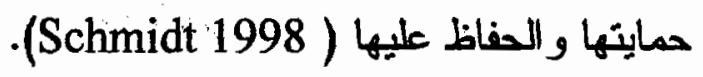


Hicks " وقد أشار كل من "Gray \& Debreceny 1998"

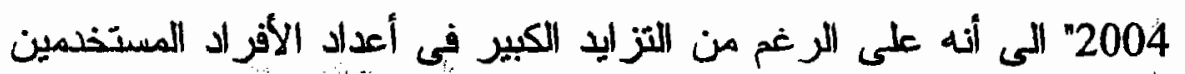

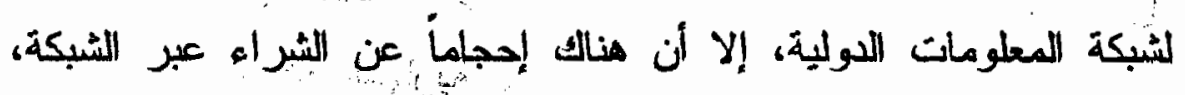

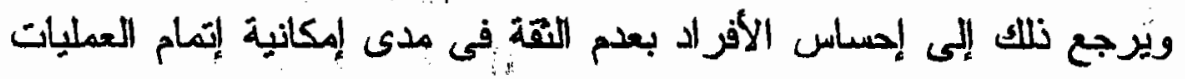
التجارية بأمان، حيث بمكن تلخيص مخاوفهم فى الآتى:

- - هل الموقع التجارى الذى بعزض السلع والخدمات يمثل منشأة موجودة

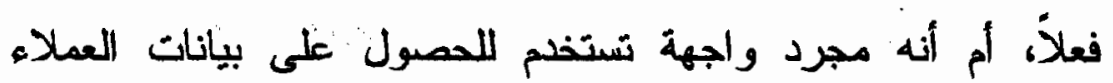
الخاصة لإستغلامها بطريقة غير قانونية ؟.

- إذا قمت بإرسال معلومات عن البنك الذاص بى، أو بطاقة الأئتمان

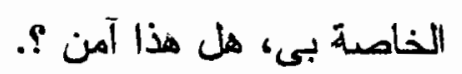

- إذا قدمدت بيانات شُخمبية المنشأة عبر شبكية المعلومات اللدولية، فما هى حلود الستخدام تلك البيانات ؟

- إذا قمت بطلب معين، هل سوف أحصل على ما طلبته فعلأ، وهل ستصل الطلبية فى الوقت المنفق عليه ؟.

- إذا تـم الغاء الاتفاق ورد المنتج وفقاً للشروط المتفق عليها، هل سأسترد أموالى؟ وما هى سرعة الأسترداد ؟.

- هل ستلزم المنثأة بما قامت بالأعلان عنه، كثوفير فطع غيار للمنتج، وتوفير خدمات الصيانة والضمان ؟.

- هل سيتم استلام السلعة أو الذمة المتفق عليها وفقــأ للسعر المنقق عليه ؟. 
- ما هو الضمان بأن الموقع التجارى سيوفر الإجراءات المقابية اللازمة لحماية البيانات الخامة بالعملاء، وبعدم قيام الموقع نفسه بإستخدام تلك الك الكارئ

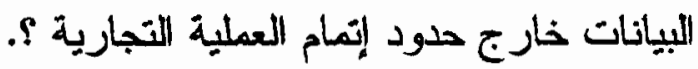

وقد دفعت هذه المخاوف و التساؤ لات معهدى المحاسبين القانونيين الأمريكى والكندى الى تقليم خدمات إضفاء الثقة على الأنظمة الالكترونية

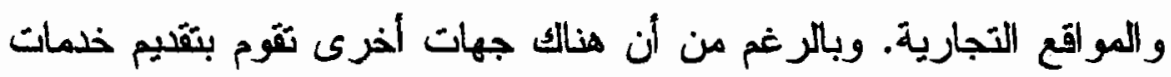
اضفاء الققة منل: Truste, BBBonline and VeriSign، إلا أن تقديم المراجع الخارجى على وجه التحبيد لتكاك الخدات، يمل إمتداداً طبيعياً لمهمنه فى التحقق من مدى صدق وعدالة القوائم المالية، إلى التحقق من مدى سلامة ودقة الإجراءات المطبقة لاى الموفع التجارى لإتعام العمليات

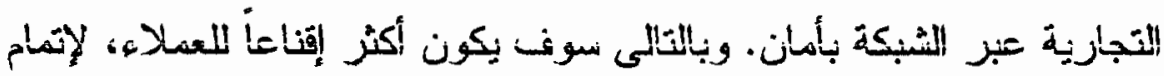

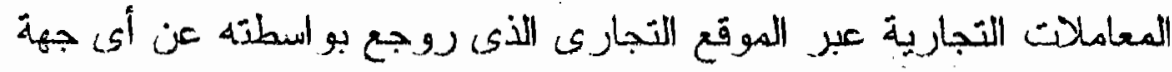
أخرى.

وتهدف هذه الدراسة الىى التعريف بدور المراجع الخارجى فى

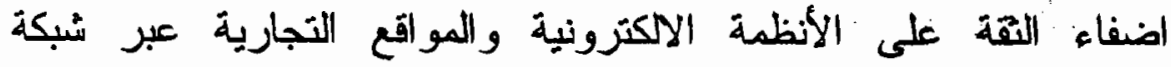
المعلومات الدولية في ضوء المبادىء والمعايير التى أصدرها معهدى المحانبين القانونيين الأمريكى و الكندى، ونلك كمساهمة منه فى تننية فجوة الثقة فى بيئة التجارة الالكترونية.

وتعنبر هذه الدراسة خطوة جادة للتعريف بأبعاد هذه الخدمات،

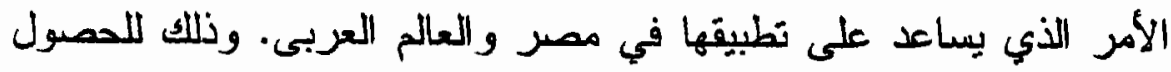

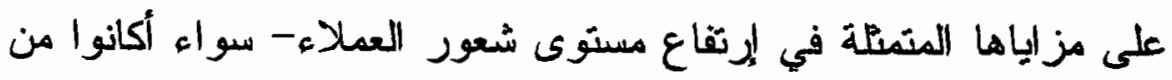

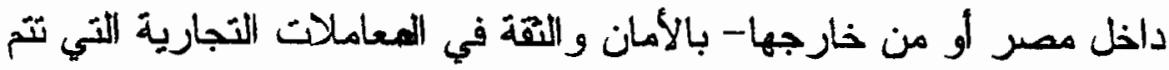

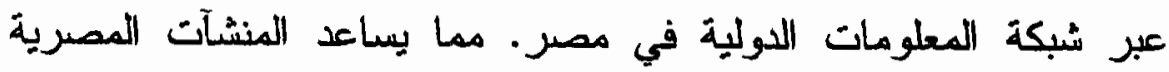


صاحبة المواقع الاتجارية على شبكة المعلوماث الدولية على إكتساب عملاء

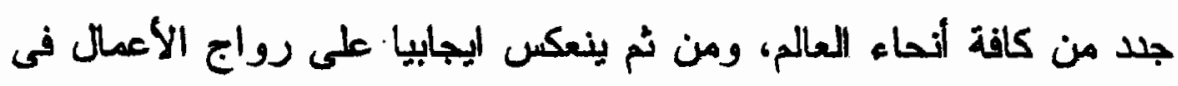

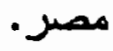

والتحقيق هن اللراسة تم تقسيم بقيتها الى ثلاثية أجزاء، يتاول

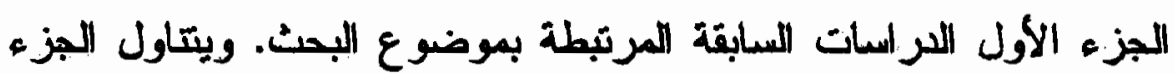

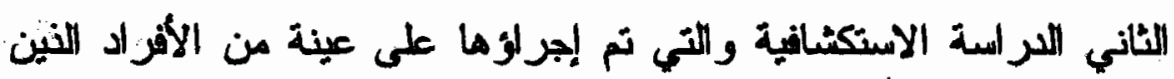

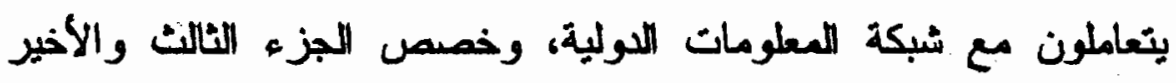

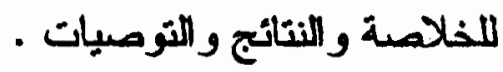

r- اللدراسات السابية

هناك العليد من الرزاسات السابقة النى تناولت خلمات اضفاء اليقة

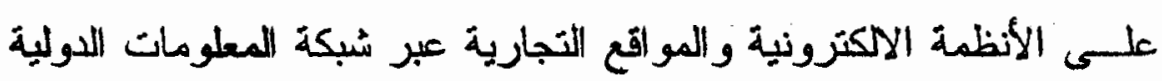

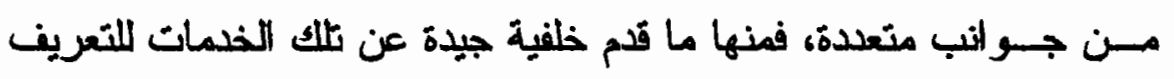

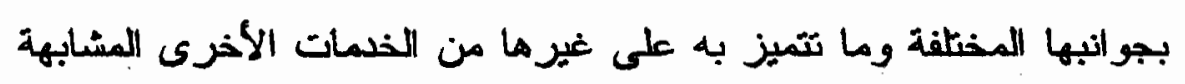

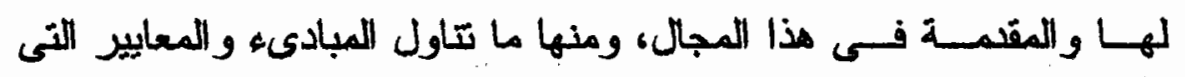

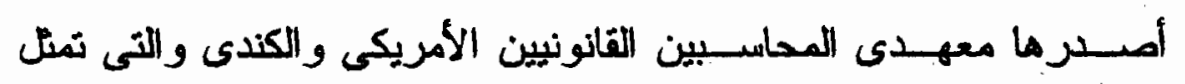

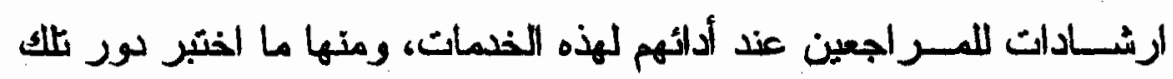

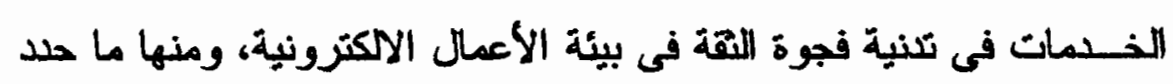

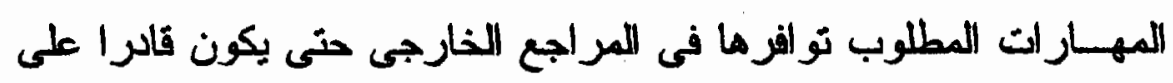

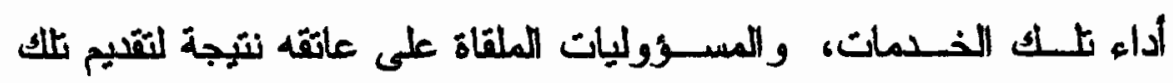

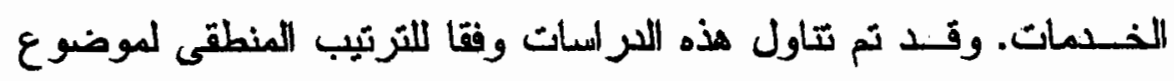

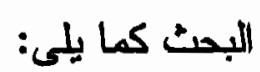




\section{(Assurance Services) مبيعة خدات إضطاء الاثقة}

كما سبق القول أن نقص الثقة فى المواقع التجارية كان وراء

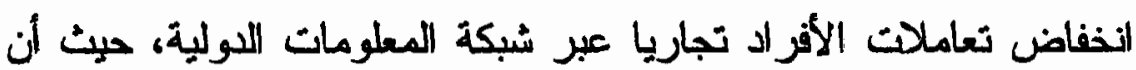
مستخدمى المواقع يرغبون دوما فى تأكبد الخصوصية والألئه الأمان لبياناتهم

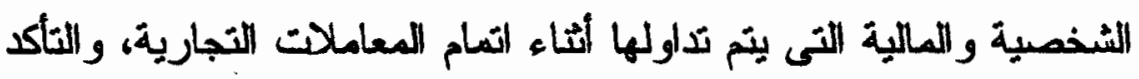

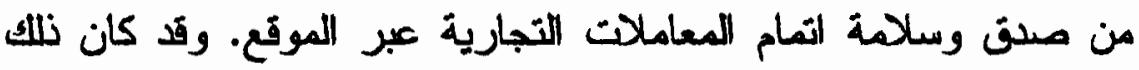

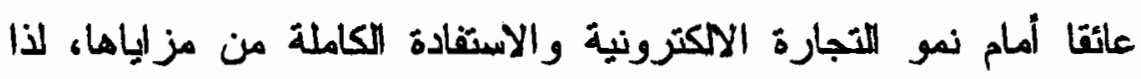
ظهرت الحاجة الملحة لخدمات جليدة تضفى اللقة على المواقع التجاربة ملية لتبكة المعلومات الدولية.

وقد بدا بتقديم تلك الخمات منشآت منخصصة في بناء وتأمين

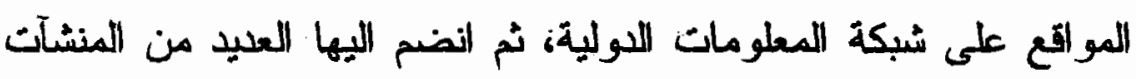

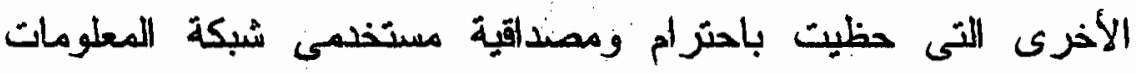

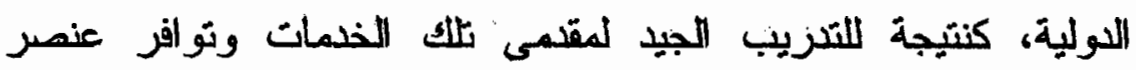
الاستقلال عند ,التتفيذ (Gray \& Debreceny 1998).

وتأكيدا لدور المعاهد المهنية فى هذا المجال فقد أمدرا معهدي المحاسبين القانونين الأمريكي والكندي مجموعة من المبادىء والمعاهي والمعايير

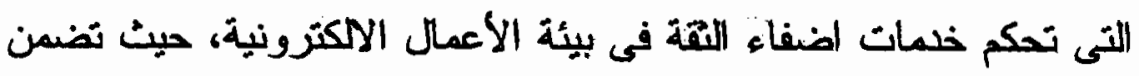

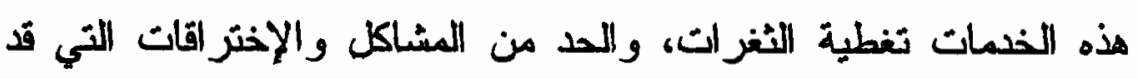
تحدث ، وذللك من خلا إجر اءات معينة تلتزم المواقع الاكترونية بنطبيقها

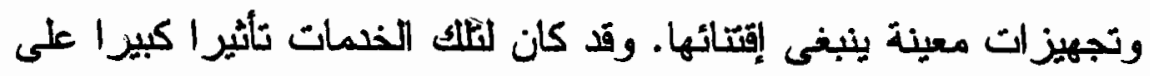
زيادة العمليات التجارية عبر شبكة المعلومات الدولية في الولايات المتحدة ولئان

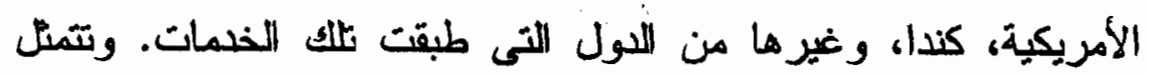


أولا: خدمة إضغاء الثتة على المواتع التجلرية (WebTrust Service)

ظهرث هذه الخدمة في 17 سبتمبر عام 199Y ، ويقوم بها

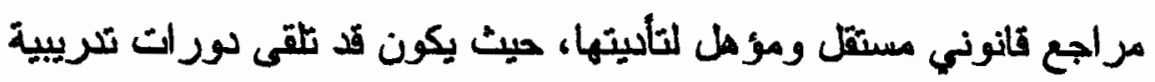
عبدة، تسمح له بغص ومر اجعة المواقع التجارية لاى المنشآت طالبة

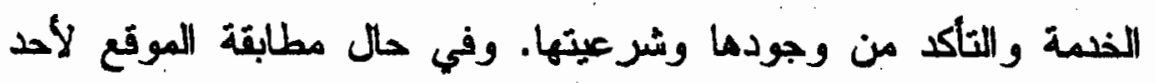

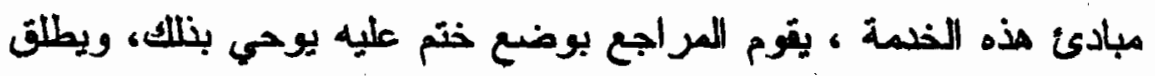

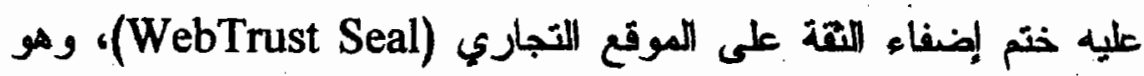
كما يلي:

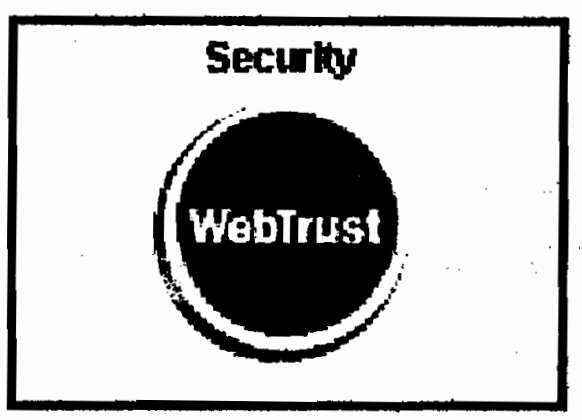

شكل رلم (1): يوضح ختم افظاء الثقلة على الموالقع التجلرية.

ويؤكد هذا الختم للعملاء أن الموقع التجاري قد تمت مراجعته من

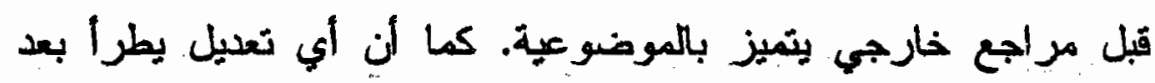

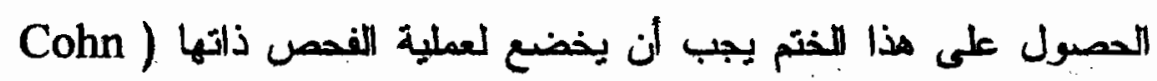
. 2001

وتتشمل عملية الفحص الثأكد من أن المنشأة تطبق إجراءات تحمي

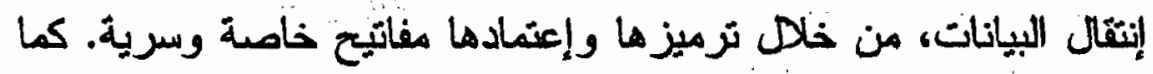

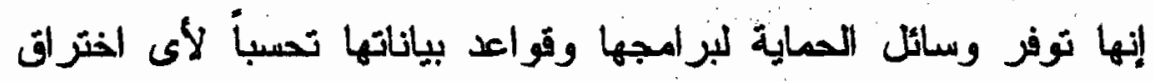

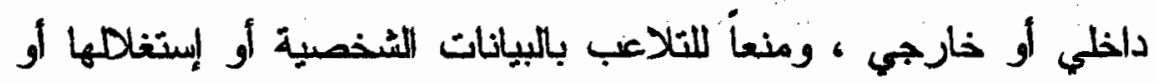


بيعها ، حفاظاً على مصداثية المنشأة. إضشافةً إلى التأكد من صحدة ودقة

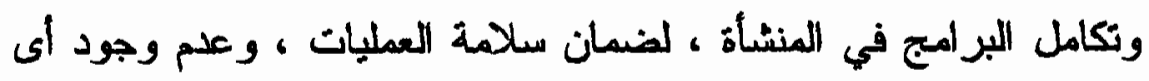

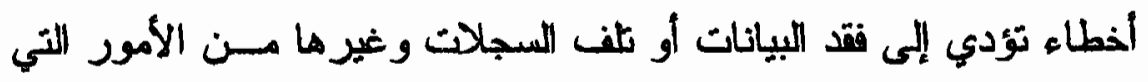
تؤثز ملبا علـى تقدسة العــلاء (Cohn 2001).

وقد الشار " Gray \& Debreceny 1998 و و "عيسى ومبارك

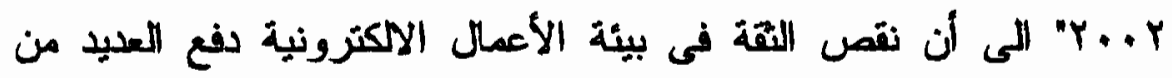

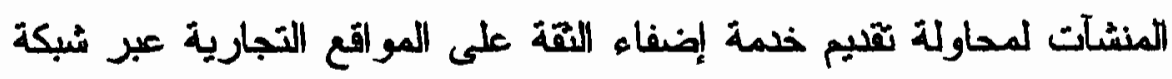
المعلومات الدولية، ومن أهمها:

- منشأة " Secure Electronic Transaction وتركز تلك المنئة على التمقق من قيام الموقع بحماية وتأمين

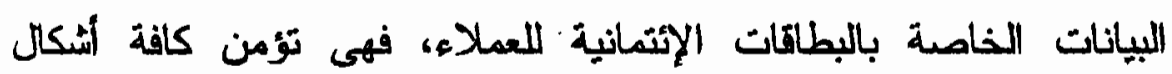

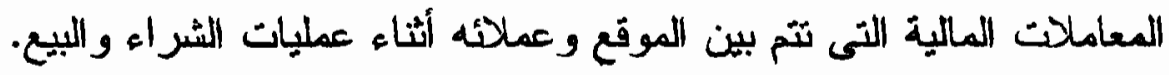

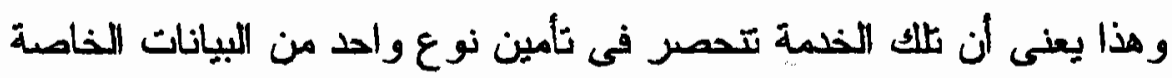
بالعملاء وهى التيى تلتعلف فقط بالنو احى المالية بكافة أنو اعها.

\section{- "Verisign" منشأة -}

وتقدم خدمة التحقق من أن الموقع التجارى يمثل منشأة موجودة

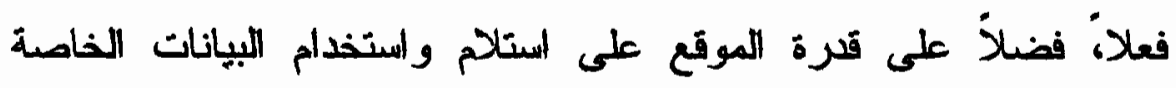

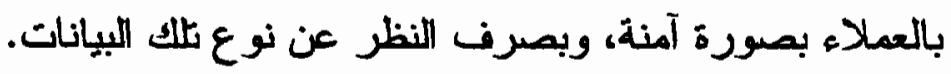

\section{- منشأة " Better Business Bureau}

وتقّم خدمة التحقق من الوجود الفعلى المنشأة، مدى سلامة الإجراءات الخاصة بالمعاملات التجارية، ومدى سلامة المعاملات التجارية

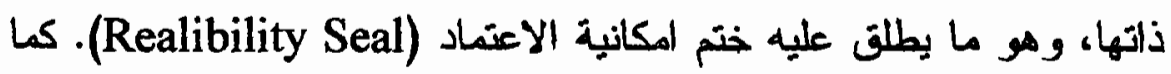


تقدم خدمة التحقق من أن المرقع التجارى يقوم نتط بتجميع البيانات الضرورية لاتمام المعاملات التجارية، فضلا عن قيامه بحماية خصوصية تثلك الثيانات، وهو مايطلق عليه ختم الخصوصية (Privacy Seal). - منشأة "Truste وتقمبم خدمة التحقت من أن البيانات الخاصة بالعملاء سوف تستخدم

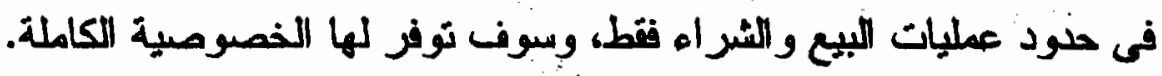

\section{- منثاة "BBBOnline"}

وتمنح ختم الإقة للمواقع الملتزمة بمبادئ ومعايير المنشأة المنعلقة بضمان سلامة إجراءات وممارسات المعاملات التجارية عبر الموقع. : "International Computer Security " منشأة وتقدم خدمة التحقق من أن الموقع ملتزم بمبادئ ومعايير الأمن

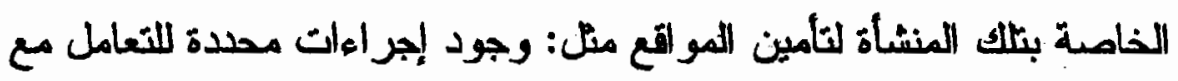

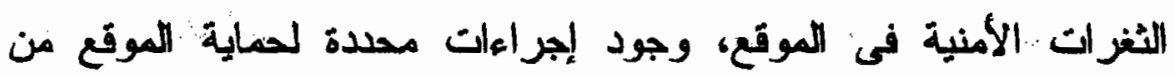

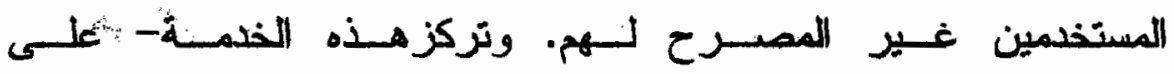
عكس ما ثقمه منشأتى "BBBOnline \& Truste" - على العنصر التقني الخاص بالمواقع التجارية. - منشأة" NCSA

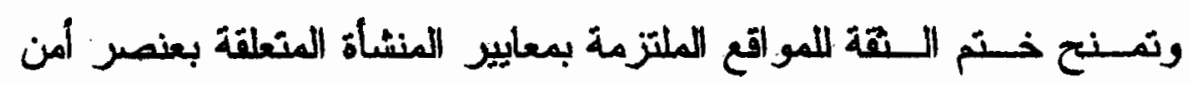
المواقع.

وممــا يدعو للآعىى أن محاولات الدول العربية فى هذا الاتجاه تلإلة

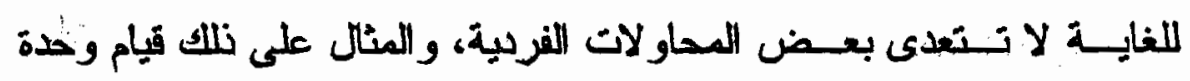

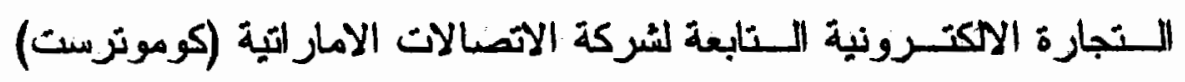


بالاشتر الك مع شركة عمان للتأمين بى اس سى بانشاء خمة هى الأولى من

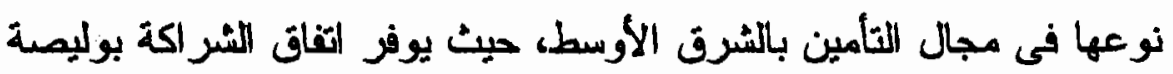

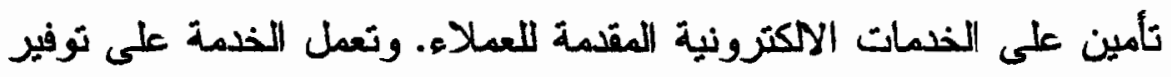

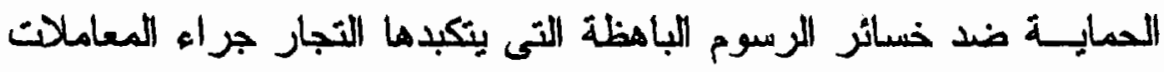

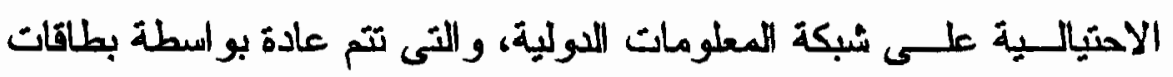

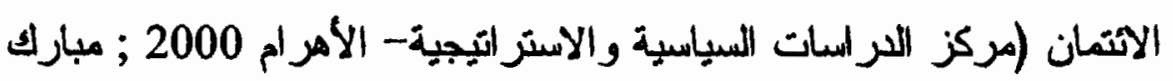
. ( Y...0

ومسن جانبها حلت الشركة العربية للتجارة الأكترونية قضية اللقة

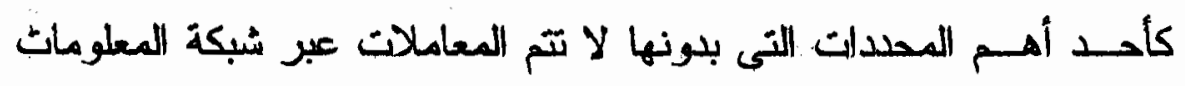

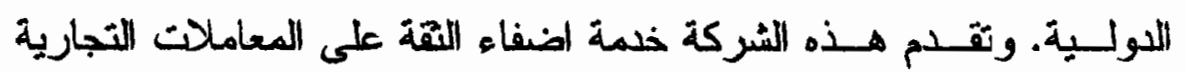
الالكتــرونية، وذلــك بغرض زيلادة حجم التجارة الالكترونية العربية، وبما

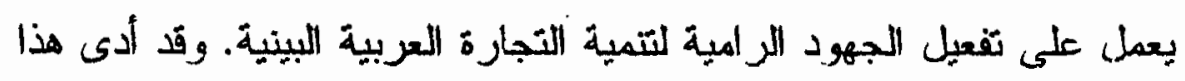

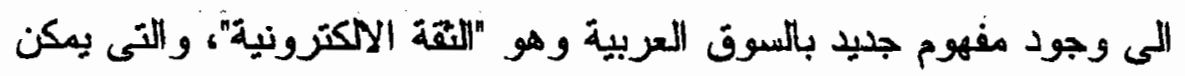

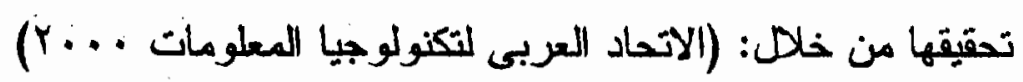

- - ضمان هوية المتعاملين عبر شبكة المعلومات الدولية.

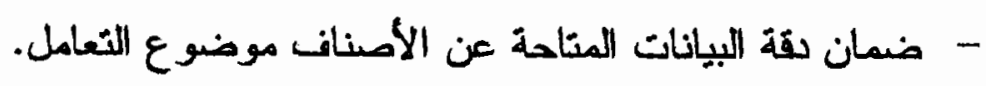

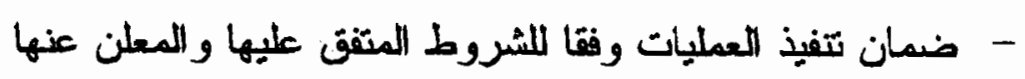
عبر المواقع التجارية على شبكة المعلومات اللولية.

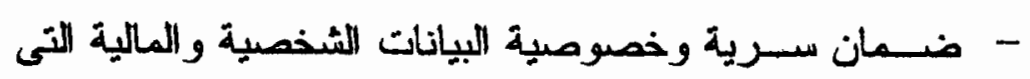
يقدها العملاء للموقع. ومن المقترح أن تقوم الشركة بتقليم مجموعة من الخلمات في مجال تأمين

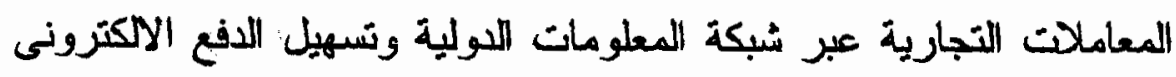
$-19-$ 


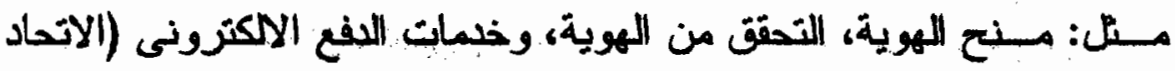

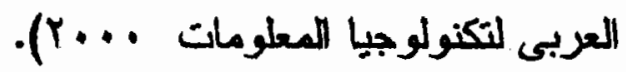

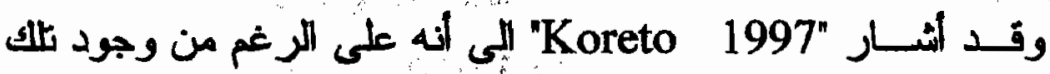

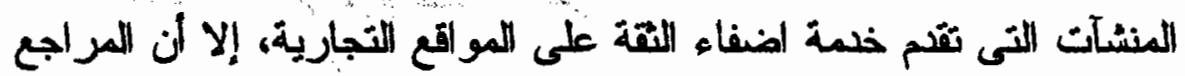

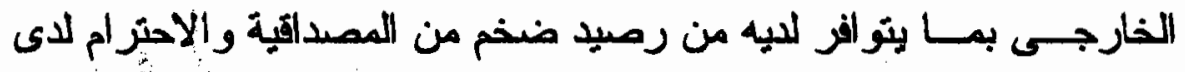
الجمهـور، سوف يودى بثمبيمه لتلك الخدمة إلى زيادة اللقة فى المعاملات

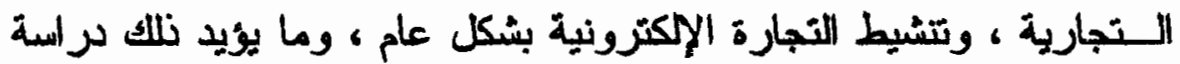

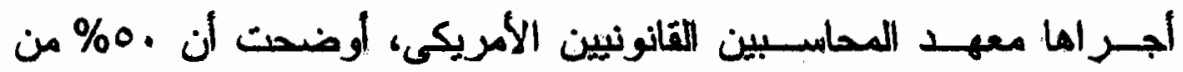

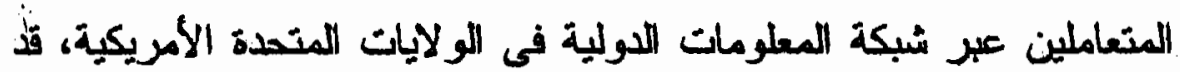

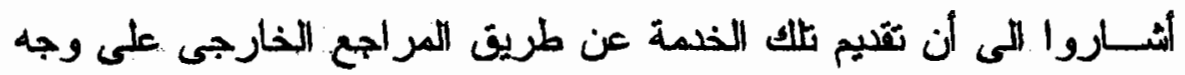
التحسيد سيجعلهم أكثر الستعدادا للشراء عبر الشبكة.

وفـى سـبيل نقّيم هذه الخدمة تعاقدا معهدى المحاسبين القانونيين

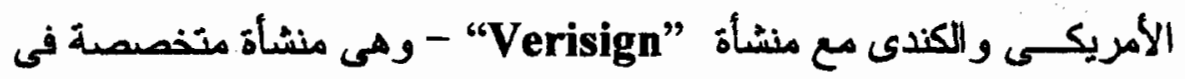

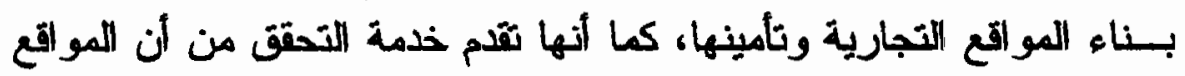
التجارية تخص منشآت موجودة فعلاً، وقادرة على استلام واستخدام البيانات

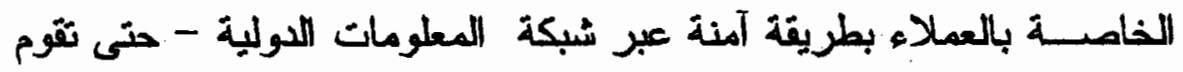

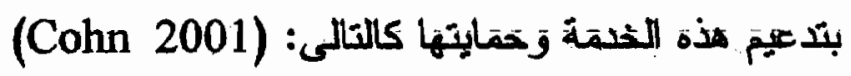

- عــند فـــام المــراجع بفحص الموفع التجارى من حيث إلتزّ امه بمبادئ ومعاييـر معهدى المحاسبين القانونيين الأمريكى والكندى واعداده تقريراً

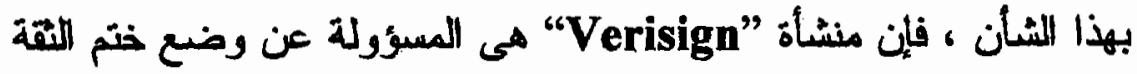

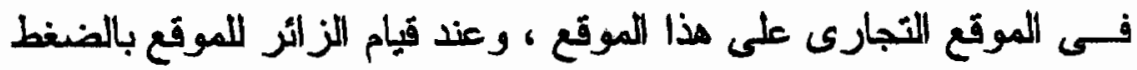

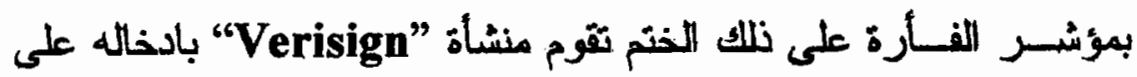
تقرير المراجع عن نلك الموقع. 
- أن هـذـه المنشأة توفر الحماية ضد الإستخدام غير المصرح به أو النسخ

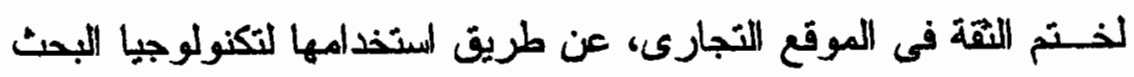
العنكبوتى فى المواقع (Spidertechnology) كل فترة دورية محدة.

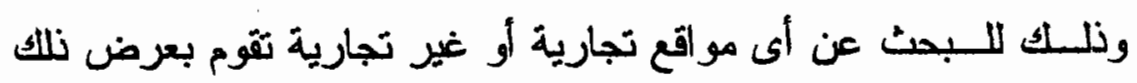

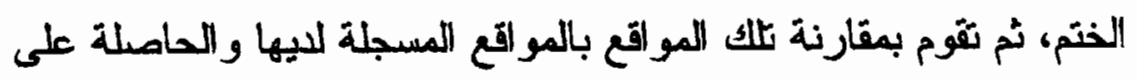

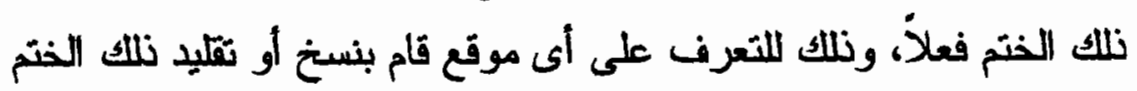
لإتخاذ الإجر اءات اللازمة ضدها.

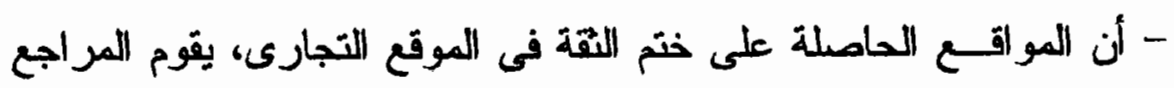

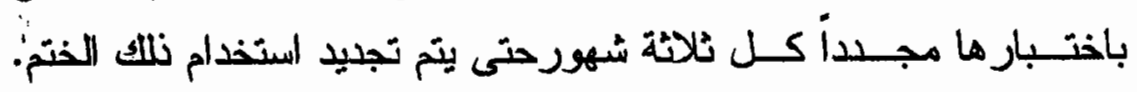
وبالثالى إذا قام الموقع برفض تجليد الاختبارات الخاصة بالخدمة المعدة

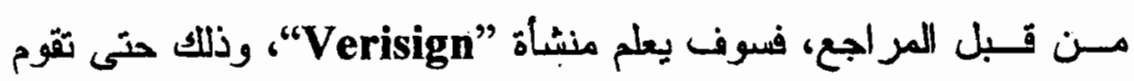
بإز اللة الختم من على الموقع التجارى المحدد.

وقد كاما معهدى المحاسبين القانونيين الأمريكي و الكندي بوضع

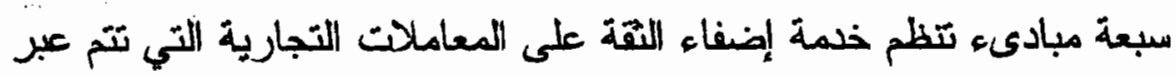
المواقع التجارية على شبكة المعلومات الدولية، وهذه المبادىه السبع هئ؛

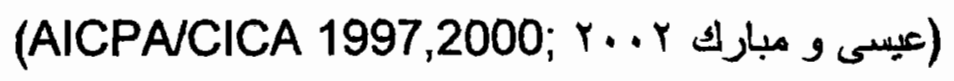

(Privacy)

1- الخصوصية:

وفيها يتحقق المراجع الخارجى من أن الموقع التجارى ملتزم

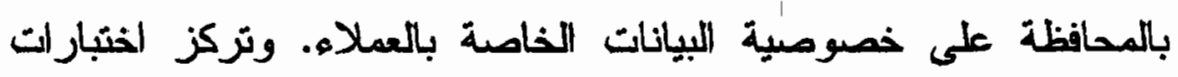

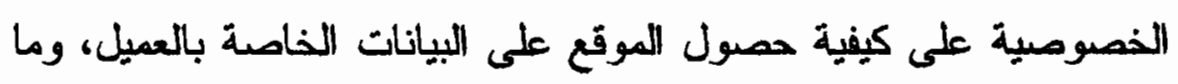
هى حدود استخدام تلك البيانات، وما هى الطرق المتبعة لتصحيح البيانات الغير سليمة في حالات الإدخال غير السليم لها، وما هى الإجراءات المنبعة 
إذا ما رغب العميل فى علم تتفيذ عملية الشُراه ، وما هى البرامج التي يستخمها الموقع التجاري كوسيلة للتعرف على الجهاز الخاص بالعميل عند (Cookies or Other Identification Technologies) إستخدامه للشبكة، ونلك ضمانا لسهولة وسرعة ربط جهاز العميل بالموقع لإعلامه بالعروض وغير بما من المعلومات المتعلقه بالموقع. Y - سلامة اهراعات العل والمعلملات التجلريه: (Business

(Practices and Transaction Integrity وينتسم هil العبدأ للى غنصرين ها: |- سلامة إهراعات العل: وفيها يتحقن المرإجع الخارجى من عناصر عبيدة منل : التحقق من قيام الموقع بثقيم وصف لحالة وطبيعة السلع والخذمات المبقدمة بدقة، إفصاح الموقع عن المدة اللازمة لتففيذ العملية بعد ثلقى أمر الشراء، وسائل

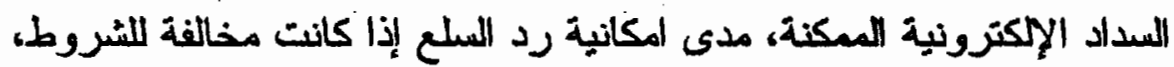

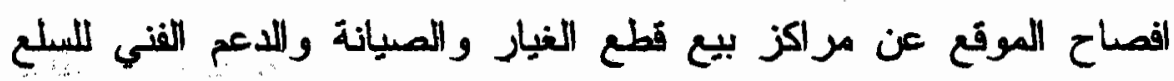

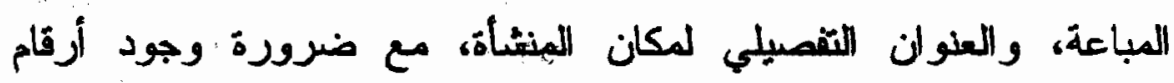
تليفونات للإتصال بالمنشأة إذا لزم الأمر.

ب- سلامة المعلملات التجارية:

وفيها يتحقى اللمراجع الخارجى من قيام الموقع بفحص طلبات

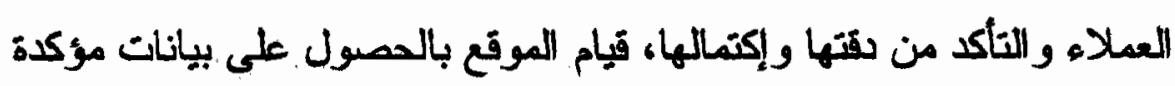

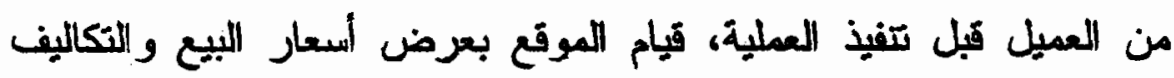
الأخرى على العميل قبل تتفيذ العملية، والتحقن من أن الموقع يقوم بالتنفيذ 
الاقيق لطلبات الشراء من حيث شحن السلع المطلوبة بحقة وبالكمية المحدة

وفى الميعاد المحدد وفقا للتعاتد .

(Security)

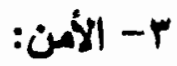

وفيه يتحقق المراجع الخارجى من عناصر عديدة متل : أن الموقع التجارى ليه خطة محدة للتعامل مع الثُغرات الأمنية فى حالة وجودها، لليه إجراءات محدة لإستعادة نظامه فى حالة توتف الموفع عن العمل، وغيرها من الأمور المتعلقة بأمن المواقع التجارية. ومن ثُ فان هذا المبدأ يضمن تأمين نظام الأعمال الأكترونية للموقع التجارى بعناصره الخمسة: البنية التحتية، البرامج، الأفر اد، الاجر اءات، و البيانات.

(Availability)

\&

وفيها يجب أن يتأكد المراجع من أن الموقع متاحا لإستخدام العملاء

بصورة دائمة، عن طريق التحقق من أن البرامج والمكونات المادية الخاصة

بالموقع يتم إختبار ها وتجليدها باستمر ار للمحافظة على إتاحة الموقع. (Nonrepudiation)

0- مدم إنكار الالتزامات:

وفيها يتحقت المراجع الخارجي من عناصر عيدة مثل: التزام

الموقع بمسئوليته عن التحقق من الأفراد المصرح لهم بدخول واستخدام الموقع، مسئوليته عن وجود إجراءات لتسجيل موافقة العميل على تتفيذ العملية، ومسؤليته في تحبد أى من الطرفين (الموقع أم العميل) مسؤولا عن أى خسارة قد تتشأ فى أى مرحلة من مراحل العملية التجارية.

$-r r-$ 
وقيها بتحقق المراجع الخارجى من أن الموقع يحافظ على سرية

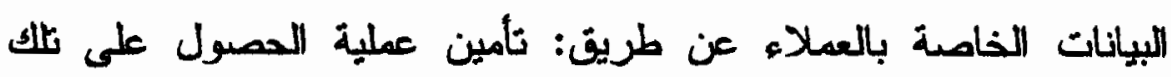

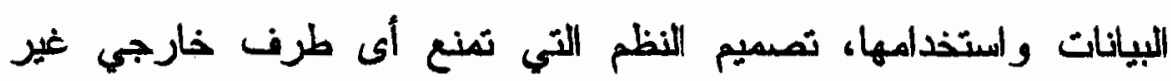

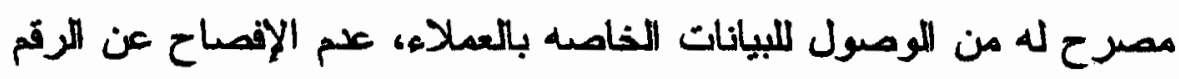
الخاص بجهاز العميل(IP Number)- ونلك لمنع وصول الفيروسات وملفات وبرامج الإخترات الى جهاز العميل- وتأمين النسخ الاحتياطية لبيانات العملاء بشكل كاف .

(Customized Disclosures) : V وبعني هذا أنه اذا رغب الموقع في قيام المراجع الخارجي بالتثرير

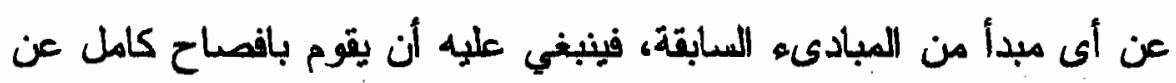
الأجراءات المتبعه للكألمز ام بذلك المبدأ.

وتتميز خممة اضبفاء النقة على المواقع التجارية (WebTrust)

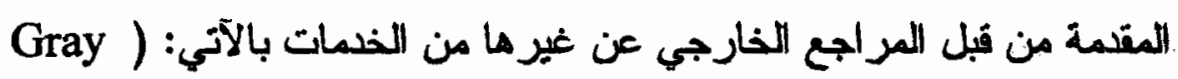
(\& Debreceny 1998 ; Cohn 2001

- أن خمة اضفاء الثقة على المواقع التجارية ، هى الخمة الموحيدة حتى الآن التى ثشعل كل ما تقدمه غير ها فى خلمة واحدة.

- يشترط فى من يؤدى خلمة الضفاء الثقة على المواقع التجارية أن يكون مراجعا خارجيا مؤهلا من قبل معهد المحاسبين القانونيين 
الأمريكي او الكندي لأداء تلك الخمة، مدا بضمن نو افر الخبرة الفنية اللازمة لأداثها.

- أن ختم الثقة فى المواقع التجارية لا يعطى للموقع إلا إذا قام المراجع

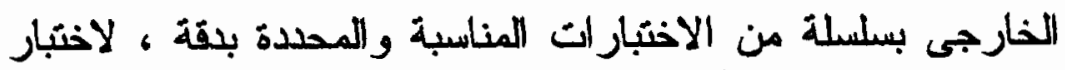

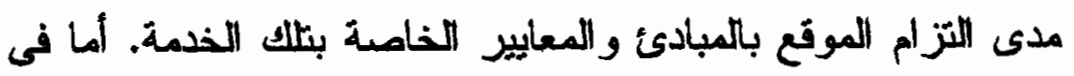
الخمة التى تؤليها منشآتى "BBBOnline \& Truste" على سبيل

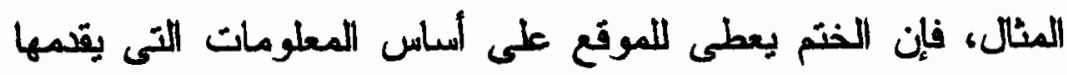
الموقع عن نفسه وبعض الاختبار ات النى يقوم بها مقدم الخلمة. - تلك الاختبار ات بجب أن تجبد كل نثلثة شهور .

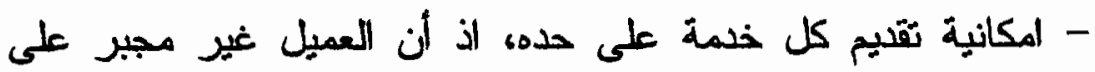

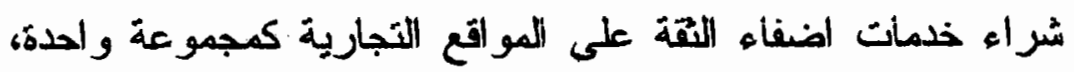

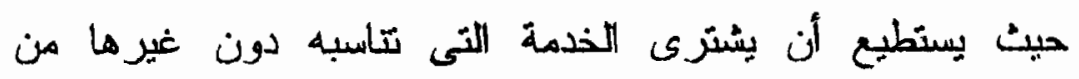

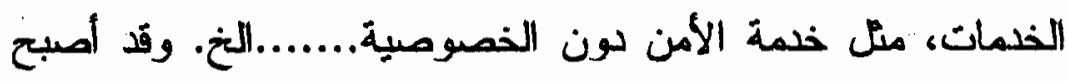

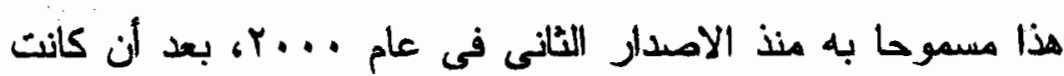
تقدم كمجموغة واحدة في الاصدار الأول.

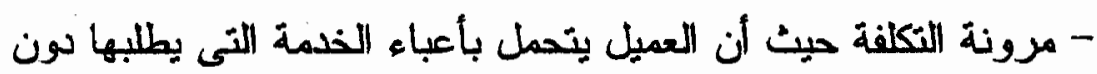

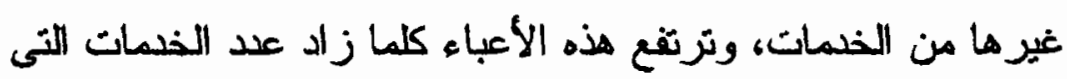
يطلبها.

وقد أشارا "Gray \& Debreceny 1998" للى أن افضل الأسوات لتيلك الخدمة هى:

- المنشآت الجليدة النى لم تبنى لنفسها سمعة جيدة بعذ، حيث ستوفر

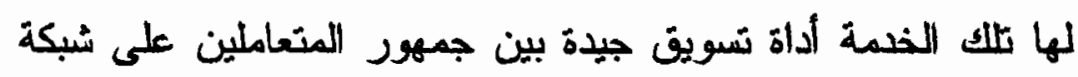


- المنشآت القائمة بالفعل والتى ترغب فى التوسع على المستوى

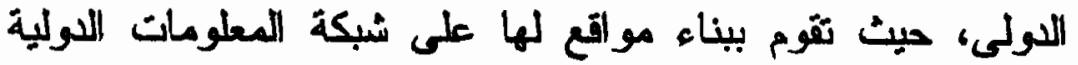

والاستفادة من تلك الخدمة فى اكتساب المصداقية والسمعة الجيدة.

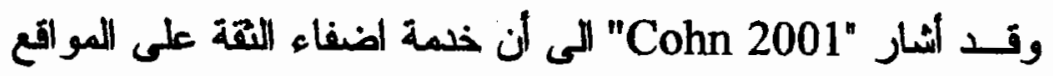

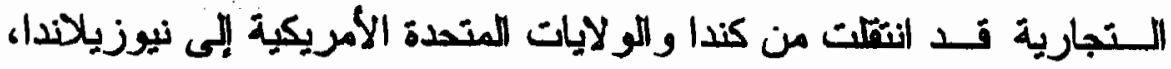

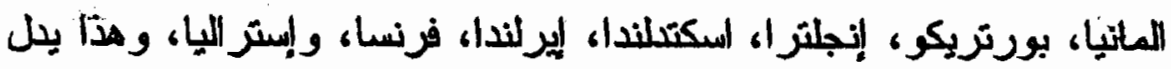

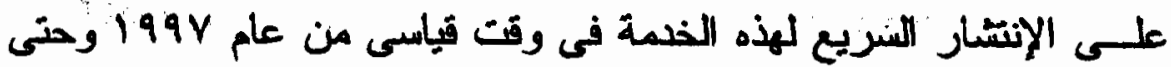

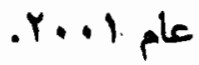

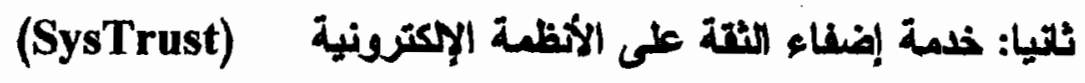

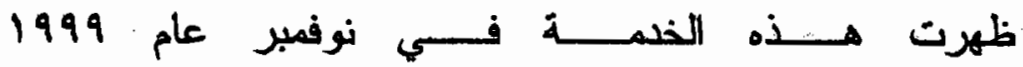

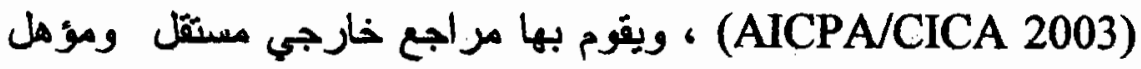

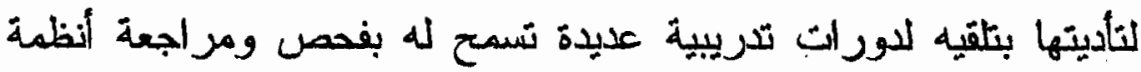

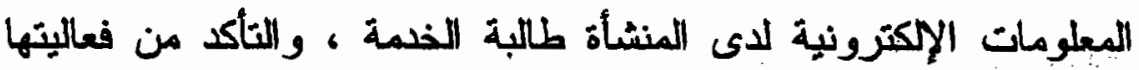

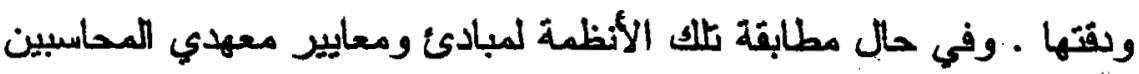

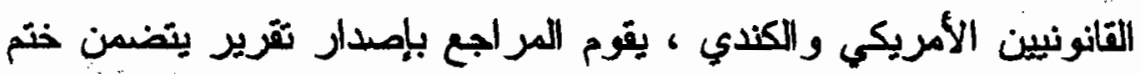

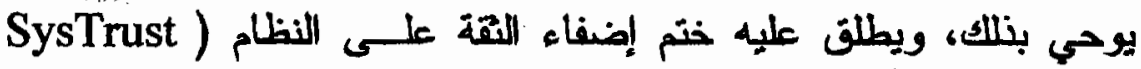

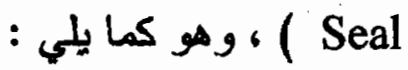

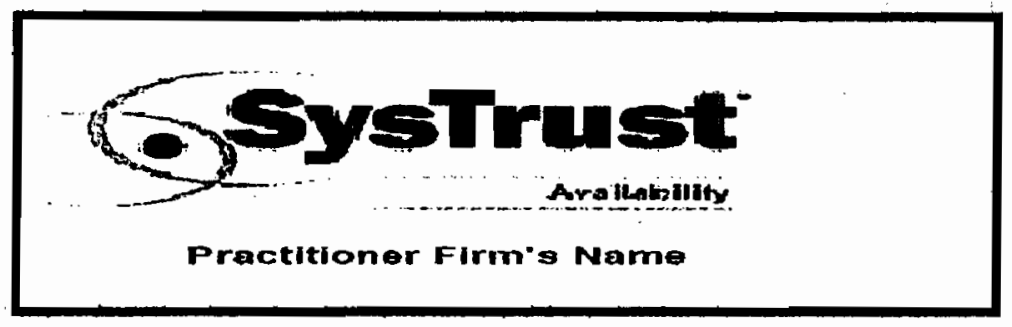

شكل رتم (Y): يوضح ختم اضفاء الثقة على الأنظة الاكترونية.

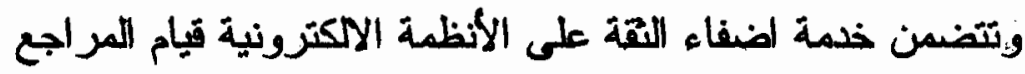
بأداء اختبارات كاختبارات المراجعة لاختبار البنية التحتية للنظام، لألفية 
اللبرامج، العاملين، الاجراءات، والبيانات، وذلك لتقييم مدى امكانية

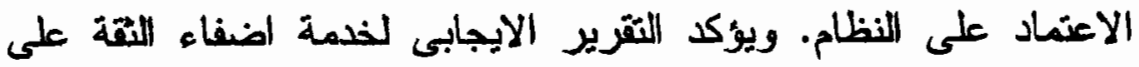

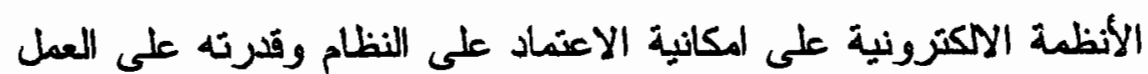

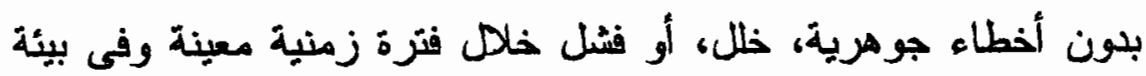

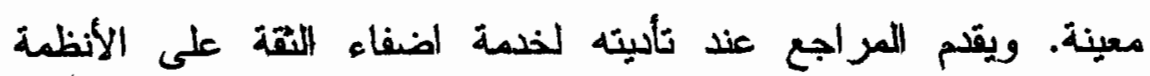

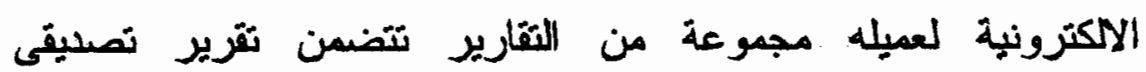
(Attestation Report) الرمابة الداخلية بما بحقت امكانية الاعتماد على النظام. وتظهر الحاجة لنكل الخدمة لتجنب ما يلى : (Pugliese \& Halse 2000) - فقد الإتصال بالنظام، وبالتالي عدم تلبية الحاجات الضرورية اللعملاء أو للعاملين بالمنشأة .

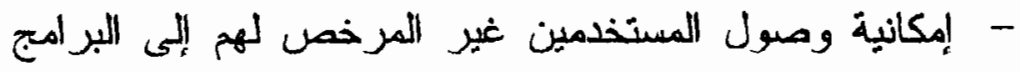

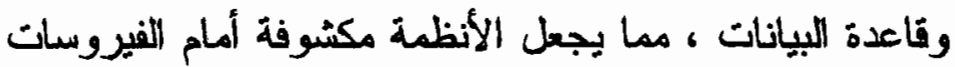

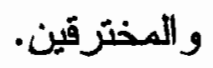

- - إحثال فقد سرية وتكامل البيانات إذا ما تعطل النظام. - نقص ثقة المستثرين والعملاء من جراء الدعاية السلبية النانجة عن تعطل النظام . - - مشاكل الصيانة التى ينتج عنها آثار جانبية سلبية كنتيجة التطان للتغيرات التى تحدث بالنظام مثل: فقد امكانية الحصول على خدمات معينة من النظام، فقد سرية البيانات أو فقد تكاملها.

وقد يزداد طلب المنشأة على تلك الخدمة عنما تز غب فى التميز

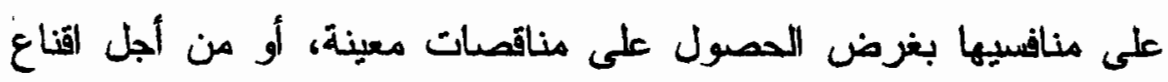

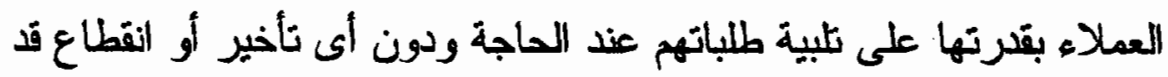


ينجم عن خلل أو تعطل النظام. ومثال على نلك عندما ترغب المنشأد فى

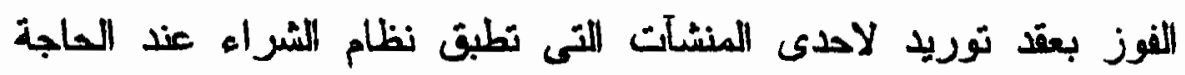
(Just- in - Time)

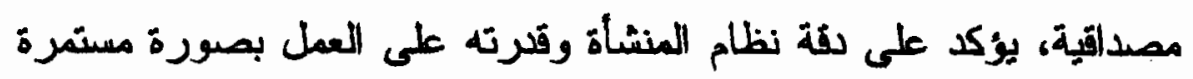

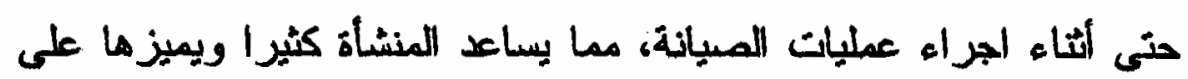

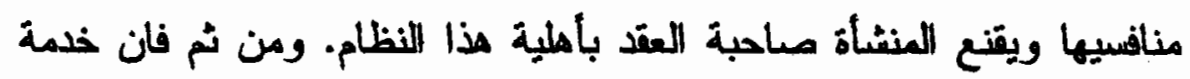

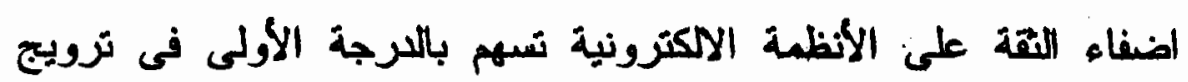

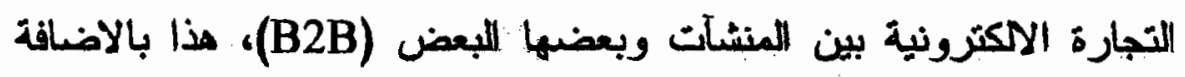
الى اسهامها فى تروبج التجارة الالكترونية بين المنتأة والعمـلاه (B2C) .(Pugliese \& Halse 2000)

ويقوم خدمة إضفاء الثقة على الإنظمة الأكترونية على أربعة

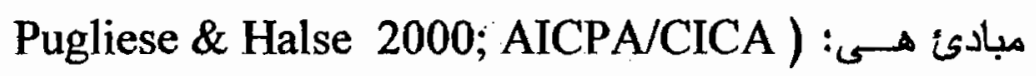

(2003

\section{(Availability)}

$$
\text { : الإحاحة }
$$

وفيه يتجقق المراجع الخارجي من أن النظام يعمل وفقا

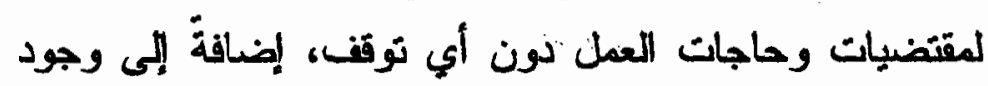

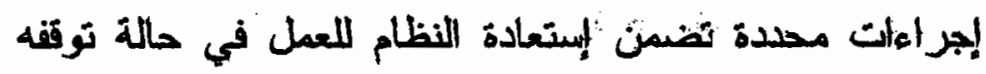

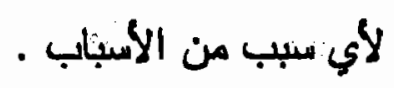

(Security)

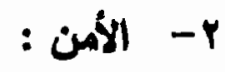

وفيه يتحقق المراجع الخارجي من أن النظام بتضمن

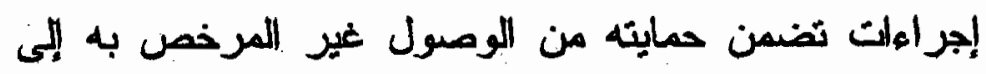


البرامج وقاعدة البيانات، ونلك من قبل المستخمين الاخليين والخارجيين.

(Integrity)

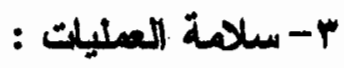

وفيه يتحقت المراجع الخارجي من قرة النظام على

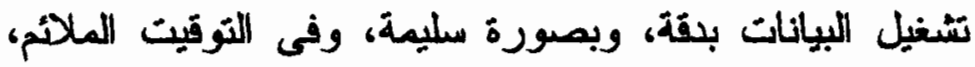

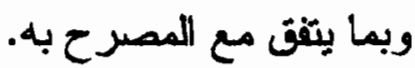

(Maintainability)

| - القابلية للصيلة :

وفيه يتحقق المراجع الخازجي من وجود إجراءات

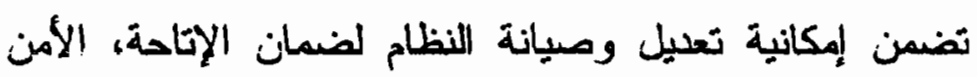
وسلامة العمليات ، ودون الحاجة إلى توقف النظام ولو لفترة

وكنتيجة للدراسات و المؤتمرات التى هدفت الى تطوير تلك الخدمة، أجريت العديد من التعليلات والتحسينات عليها، الأمر الذى أدى الى نشر لإلى الاصدار الثانى فى يناير عام I...ب، وهو الاصدار الأخير حتى الآن.

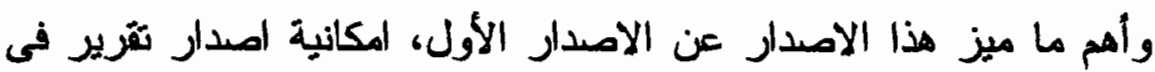
أى مبدأ من المبادىء الأربعة بشكل منفصل ودون الحاجة الى التزام المنشأة بالمبادىء الأخرى. وهذا الأمر كان غير ممكنا فى الاصدار الأول، حبث لم يخول للمراجع الا اصدار تقرير يتتاول المبادىء الأربعة مجتمعة.

وتهتم خدمة اضفاء الثقة على الأنظمة الاككرونية بالاتى:

(Pugliese \& Halse 2000) 
- تقييم اجر اءات الرقابة الداخلية استخادا الى مبادىء ومعايير

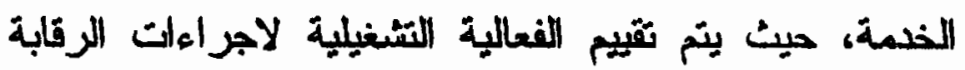
الداخلية وفقا لكل معيار من معايير الخمة.

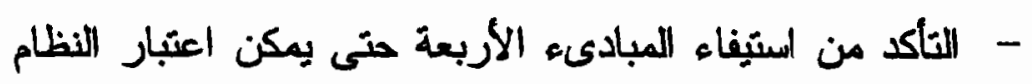

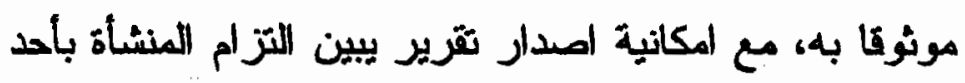
المبادىه، على أن تلتزم بجميع المعايير العائدة له.

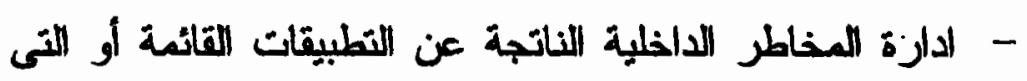
تم تطويرها.

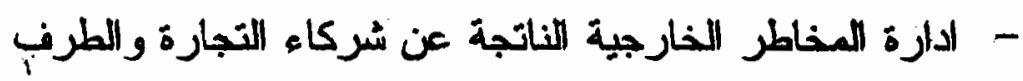
الاثلث فى بيئة التبادل الاكترونى للبيانات. ويتملّل المستفيدون من خدمة اضفاء الثقة على الأنظمة الاكترونية فى: (Pugliese \& Halse 2000)

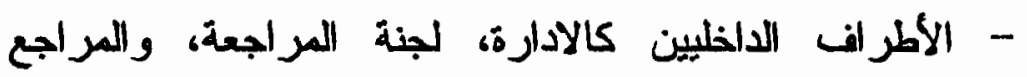

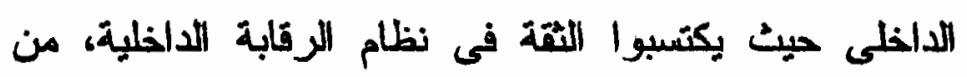

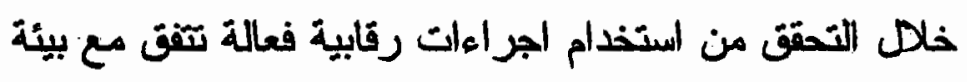
الأعمل الالكترونية.

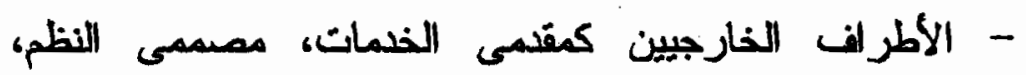
الشركاء التجاريين، ومستخدمى النظم، والنين يكونوا في

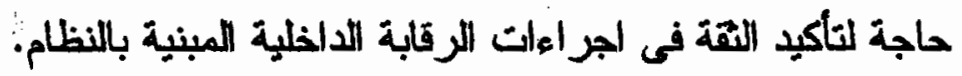

ويمكن ابراز الثقارب بين خلمة اففاء الثقة على المواقع التجارية

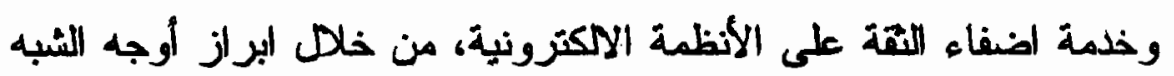
والاختلاف بين الخدمتين كما يلى: 


\begin{tabular}{|c|c|}
\hline خدمة اضطاء الاثلة عى الأكطمة & خدمة اضفاء الثنة على المواتع \\
\hline 1- ثقوم على مجموعة من المبادىه. & جموعة من المبادىء. \\
\hline 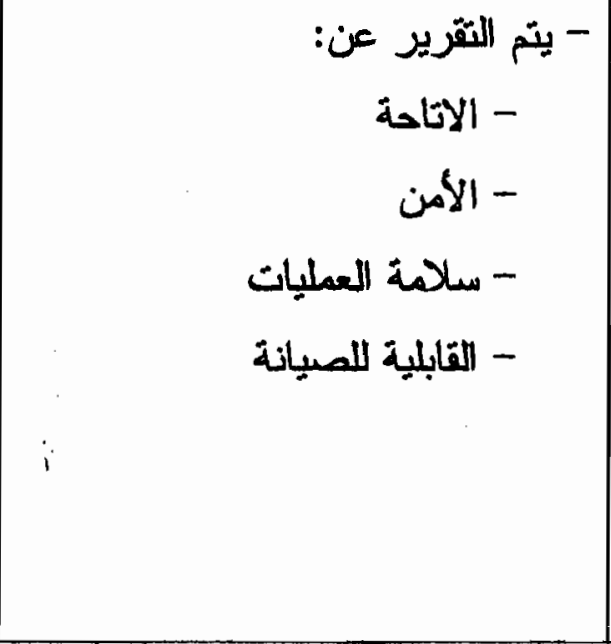 & 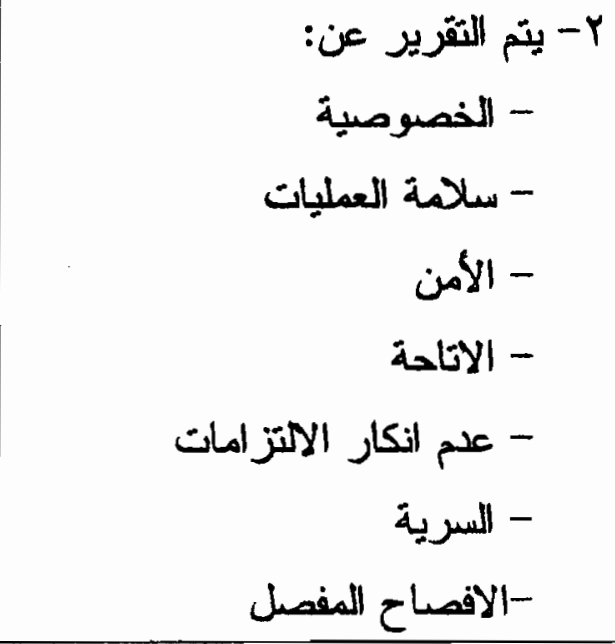 \\
\hline 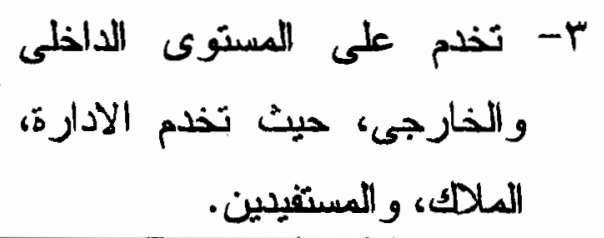 & بـ- تخلم على المستوى الخارجى فقط، \\
\hline 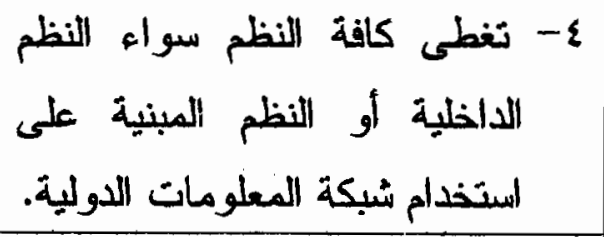 & ع- تغطى النظم المبنية على الستخدام \\
\hline 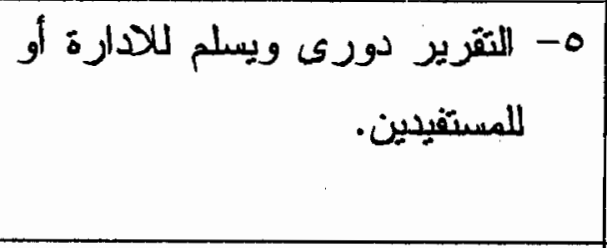 & 0- التقرير يغطى فترة محدودة وينم \\
\hline 4- تزكز على امكانية الاعتماد على النظام. & تا تزم عبر شبكة على العمليات التجارية التى \\
\hline
\end{tabular}

جلول رقم (1) : يوضح أوجه الشبه والاختلافت بين خدمتى الثقة. 
ونظراً للثقارب الكبير بين خلمتى اللقة، ولكونهما الخدمتين

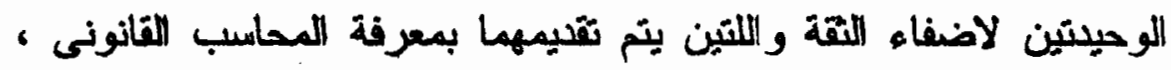

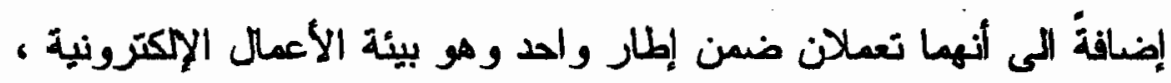

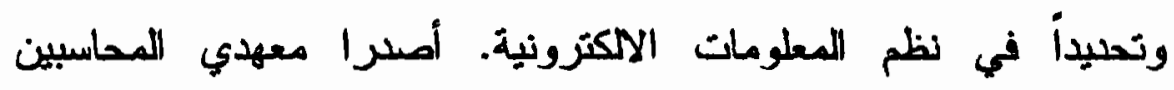

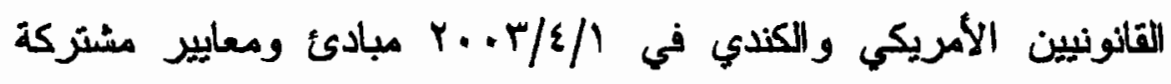
لهاتين الخمتين تحت اسم خمات إضفاء التقة ( Trust Services ) وهي: الأمن ، الاحلحة، البرية ، الغصوصية ، وسلادة العمليك. وقد تم معالجة كل مبدأ وفقاً لأربعة مراحل كما يلى: (AICPA/CICA 2003)

أولاً : السيلسلت (Polices ) : يجب على المنشأة أن تُشرتن

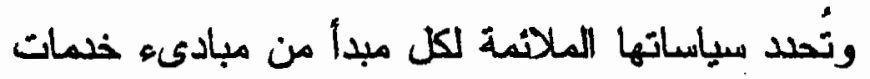

القةة.

ثانياً : الإنصالات (Communications): يجب على المنشأة

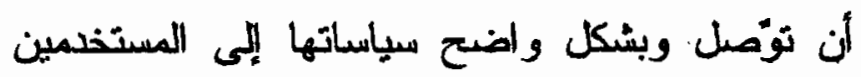

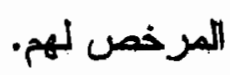

ثلاثاً : الإجراءات (Procedures) : يجب على المنشأ أن

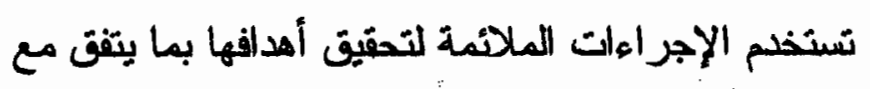
السباسات المحدة.

رابعاً : العرالبة ( Monitoring ) : بجب على المنشأة أن

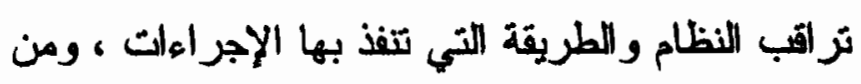
تُم تصحيح الخلل بما بيفقى مع السياسات المحلدة. 
كما تم وضع مجموعة من المعايير (Criteria) وُزعت على هذه

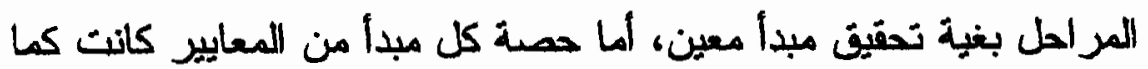
يلى: (AICPA/CICA 2003)

$$
\begin{aligned}
& \text { - } \\
& \text { - T T ب معيار التحقيق مبدأ الإتاحة. }
\end{aligned}
$$

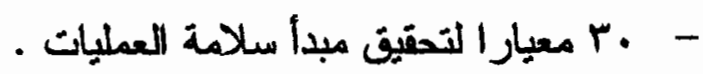

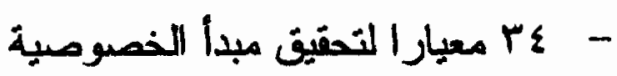

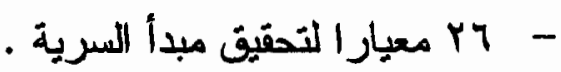

ولتحقيق مبدأ ما يجب أن تطبت معاييره كاملة، هذا ويهكن تقليم

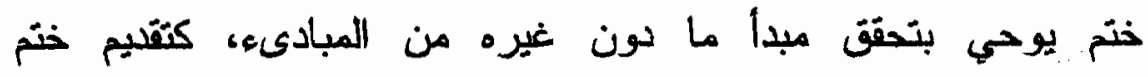
للخصوصية مثلا. وبالتالي يمكن تقديم هذه المبادئ وفقا للحاجة إليها، وبشكل مستقل عن بعضها البعض (Pugliese \& Halse 2000).

ولا تبتلف معايير كل مبدأ بين خدمة إضفاء الثقة على الأنظمة

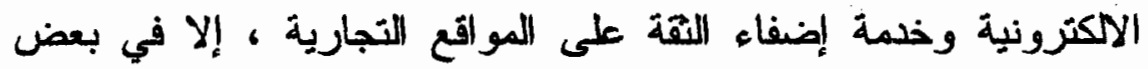

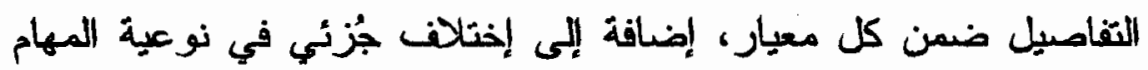

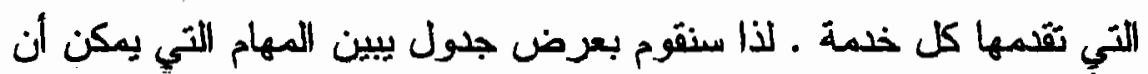

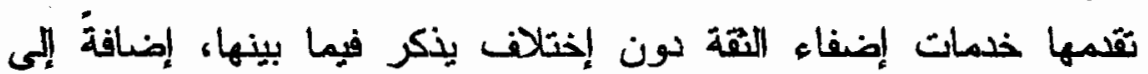

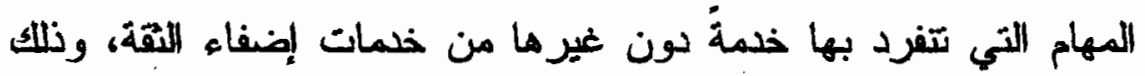

\begin{tabular}{|c|c|c|}
\hline نظم التجارة الاككترونية & نظم السطوبات الاكترونية & نوع العهة \\
\hline WebTrust & Systrust & الأمن \\
\hline WebTrust & - & الخصوصبة \\
\hline WebTrust & Systrust & سلهة العمليك \\
\hline
\end{tabular}

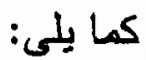




\begin{tabular}{|c|c|c|}
\hline WebTrust & Systrust & |إحاحة \\
\hline WebTrust & Systrust & السيرية \\
\hline WebTrust & - & شرئة إلمدار الثهلدة \\
\hline WebTrust & - & حماية المستهلك \\
\hline- & Systrust & إكاثية الأعتعد على النيلم \\
\hline WebTrust & Systrust & مهام ششتركة أخرى \\
\hline
\end{tabular}

\section{جلول رتم (Y): يوضع المهلم التى تؤنيها خدمات اضفاء الثتة.}

وعلى الرغم من أهمية كافة مبادىء خمات اضفاء الإقة، الا أن

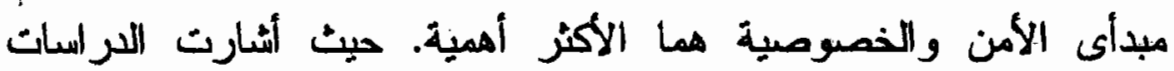
العنابقة (أنظر على سبيل المثال: Schmidt 1998; Houston \& Taylor (1999; Portz et al 2000 الممارسة الكاملة للتجارة الالكترونية بسبب خوفهم من سرقة البيانات أثناء

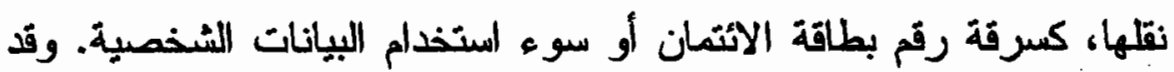

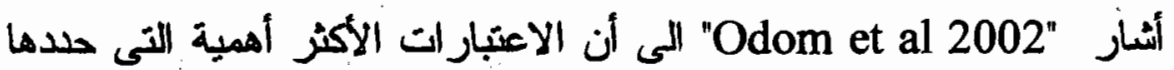

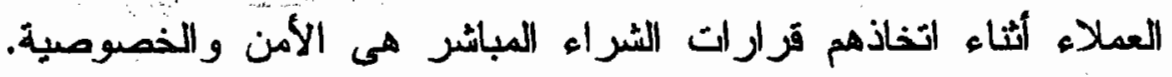

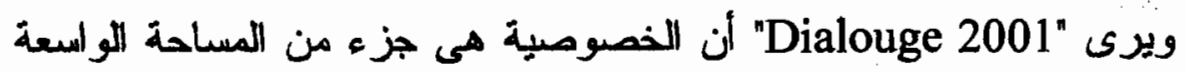

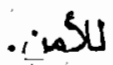

وقد أنشار "Odom et al 2002" الى أن استخدام تقنية الترميز (Encryption)

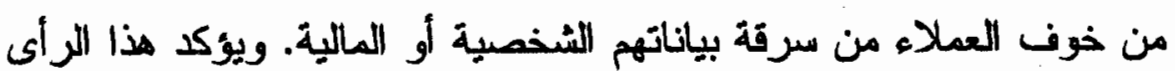

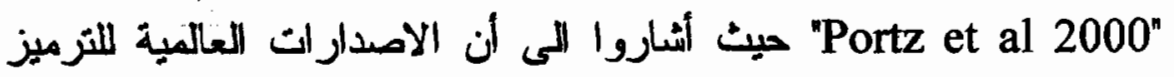
تتطلب كما كبيرا من الجه وقوة حاسبات خارقة ومتفوقة لكى تيخترقها. ويرى كل من "Richardson 2004" أن استخدام بطاقة الاثتمان في الشراء 
التقليدى أو الستخدامها عبر الهاتف، بعد أخطر من استخدامها على موقع

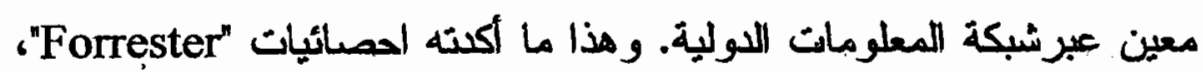
حيث أشارت الى أن التزوير التجارى عبر شبكيكة المعلومات الدولية نسبته

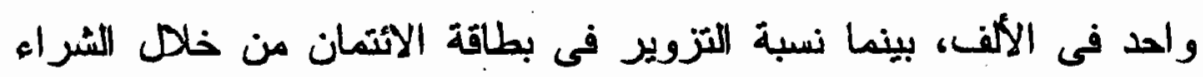

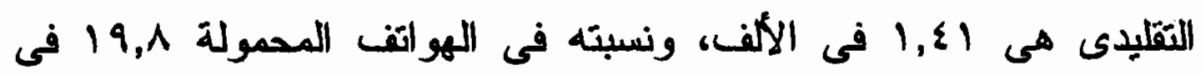

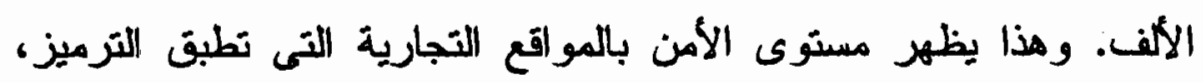
وصعوبة اختراق هذه التمنية.

والسؤال الذى يطرح نفسه الآن، اذا كانت تقنية الترميز توفر هذا

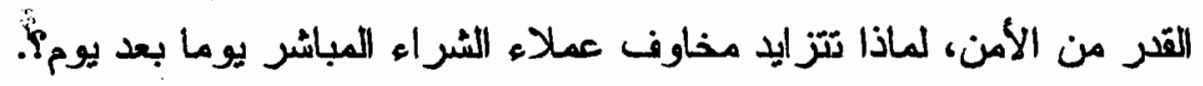
وتقع الاجابة على هذا السؤال على عاتق الصحافة التى تقوم بتضخيم الأمور

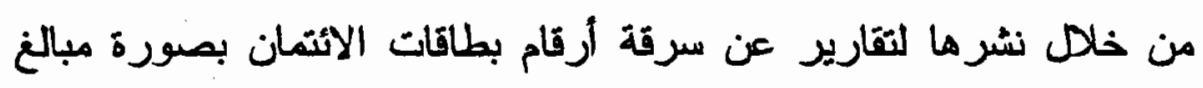

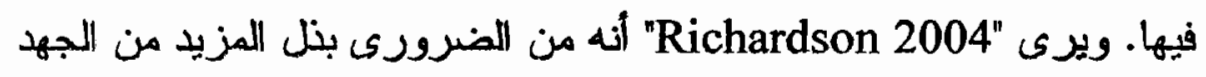

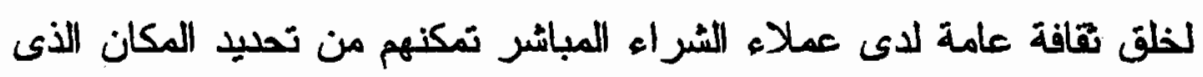

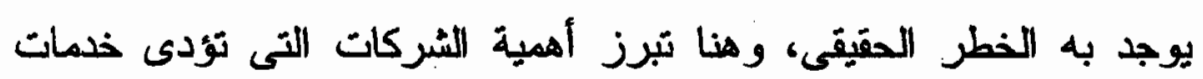

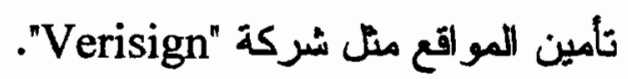

وقد أثشار "Tribunella 2002" اللى أن هناك العليد من الأسباب

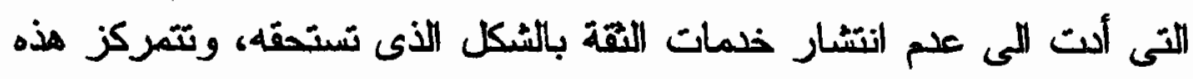

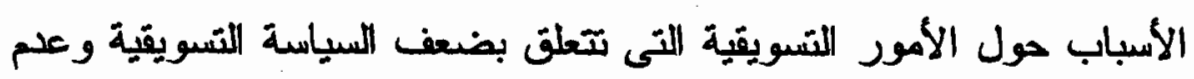

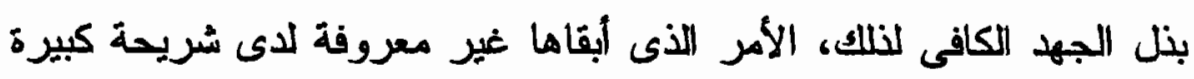

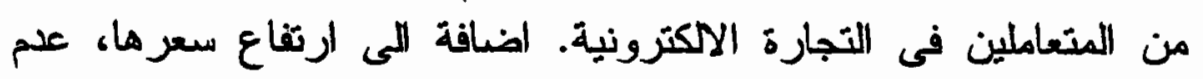

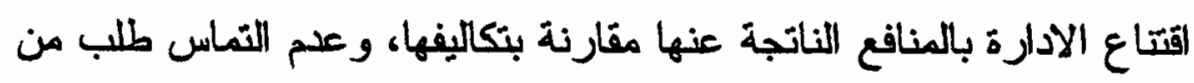
العملاء عليها لكونها خمات غير معروفة. 
وادراكا من المعهد الأمريكى للمحاسبين القانونيين لأهمية التسويق

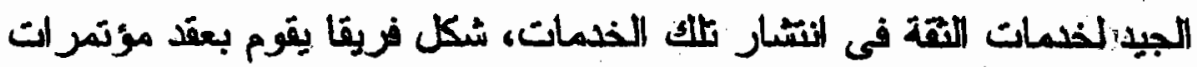

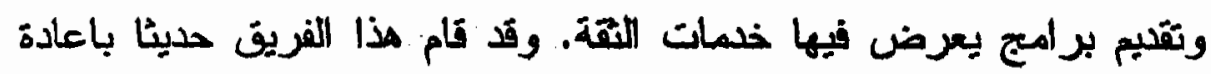

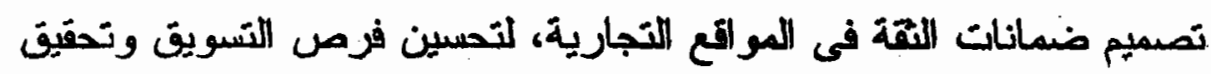

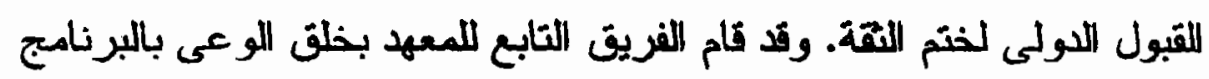

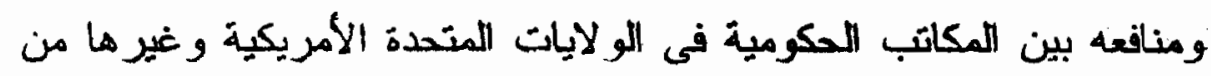
الدول التى تبنت هذا البرنامج مثل: كندا، فرنسا، انجلترا، الستر اليا، أيرلندا،

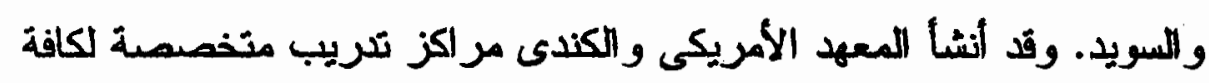
المحاسبين القانونيين النين يرغبون فى تأدية هذه الخدمات فى بلاددهم لتحقيقي

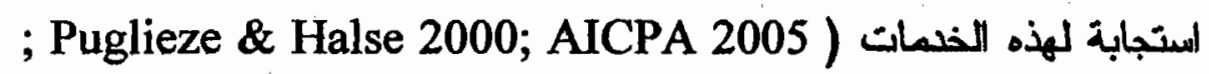

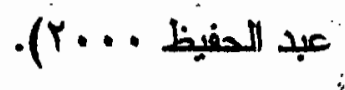

ومما يدمو للتقاول أنه لايوجد من بين أسباب عدم انتشار خدمات

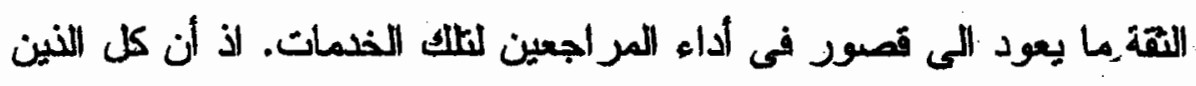

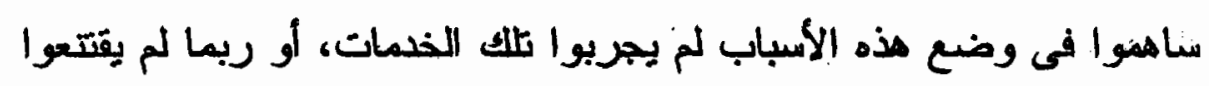

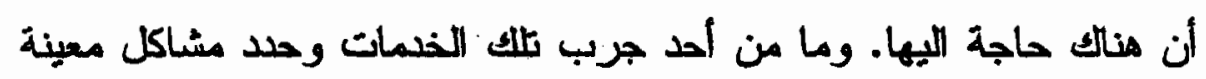

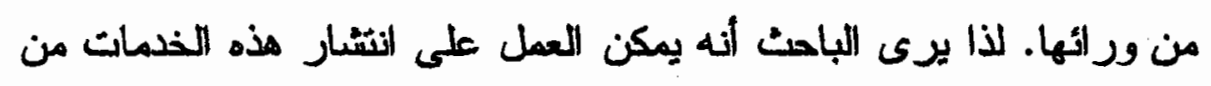

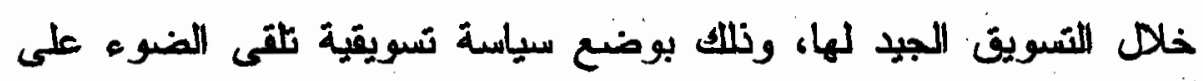
مخاطر التجارة الالكترونية وانعكاساتها العلبية على مستقبل المتعاملين.

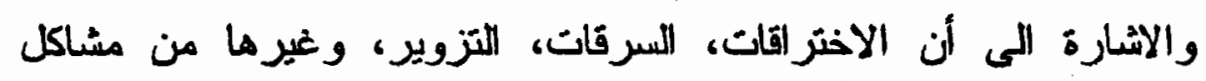

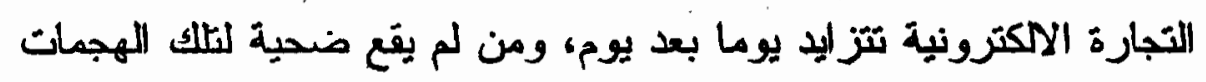
اليوم ربما سيكون غدا أو بعد غد. 


\section{المهرات المطلوب توالثما في المراجع لأداء خدمات الثقة}

تتو افر لدى المراجعين المبادىه والمعايير الأخلاقية المطلوبة التقييم واضفاء الثقة على نظم التجارة الالكترونية، ويمتكون المهارات

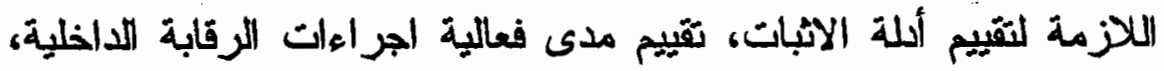

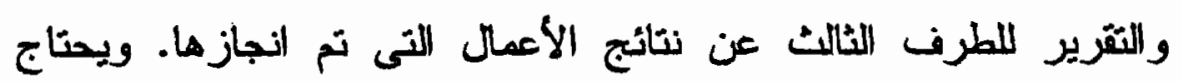

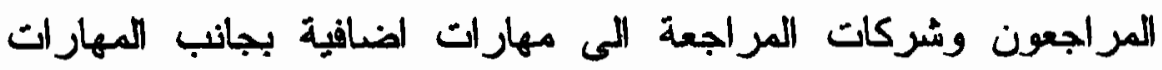

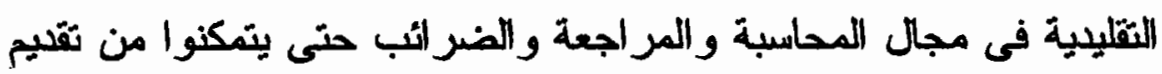

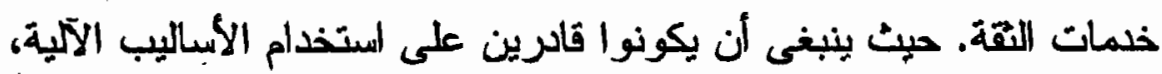

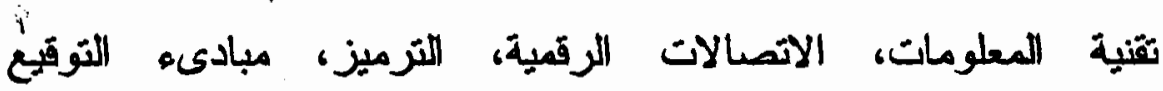
الأكترونى، والقرة على تخزين واستدعاء الأحجام الكبيرة من البيانات،

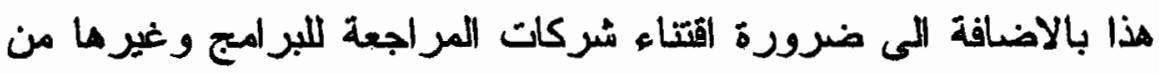
أدوات المر اجعة المبنية على التقنية الحسينة (AICPA 2005).

وقد أثارت اللجنة المنبقة عن معهدى المحاسبين القانونيين الأمريكى والكندى المى أن التأكيدات المطلوبة لخدمات الثقة بمكن أن

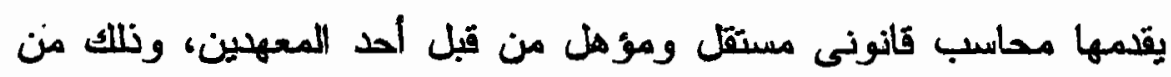

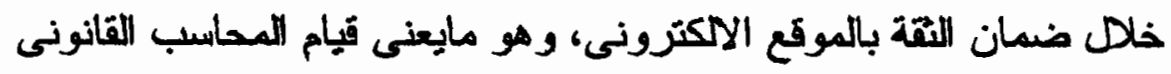

بالآنى: (Lanz 2002)

1- تقييم تطبيقات الأعمال لدى الموقع التجارى.

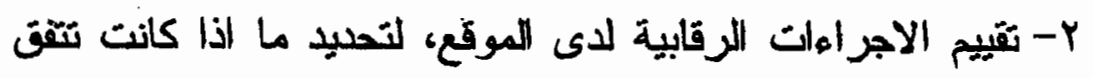

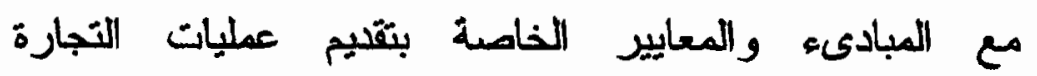
الالكترونية وحماية البيانات الخاصة بالعملاء.

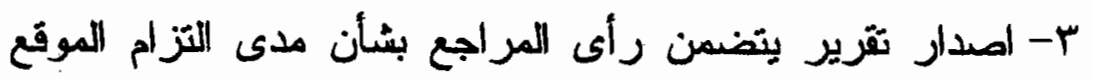

بهذه المبادىء و المعايير . 
ولكمى يكون البراجع تادرا على أداء خدمات اضفاء اللتحة بما يتفق

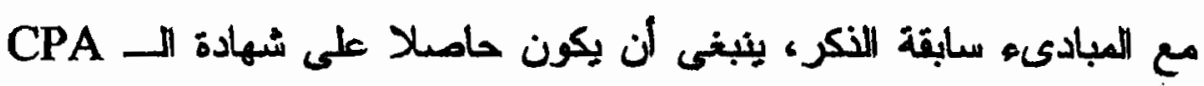

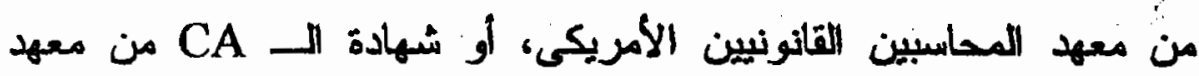

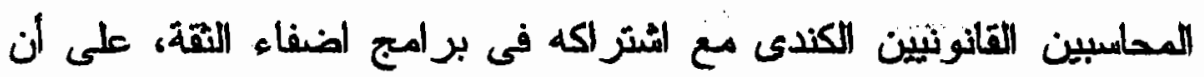

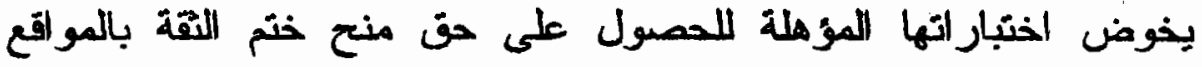
التجارية (Trust Seal)، والذى يضمن لعملاء وزاترى المواقع التجارية

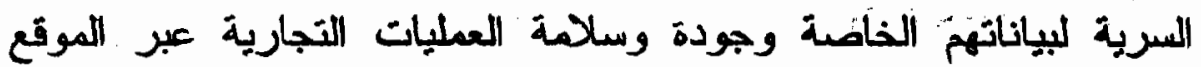

.(Fleming 1999)

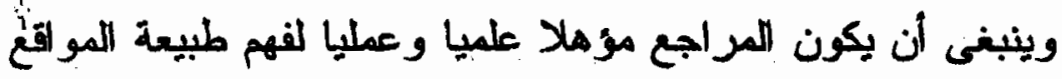
التجارية وما تنطوى طليه من ثثنية معلوماتية جليدة (Elliott 2000).

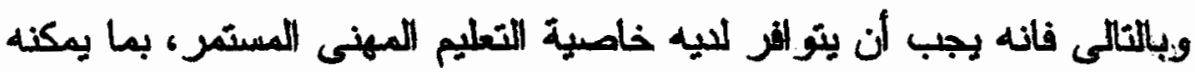

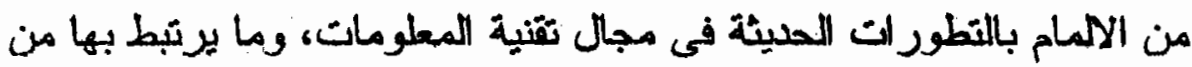

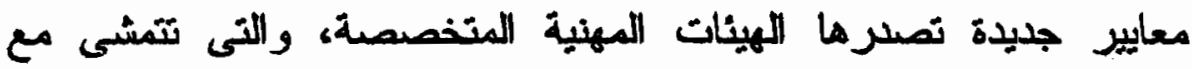
الخمات الجديدة المقمة فى مجال المراجعة (1997 (Elliott).

وقد أصدر الاتحاد الدولى للمحاسبين (IFAC) برامج دراسية

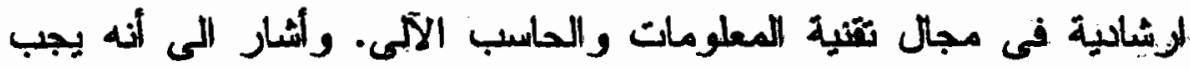

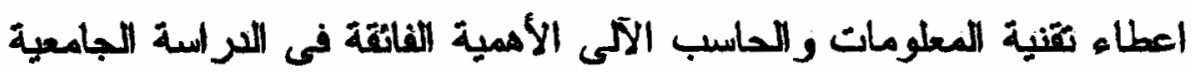

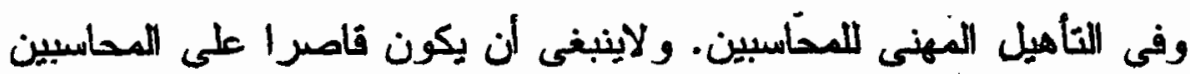

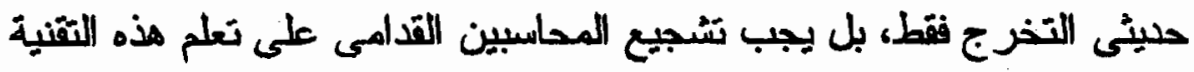
من خُلال برامج التعليم المهنى المستمر (Elliott 1997).

وقد تذاولت البرامج التى أصدر ها الاتحاد الدولى للمحاسبين ما يلى:

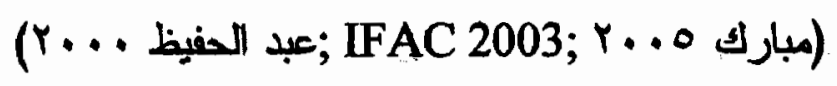


أولا: منطلبات التعليم العام اللززم لتثنية المعلومات، حيث بيضمن هذا البرنامج فترة معينة تتكون من فصلين دراسيين بجلب أن يغطى فيها

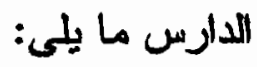

1- مفاهيم تقنية المعلومات للنظم التجارية الحيثية، حيث بشمل هذا

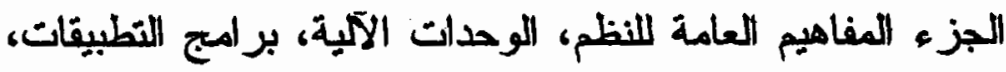

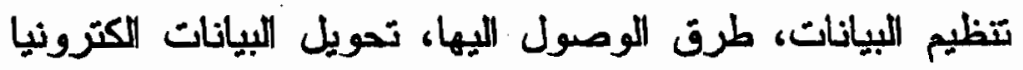
من خلا شبكة المعلومات الدولية، والتطبيقات المحاسبية

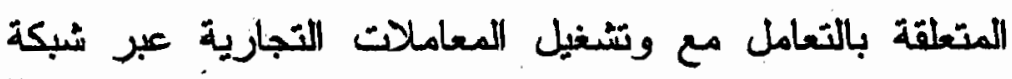
المعلومات الدولية.

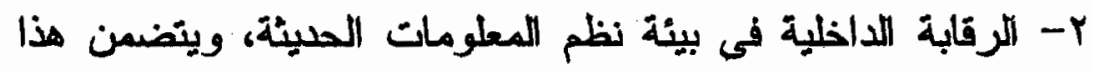

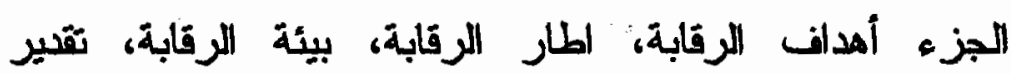

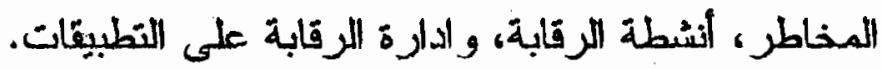

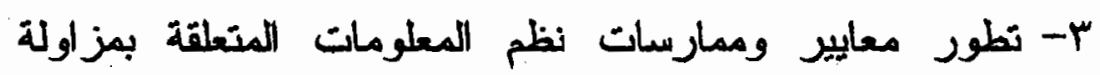

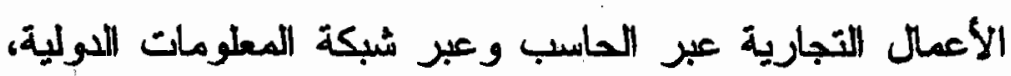

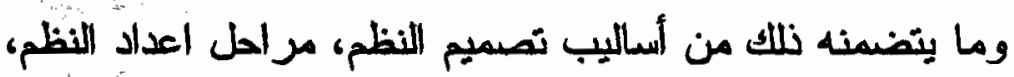

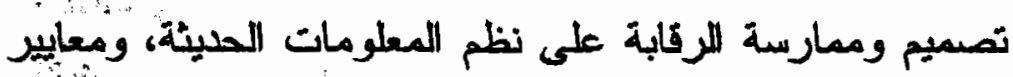

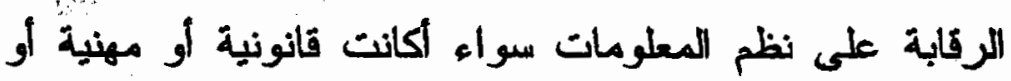

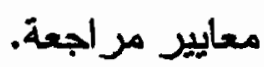

ثلتيا: معلومات خاصة ومهارات محدة ينبغى تو افرها لدى الدارس، ويتضمن هذا البرنامج فترة تتكون من فمل دراسى واحد، ويجب أن يغطى فيها الدارس ما يلى فئى

1- دراسة كافة الجوانب المتعلقة بتطبيقات ثقنية المعلومات وما تحتاجه من مكونات مادية، وخصوصا العناصر الأساسية 
المتعلقة بالشبكات ومكوناتها الرئيسية، وأفضل النماذج التجارية

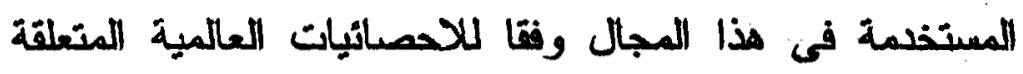
بالمكونات الأساسية للحاسبات والشبكات.

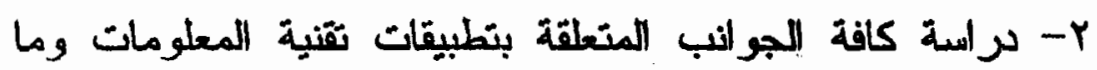
تحتاجه من برمجيات أساسية للحاسب تبدأ من نظم التشغيل المختلفة والمقارنة بينها، أوجه القصور في كل منها، البرمجيات

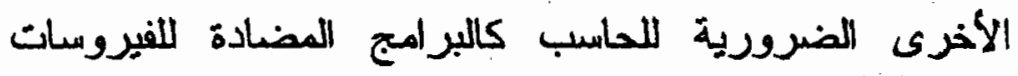
وحوائط النار (Firewalls) التى تستخدم في ردع المخترقين،

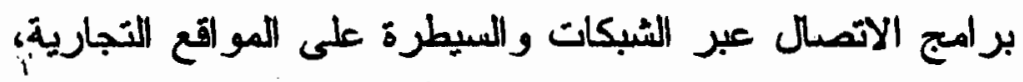

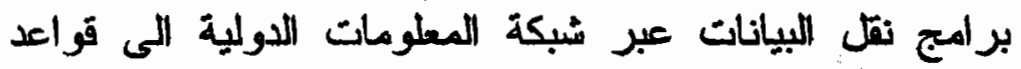

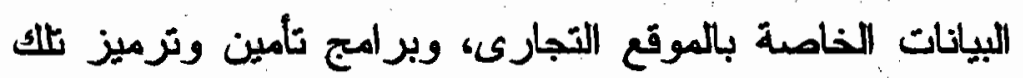
البيانات ومنع الوصول غير المصرح به اليها.

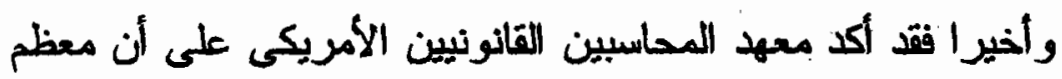

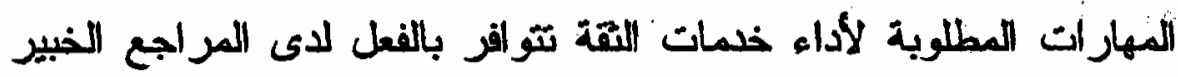

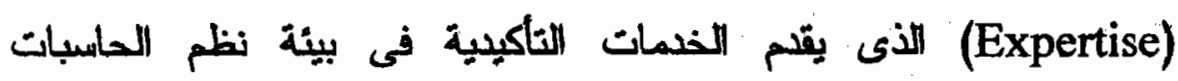

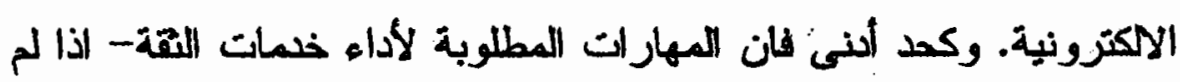

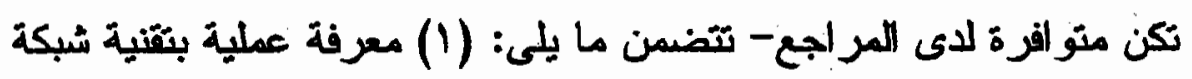

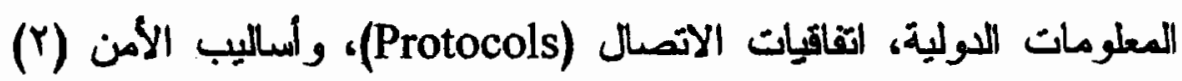

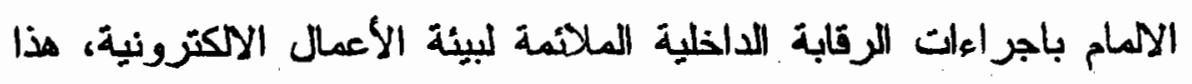

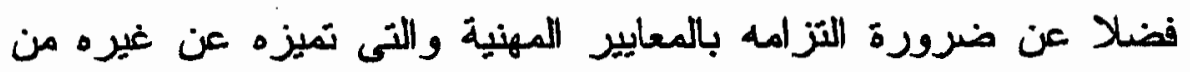
مقمى خدمات النقة (AICPA 2005). 


\section{دور خدمات الثمة فل تدنية فهوة الثمة في بينة التجارة الاكترونية}

يواجه أعمال التجارة الاكترونية على الألمل الثين من التحديات

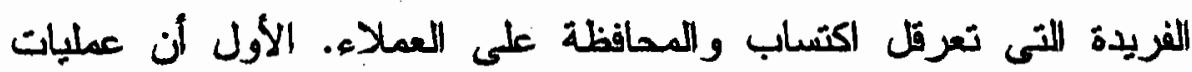

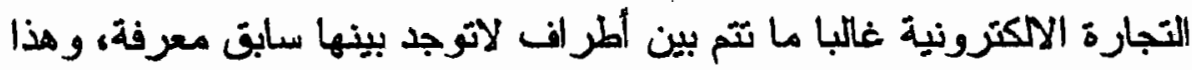
قد أدى إلى زيادة اهنمام العملاء بالخصوصية، الأمن وسلامة الأعمال.

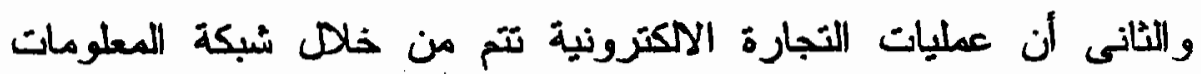
الدولية التى بنقصها الأمن. وكنتيجة لهذه التحديات فان العملاء لايتقون

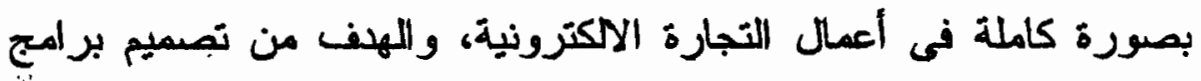

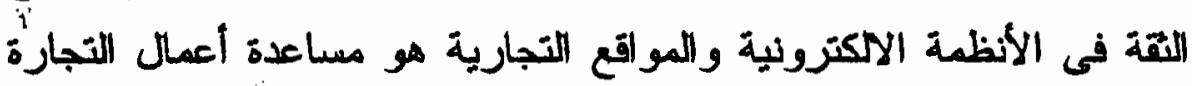
الاككترونية فى التخلب على هذه التحديات (AICPA 2004).

وقد ظهرت فجوة الثقة هذه فى سوق الأعمال الحيث، وزاد اهتمام

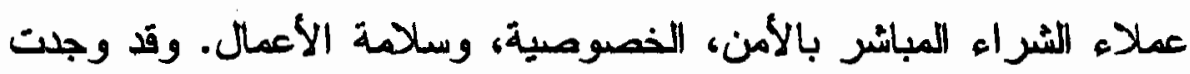

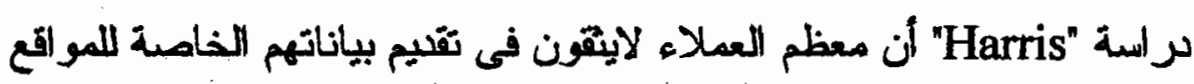

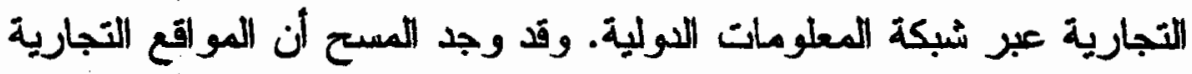

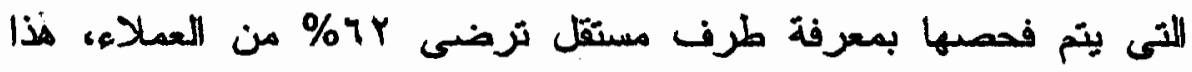

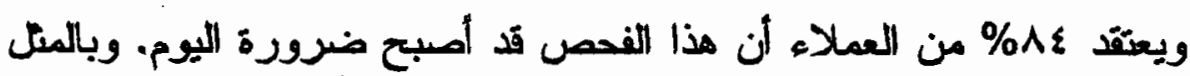

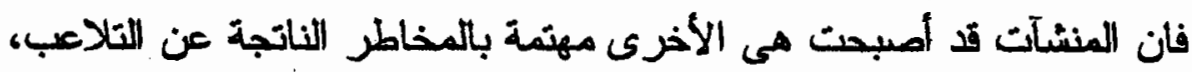

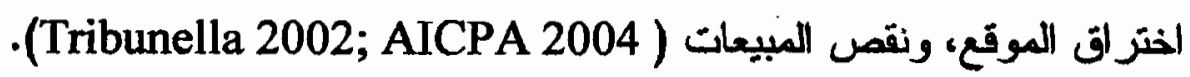

وتتمبز برامج الثقة فى الأنظمة الالكترونية والمواقع التجارية

بالآتى: (AICPA 2004)

ا-تشمل مجموعة من معايير التجارة الالكترونية، والتى تتكون من أفضل الممارسات والمنطلبات المنعارت عليها دوليا. 
Y- الفحص المسنقل للتحقق من أن الموقع يقابل هذه المعايير -

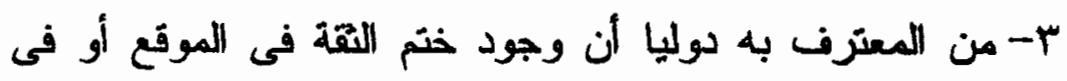
النظام، بعنى مقابلته لمعايير حازمة فى هذا المجال.

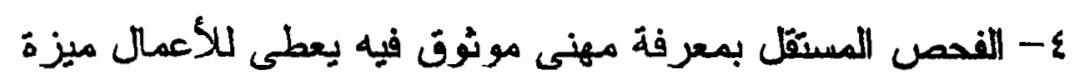
تنافسية. 0- الالتز ام بالمعايير العالمية يعنى العمل فى الأسواق الجنيدة بصورة أكثر فعالية. T- تننية مخاون العملاء، مما بعنى المحافظة عليهم واكتساب

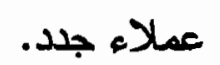
V- تحويل العملاء الثقليديين الى عملاء اللشراء المباشر، مما يؤدى الى تلنية تكلفة العمليات. 1- تبادل الخبرة الفنية فى مجلال التجارة الاككترونية عبر أنحاء

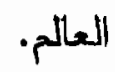

وقد أشار معهر المحاسبين القانونيين الأمريكى الى أنه بالنسبة

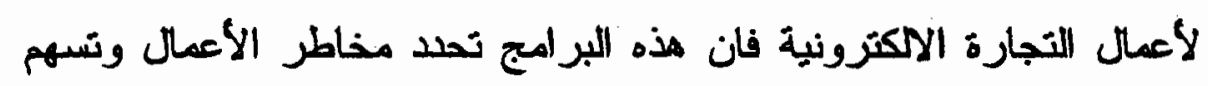

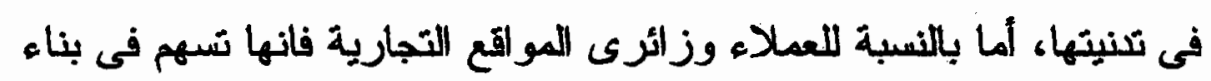

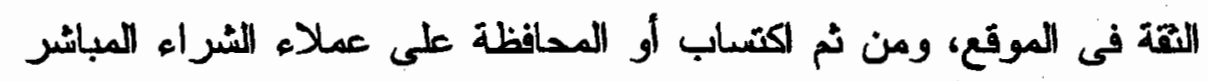
(AICPA 2004)

ويمكن للمنشآت النى نزاول التجارة الالكترونية واستوفت معايير

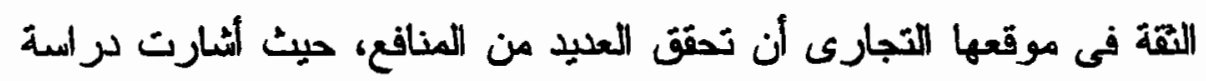

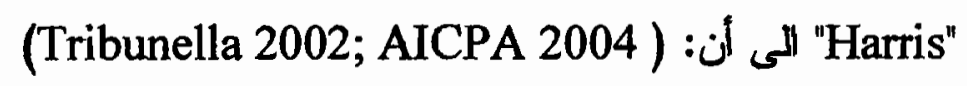

- التجارى تم فحصد بمعرفة طرف مستقل. 


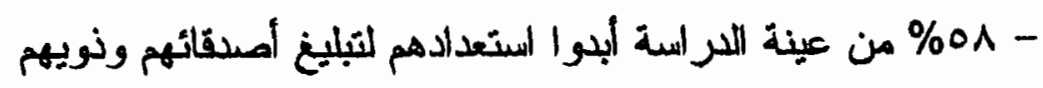
بالموقع التجارى فى حالة فحمه بمعرفة طرف مسنقل واستئفائه لمعايير الثقة.

وأيضا يؤدى الفحص المستثل للموقع التجارى الى تجنب مخاطر

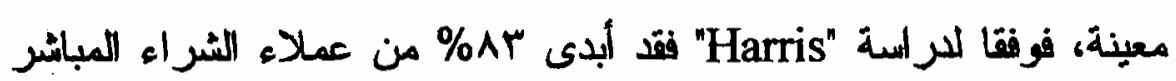

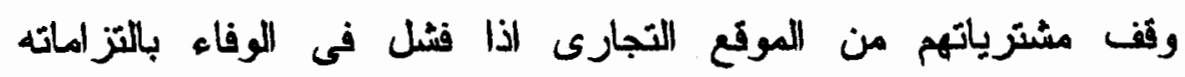

.(Tribunella 2002)

ونركز خدمات اللقة باعتبار ها خدمات تصديقية على مناطق الخطنز

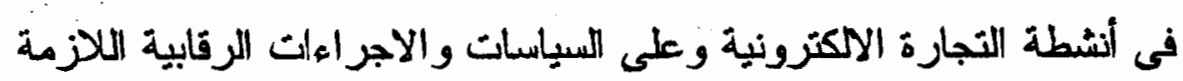
لادارة هذه المخاطر، ونلك الصالح كل من المنشأه وعملائها، وتككن

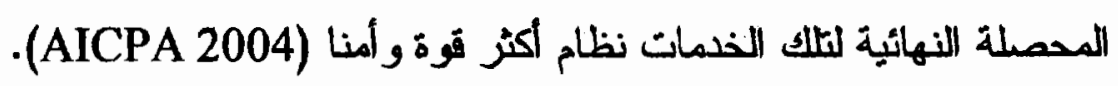

ويؤدى الفحص الثامل للموقع التجارى بمعرفة أخصائى مؤهل،

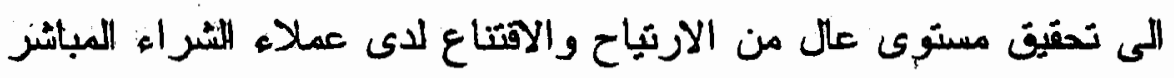

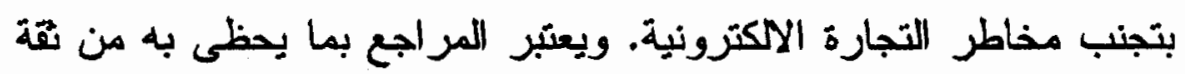

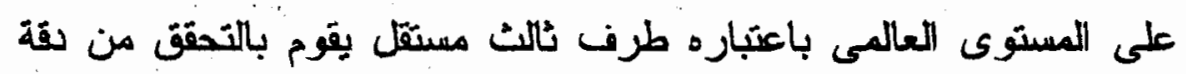

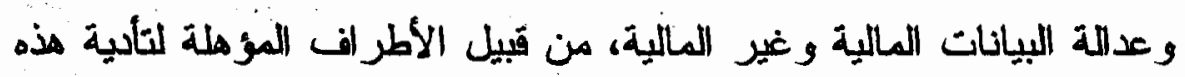
الخنمات. وتد بنت منشآت المحاسبة والمراجعة سمعتها كخبراء فى مجال

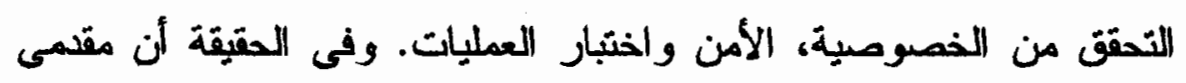

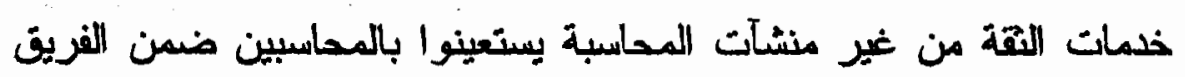

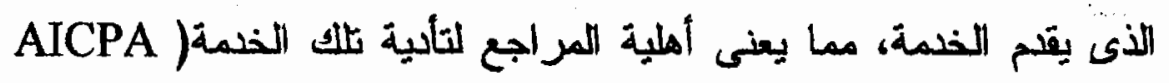
. 2004 
وثد أكد هذا كل من "Pugliese \& Halse 2000"، حيث أشثارا

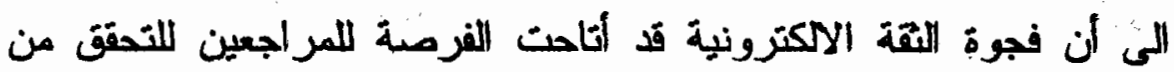
الأنظمة الاككترونية أو لفحص الجوانب الأساسية للتجارة الالكترونية، ونلك الكية

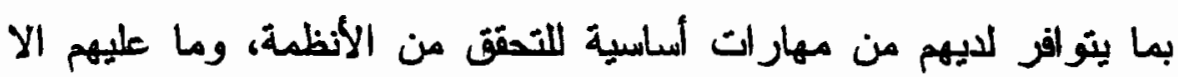

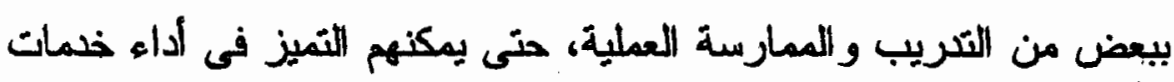
الثقة.

وقد توملت نتائج رلسة "Portz et al 2000" والتى شملت 9 وع

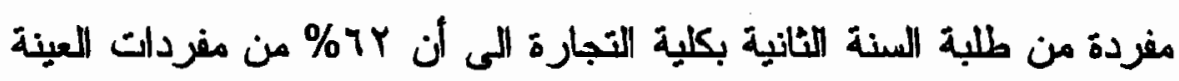

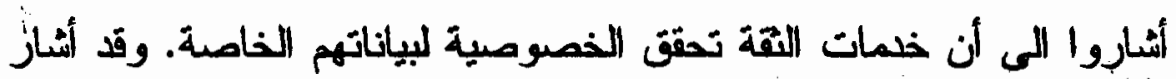

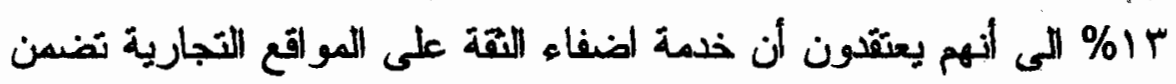

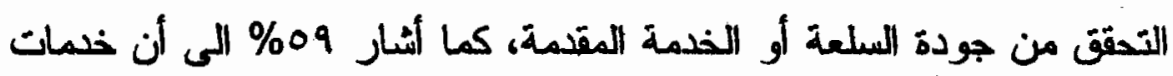

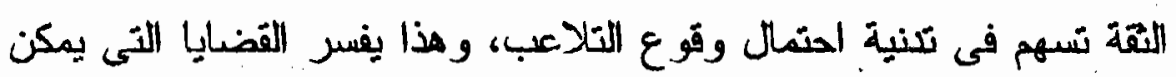

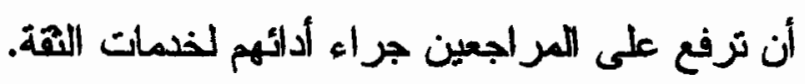

\section{مسنولية المراجع الخارجى عثد تقديم لخدمات الثقة}

أدى ظهور خدمات اللقة فى الأنظمة الاكترونية والمواقع التجارية

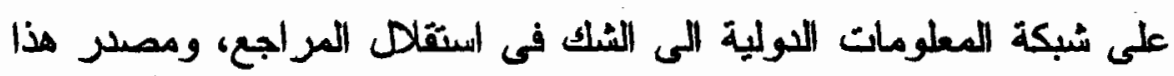

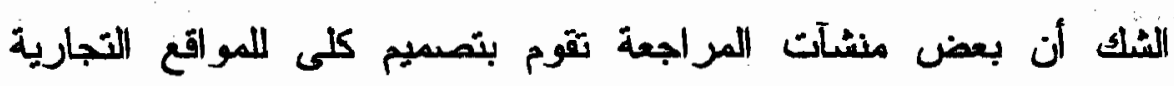

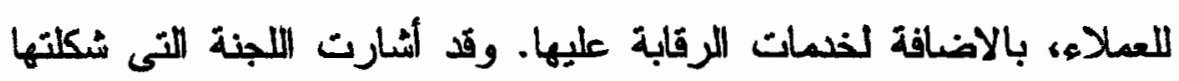

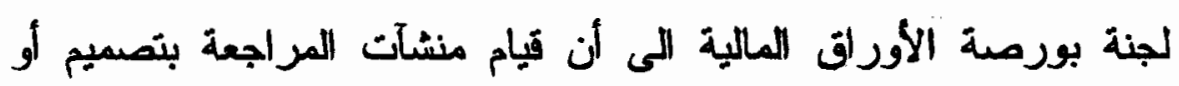

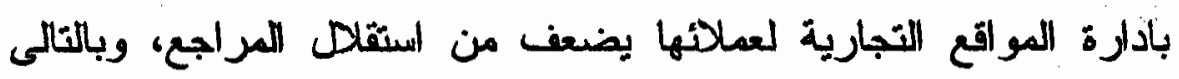
تضاف للعطليات التى تؤنز على استقلاله (2000 Salterio). 
وقد أشارا "Houston \& Taylor 1999" الى أن المفاهيم الحديثة

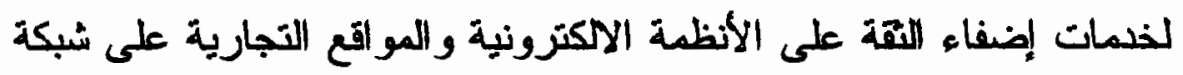

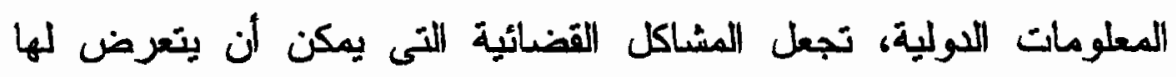

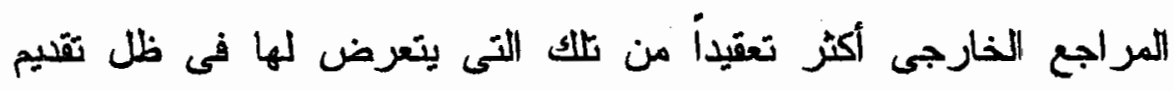

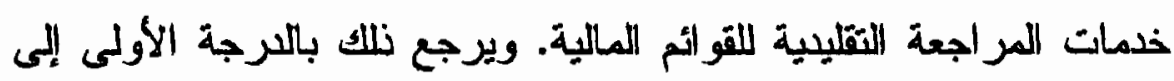

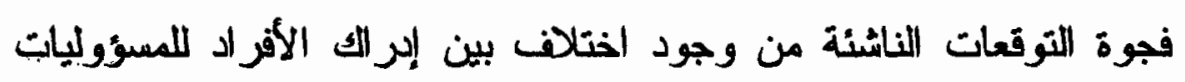

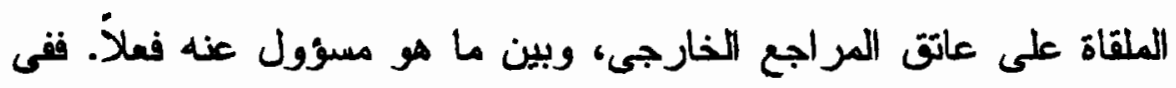

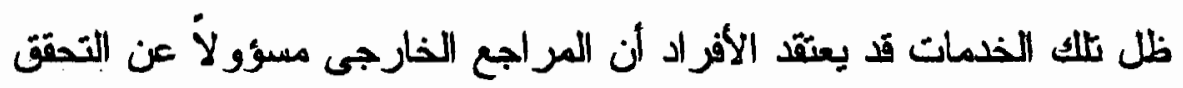

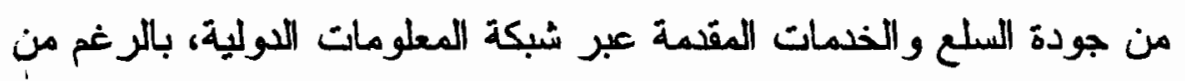

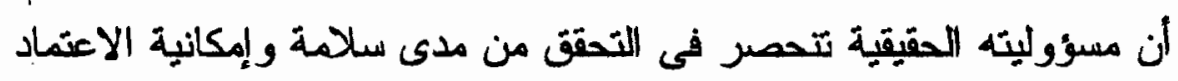

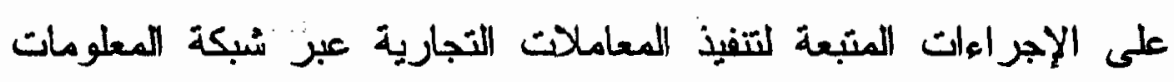
المولية بطريقة آمنة.

وقذ قدم معهد "المحاسبيين القانونيين الأمريكى نموذجاً، كمحاولة

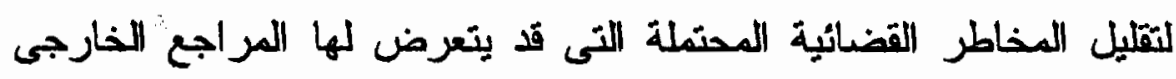
نتيجة لتقبيمه تلك الخمات، ويتضمن هذا النموذج خطوتين هما: ( Pacini (\& Sinason 1999

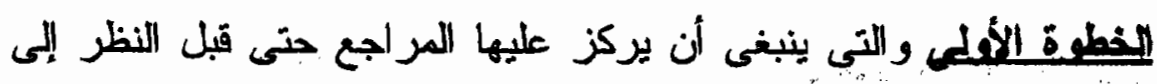

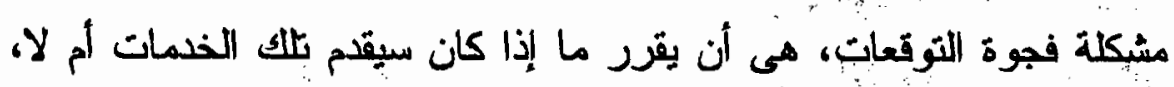
بناء على عدة عنامر منها:

- - ينبغى على المراجع الخارجى النظر إلى العوامل التى فذ تساعد

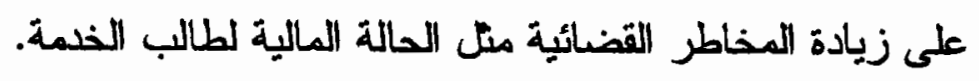


- ينبغى عليه أن يقوم بتقبير مقدار الخسائر التى قد تتسبب نتيجة وجود مساعلة قانونية، قبل الالتز ام بتقيم تلكئك الخدمات.

- مقارنة المخاطر بالعائد المحقق من تلك الخدمات، ثُم بعد نلك يقرر ما إذا كان سيقدم تلك الخمات إلى العميل أم لا.

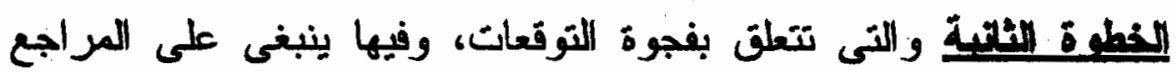
الخارجى أن يلفت نظر مستخدم الموقع التجارى لحدود بلك الخمات وحقيقة ما تيضمنه، فعلى سبيل المثلال:

- ينبغى أن يذكر المراجع الخارجى أن تلاك الخدمات لا تقدم ضماناً لجودة السلع والخمات المقدمة عبر الموقع.

- أن تلك الخمات لا تُقم ضماناً بان السعر الذى سيتم على أساسه

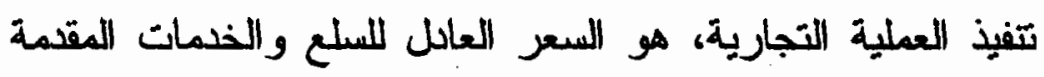

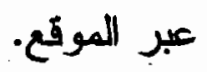

وينبغى أن نعرض مثل ثلاك الأمور على الموقع التجارى نفسه، او ترفق بتشرير المراجع الخارجى.

ويرى "Houston \& Taylor 1999" أن وجود احتمال للمسائلة

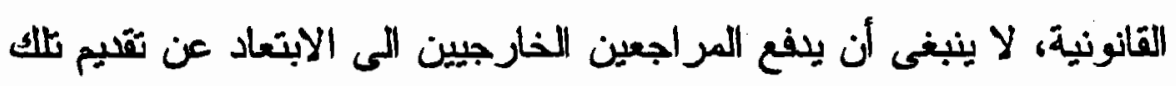

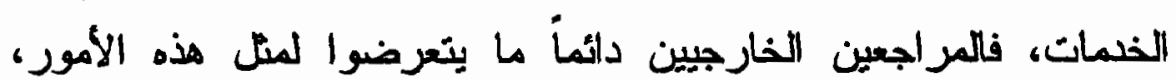
وحيث أن ثلاك الخمات هى خلمات جليدة، فإن مقدار المخاطر المرنبطة بها غير محددة حتى الآن.

ونظلص مما سبق الى أن أداء المراجع لخدمات اضفاء الثقة بما ينو افر لليه من مصداقية ومهارات تؤهله لنلك، يمكن أن يؤدى الى تلنية 
فجوة التقة فى بيئة التجارة الالكترونية. و هذا ما سعى الباحث لاستكثافه من

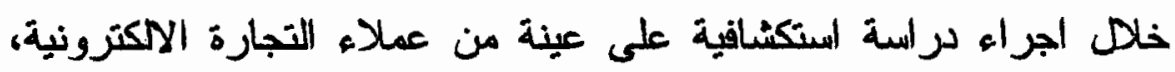
وذلك فى الجزء التالى من البحث.

\section{بـ الدراسة الاستكشافية}

لأغراض تحقين هدف البحث والذى يتمثل فى التعريف بلور

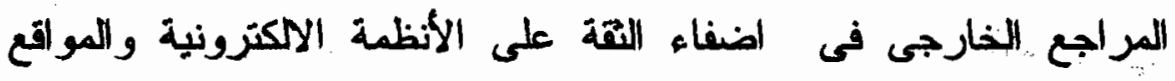
التجارية عبر شبكة المعلومات الدولية فى ضوء المبادىء والمعايير التى

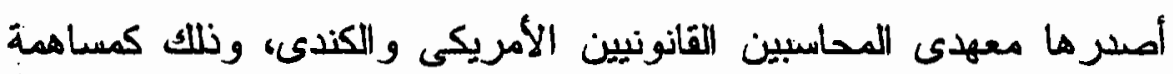

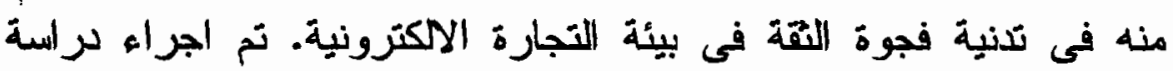
استكشافية، وخللك وفقا للخطو ات الآتية:

1// - عينة الدراسة الاستكشافية

تضمنت عبنة الدر اسة الاستكشافية 10 مفردة من طلبة الدراسات العليا

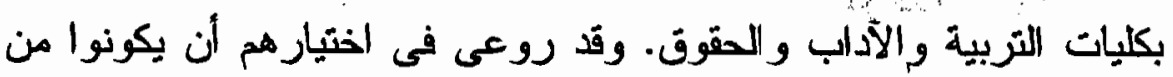

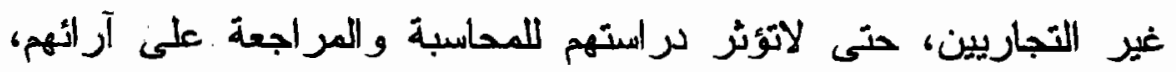

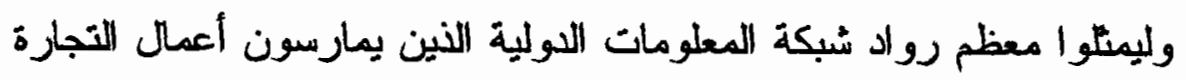

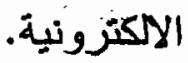

r/r/ أسلوب جمع بياتات الدراسة الاستكثلقية

تم جمع بيانات الدراسة الاستكشافية بإستخدام أسلوب قائمة

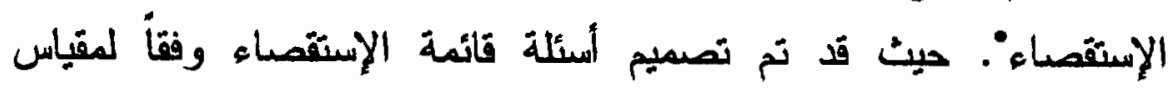
"ليكارت" نو الست نقاط، بإستاثاء سؤ الين تم صياغتهما للاجابة عليهما بنعم 
أو بلا. وفي بيان مرفق بقائمة الاستقماء، تم توضيح بعض المغاهيم الواردة بقائمة الاستقصاء مثل: التجارة الاكترونية، خلمات اضفاء الثقة ( Trust

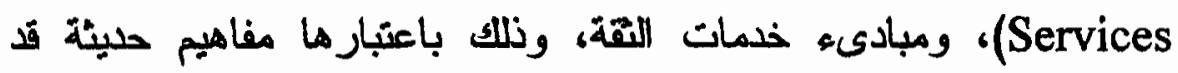

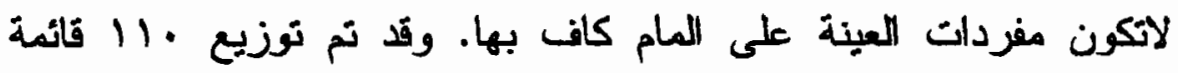
إستقصاء على عينة الدراسة، استلم منها 90 قائمة إسنقصاء إسبتبعد منها نالثة لعدم إستيفائها بالكامل وسبعة لعلم ممارسة المستقصى منهم اللتجارة الالكترونية من ثمبل. وبهذا تكون تو ائم الإستشصاء الكاملة والملائمة والتي إستخدت في التحليل مي قائمة، وهي التي تمثل إينجابات مفردات عينة

الار اسمة الاستكثافية.

r/r- الأسليب الإحصائية المستخدمة في تحليل بيانات الاراسة

الاستكشافية

قام الباحث عند تحليل البيانات التي تم الحصول عليها عن طريق الاستقصاء، باستخدام أسلوب النسب المئوية ، حيث تم التمثيل البياني لنتك النسب، واستخدامه كمؤشر ات وصفية لاستجابات عينة الدر اسة الاستكثافية.

r/ - تحليل بياتات الدراسة الاستكشافية

باستخدام أسلوب النسب المئوية كمؤشرات وصفية لاستجابات مفردات عينة الدراسة الاستكشافية، ومن خلال التمثيل البيانى لها تم التوصل الى النتائج الآتية:

1- أشارت نتائج الاسنقصاء الى أن ما بتراوح بين • و و 90\% من

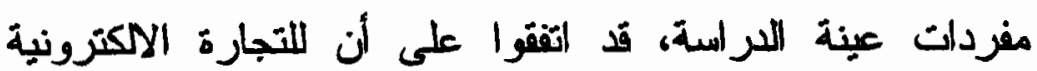
مزاياها من وجهة نظر العملاء، و هذه المزايا وفقا لترتيب مفردات

العبينة كما في الشكل الآتى:

$-\{A-$ 


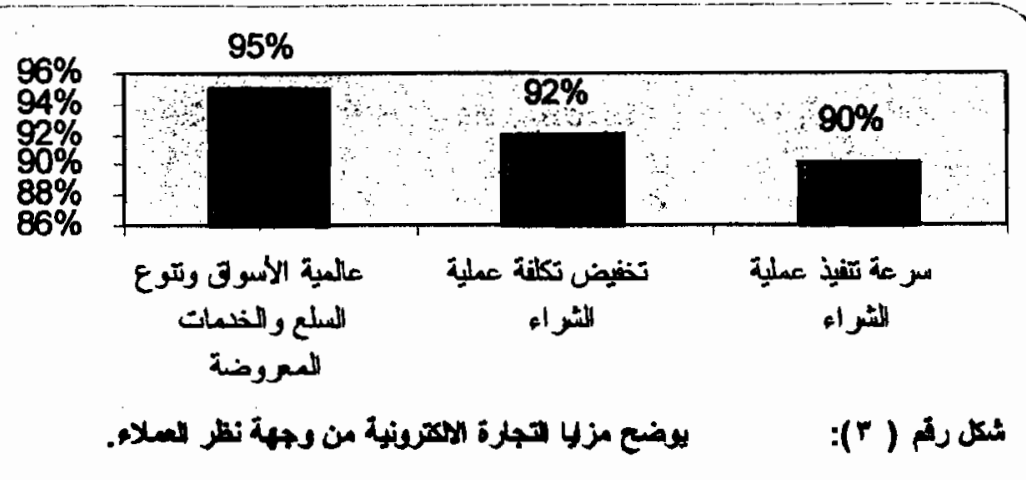

وهذا يشير الى ادراك مفردات العينة للمزايا التى يمكن أن تفقها التجارة الالكترونية بالنسبة لهم.

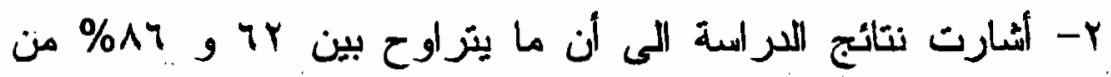

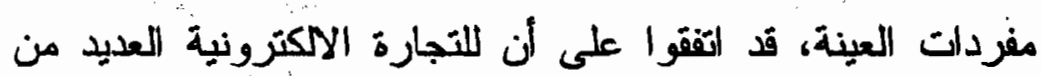
المخاطر ، وهى وفقا لترتيب مفردات العينة كما بالشكل الآتى:

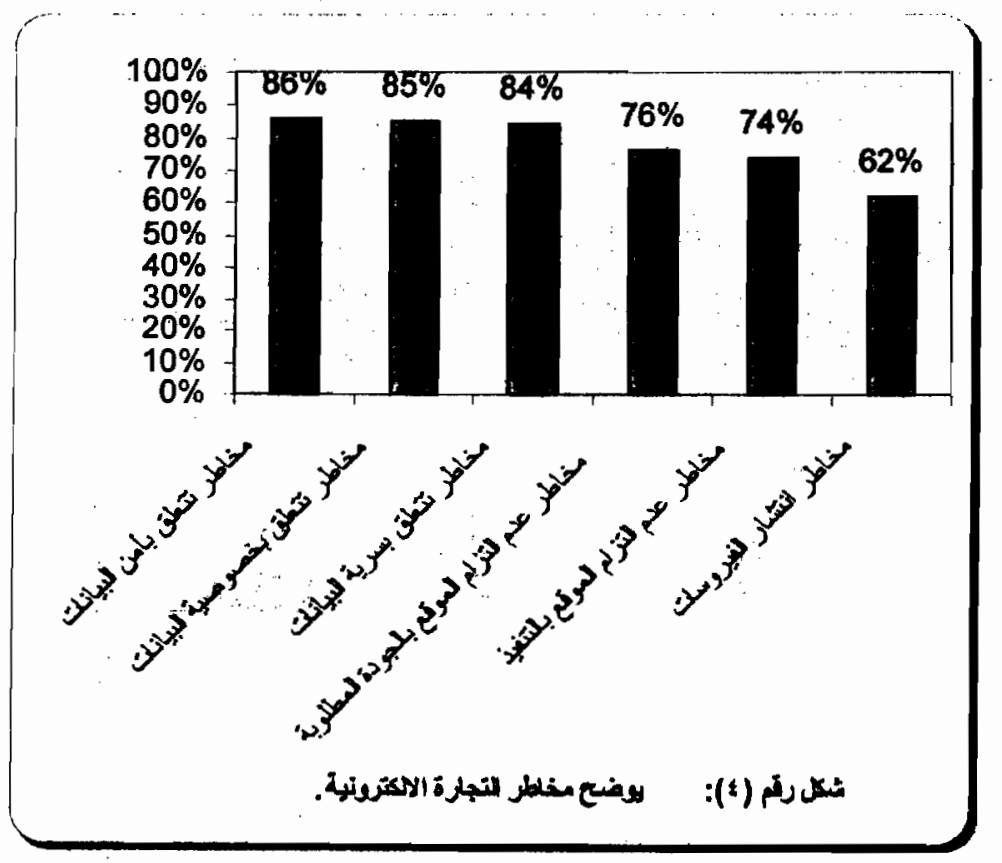

وتقسر هذه النتائج مدى اهتمام عملاء التجارة الالكترونية بالمخاطر التى تحيق بأمن، خصوصية، وسرية بياناتهم الخاصة، حيث احتلت عندهم 
أولوية متقدمة. وتتفق هذه النتائج مع غير ها من نتائج الدراسات السابقة،

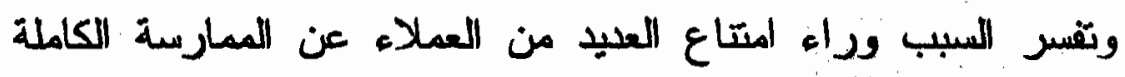

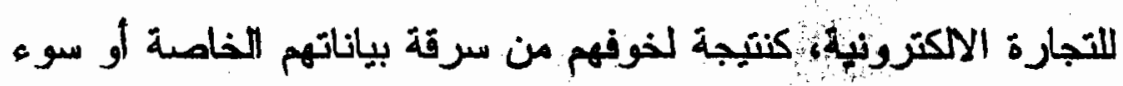
استخدامها.

r- أشارت نتائج الاستقصاء الى أن 919\% من مفردات عينة الدراسة

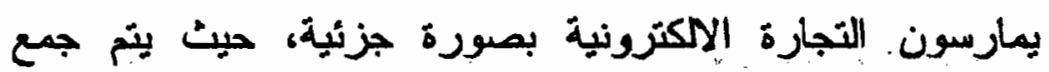

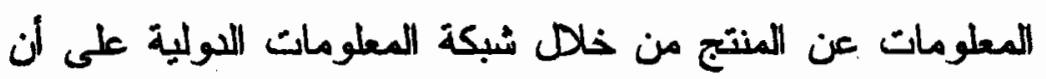

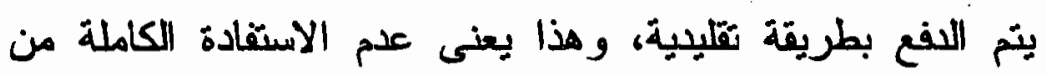

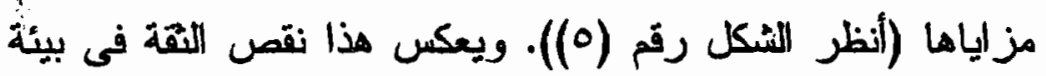

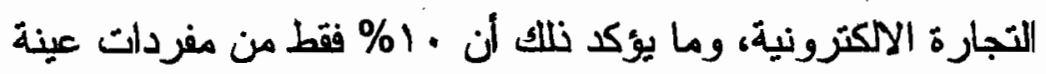

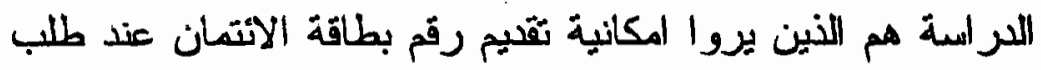

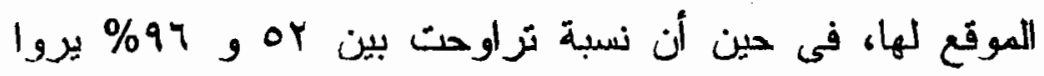

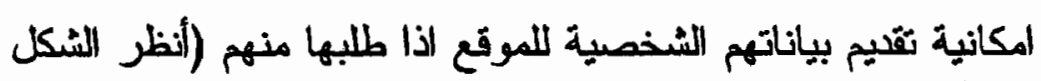

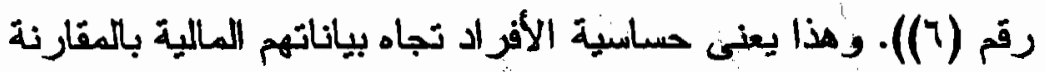

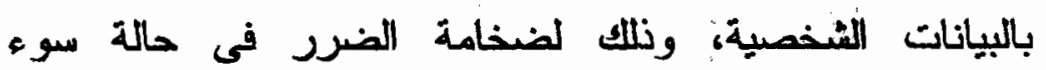

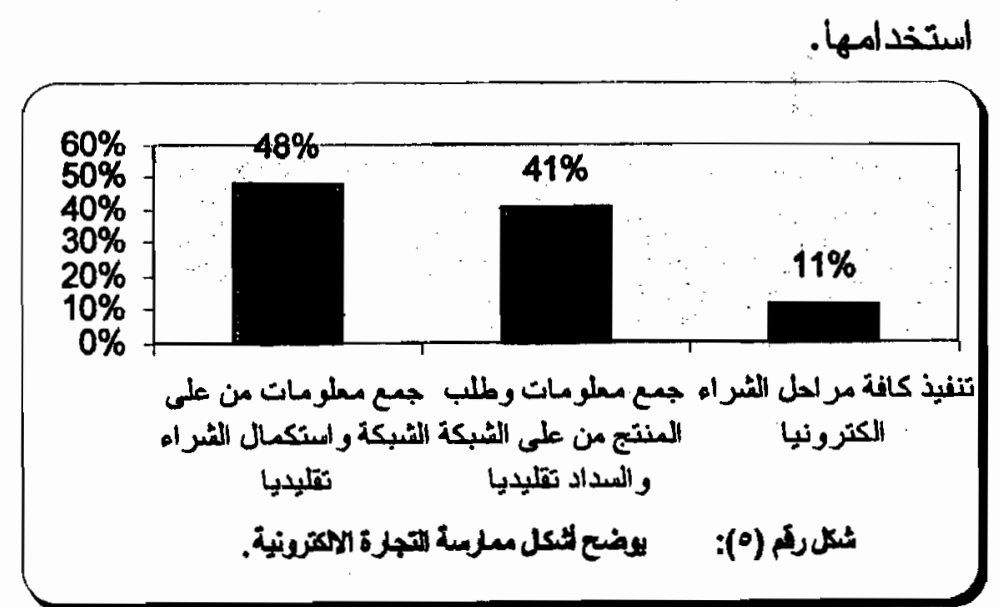




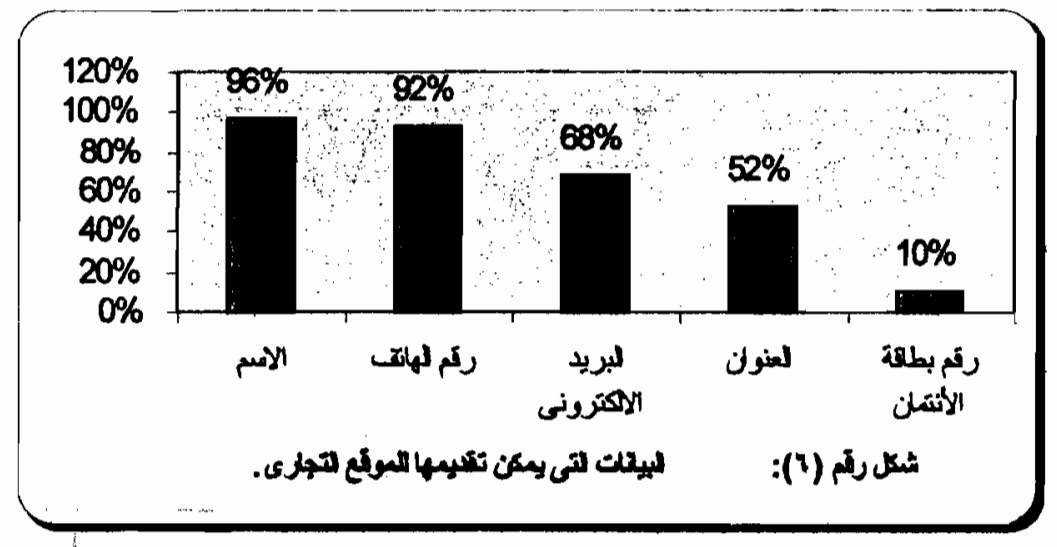

وتفسير نلك أن مخاطر التجارة الآكترونية قد ولات لدى الأفراد عدم الثقة فى المواقع التجارية، جعلتهم بحجمون عن تقليم بياناتهم الخاصةً

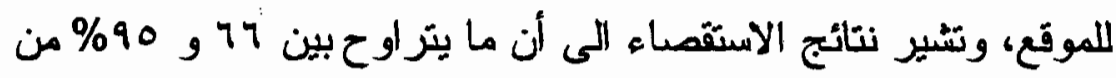

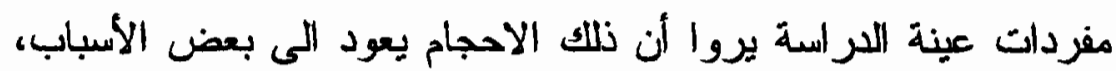
وهى وفقا لأهميتها من وجهة نظر هم كما بالشكل الآتى:

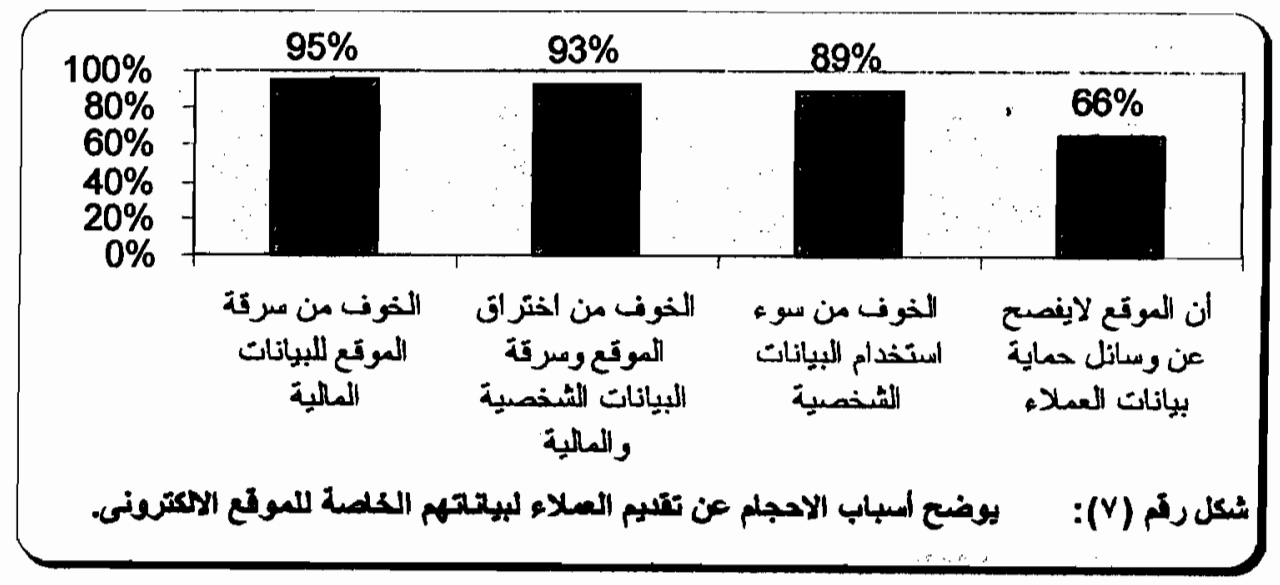

ولعل هذه المخاوف تمثل الحافز والمحرك الرئيسى المؤسسات المهنية فى مصر والعالم العربى نحو تطبيق خذات الثقة، وذلك حتى يمكن تننية فجوة الثقة فى بيئة التجارة الاكترونية. 
ع- أثارت نتائج الاستقصاء الى أن 10\% فقط من مفردات عينة

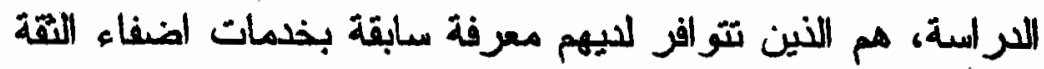

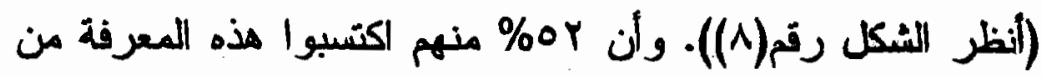

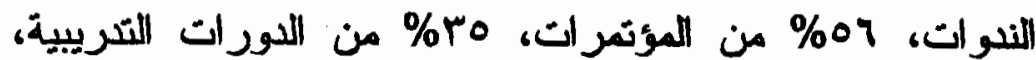
و 0 ؛ من خلال القراءة عن تلك الخدمات فى الكتب أو المجلات

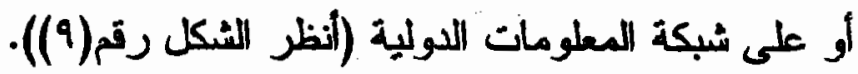
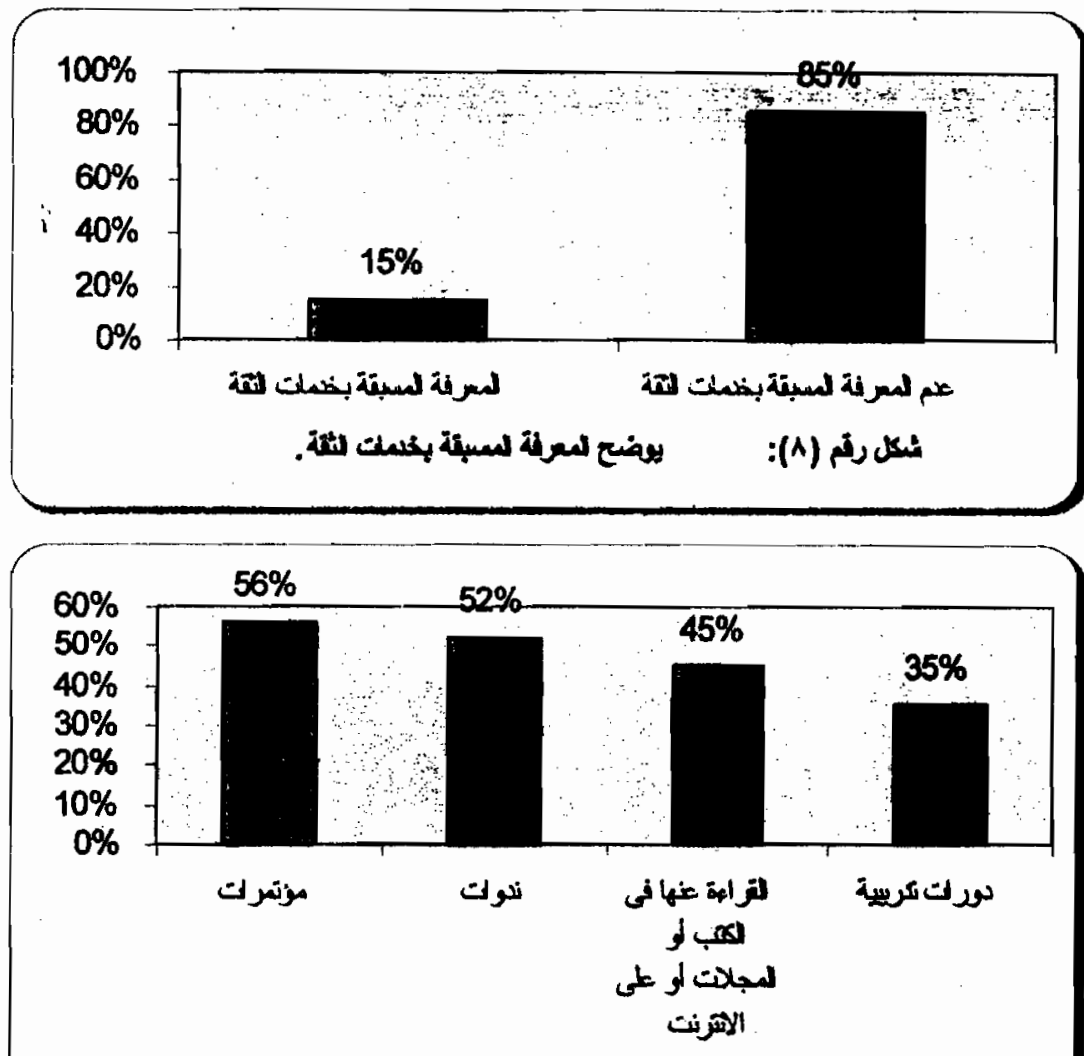

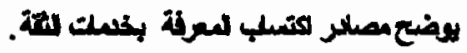

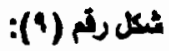

ويلل هذا على أن خمات الثقة لم تتل حظها من الاعلان الكافى عنها

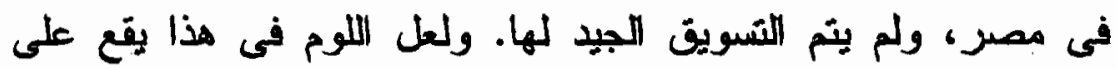

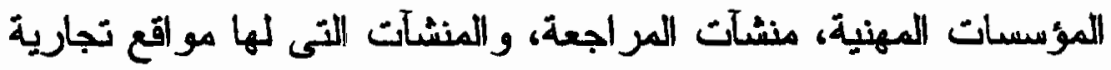
على شبكة المعلومات الدولية، حيث لم تعطى تلك الخدمات ما تستحقه 
من الاعلان. وهذا ما ينبغى أن تضنعه فى مقدمة أولوياتها خلال الفترة

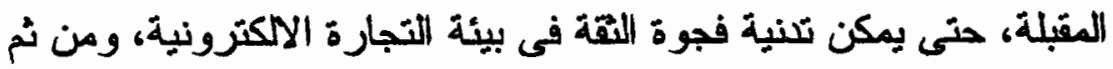
رواج التجارة الالكترونية، وبصفة خاصة على المستوى العربى.

0- أشارت نتائج الاستقصاء الى أن 79\% من مفردات عينة الدراسة

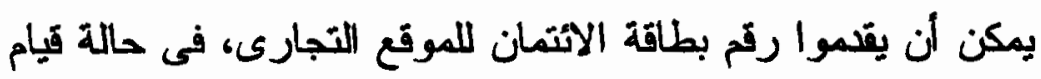

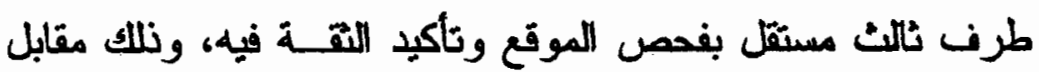

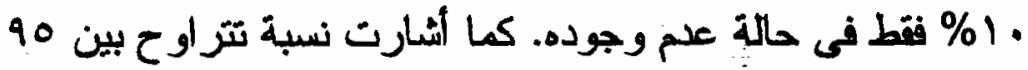

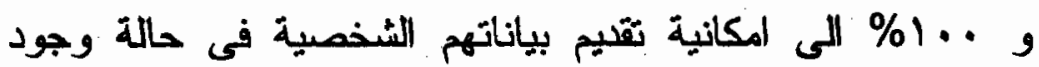

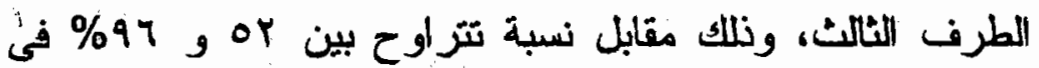
حالة عدم وجوده، ونلك كما يتضح من الشكل الآتى:

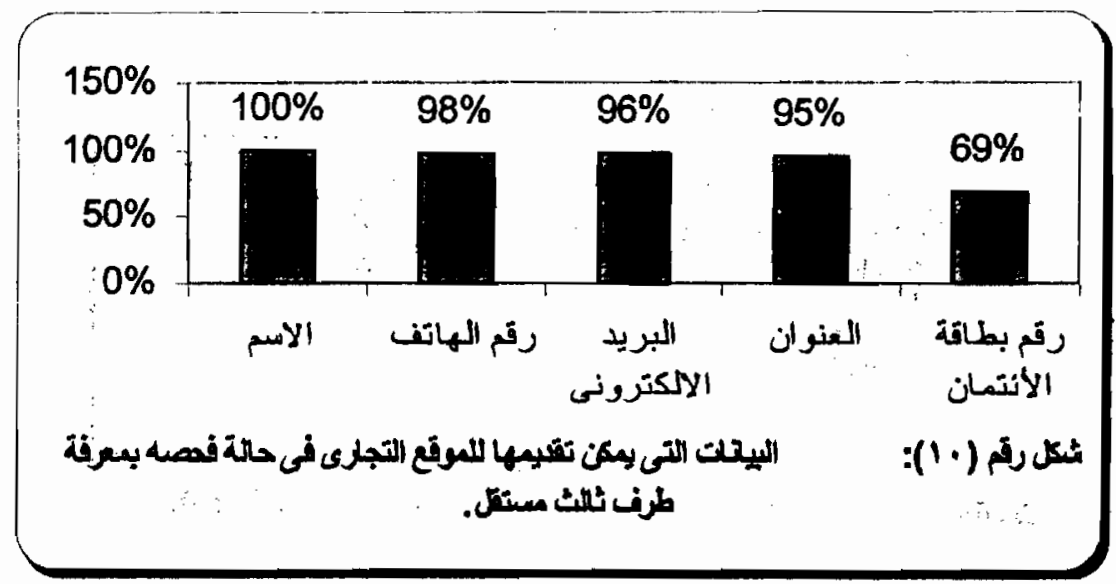

وقد أشارت النسبة الأكبر من مفردات العينة وهى 0؛ \% الى أنهم

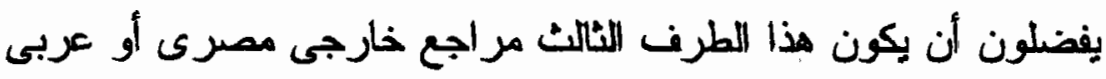

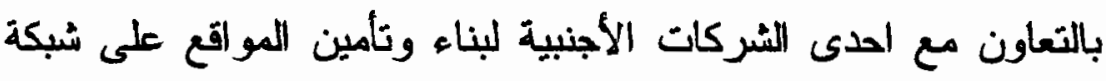

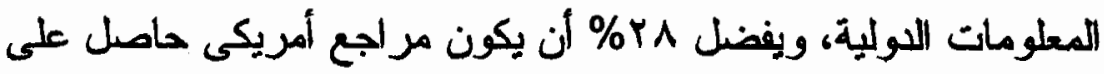

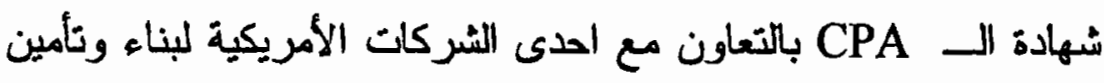

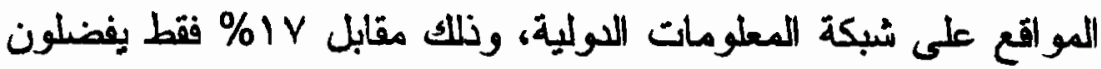


أن يكون الطرف الثالث مراجع خارجى مصرى أو عربى بالتعاون مع الثع المعاء احدى الثبركات المصرية أو العربية لبناء وتأمين المواقع على شبكة القيا المعلومات الدولية، ونلاك كما بالشكل الآتى:

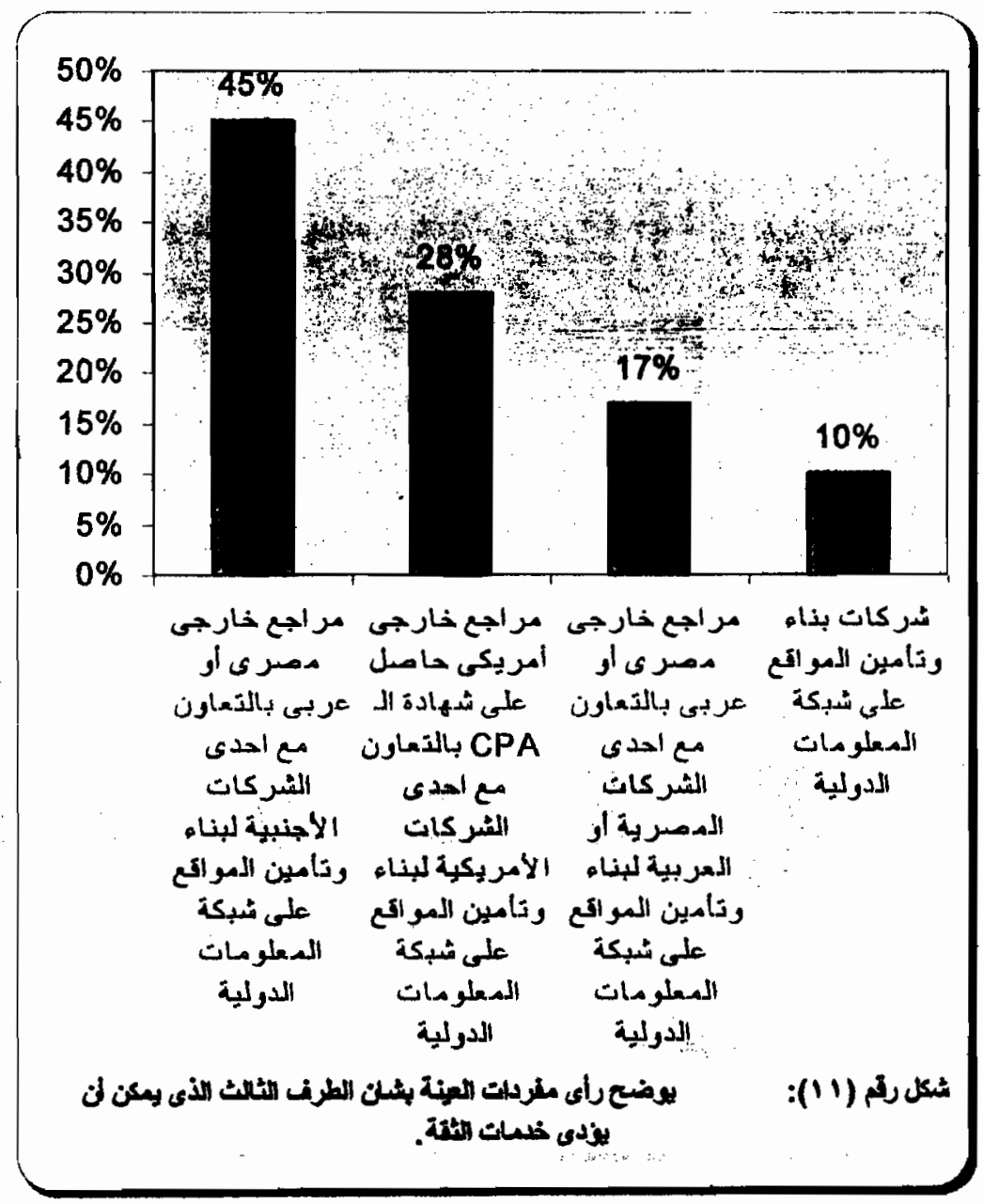

ولا يرجع هذا الثفضيل لعدم تقة فى المراجع الخارجى المصرى أو

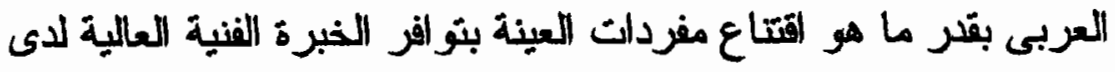

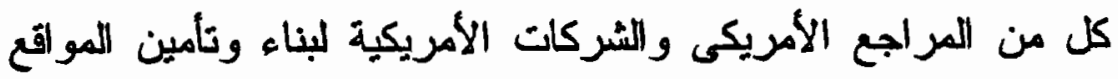

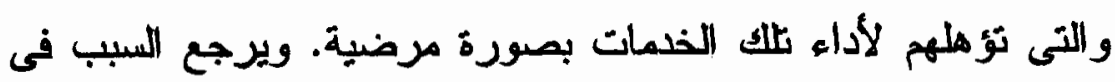
نللك الى أن لهم السبق في هذا لادهاء المجال، ومن هنا كان رأى مفردات

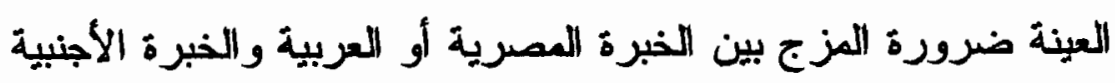


بغرض نقديم خدمات الثقة فى السوق العربى، بما يؤدى الىى تلنية فجوة الثقة فى بيئة التجارة الاككزونية فى السوق العربى.

7- أشارث نتائج الاستقماء الى أهمية تحقيق كافة مبادىء خبمات

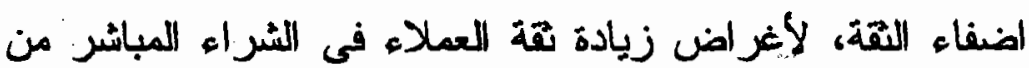
المواقع التجارية على شبكة المعلومات الدولية، حيث نز اوحت نسبة الاتفاق على أهمية تحقت هذه المبادىء بين ع V و ب9\%، وذلاك كما يبين الشكل الآتى:

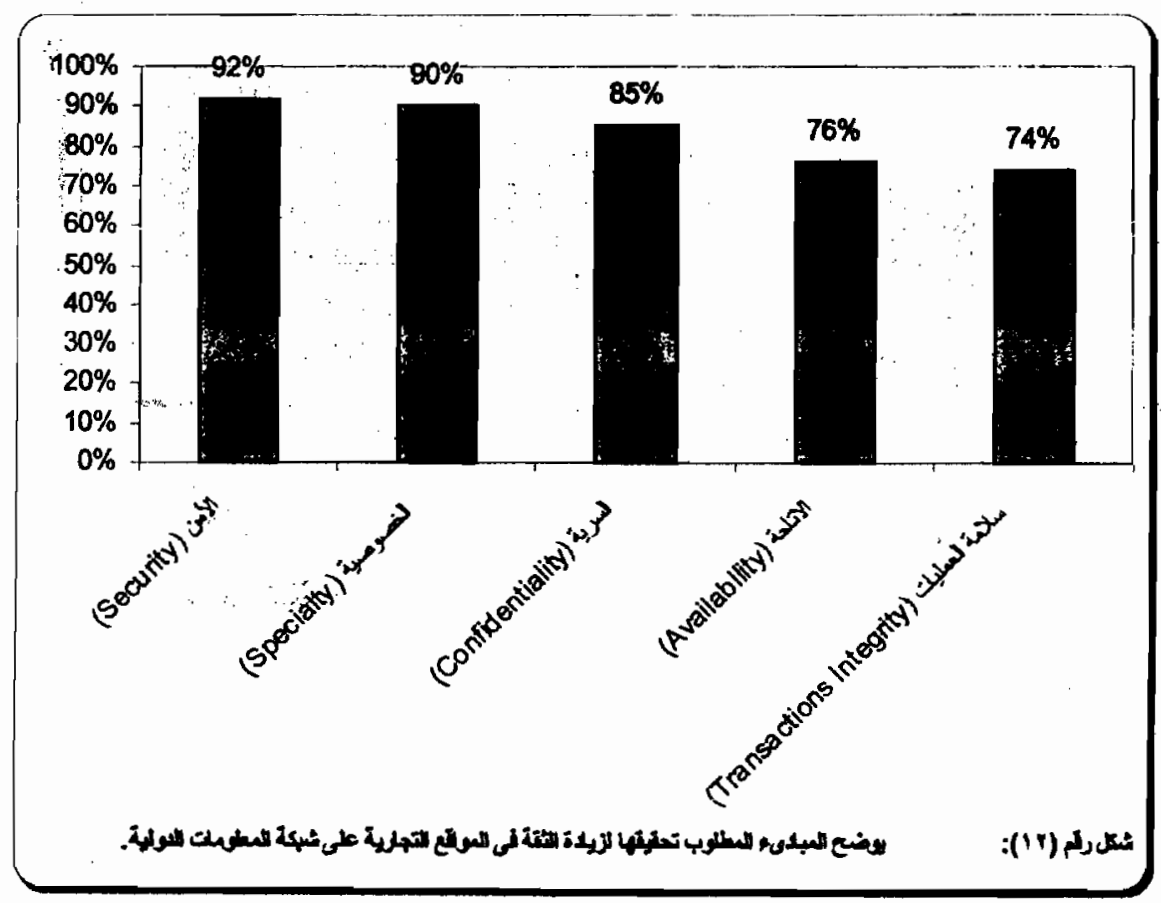

ويتضح من الشكل السابن أن مبادىء الأمن، الخصوصية، و السرية كان لها الأولوبة الأولى. وهذا يعنى مدى حرص الأفر اد على تجنب سرقة أو سوء الستخدام بياناتهم الخاصة عند ممارسة التجارة الاكترونية، للى الحد الذى يفوق حرصهم على ضمان تنفيذ الموفّع التجارى لالتز اماته. 


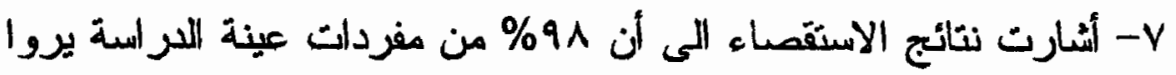

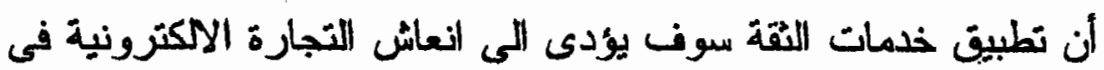

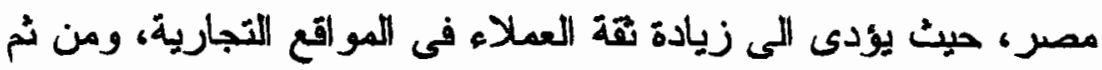

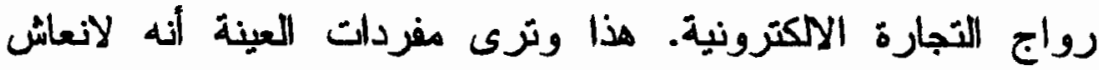
التجارة الاكترونية، بجب بالاضافة الى تطبيق خلمات الثقة أن ينت تحسين البنية التحتية ونشر الثقافة الاكترونية، ونلك كما بالشكل الآتى:

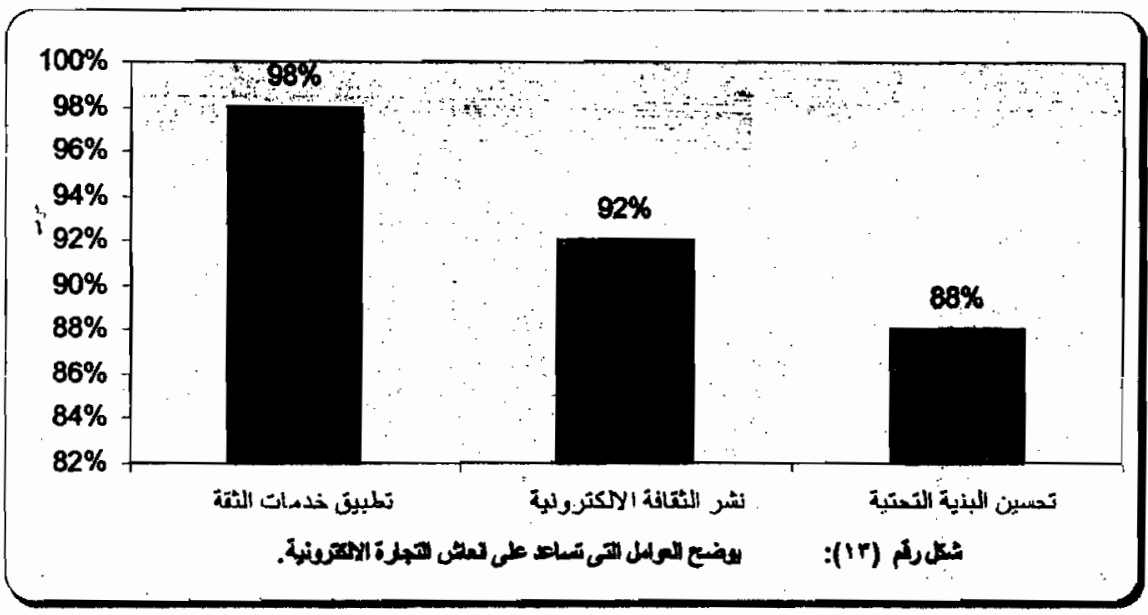

1- أشارت نتائج الاستقصاء الى أن مفردات عينة الراسة تزى أن

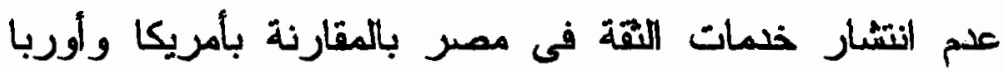

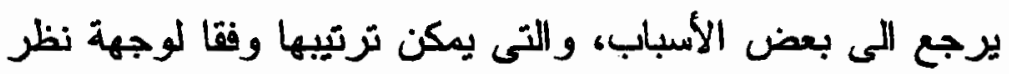

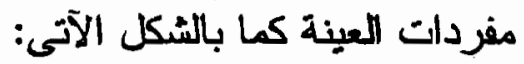

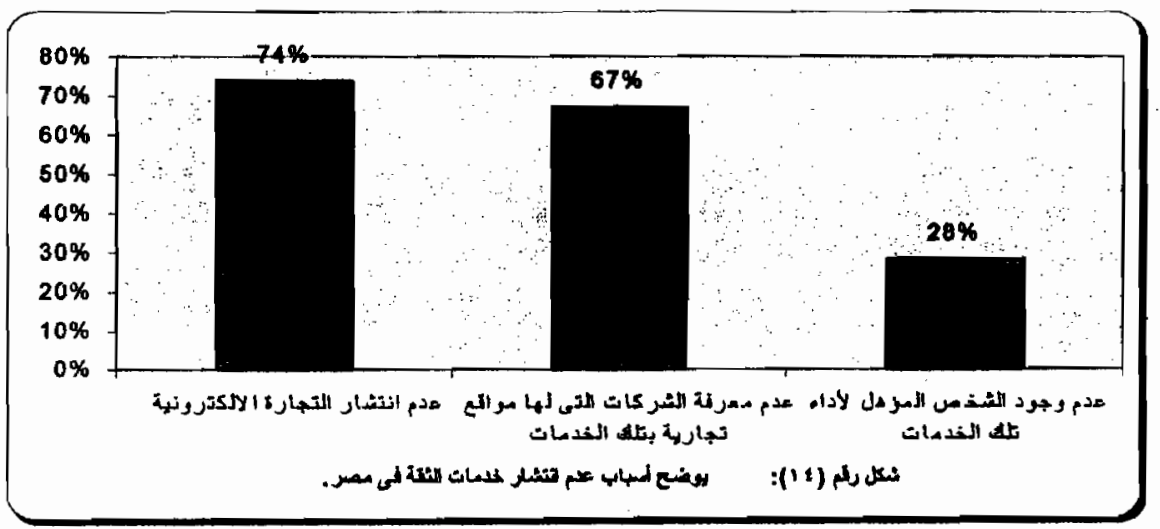


وهذا يؤكد على ضرورة الاعلان والتسويق الجيد لخلمات النقة فى في

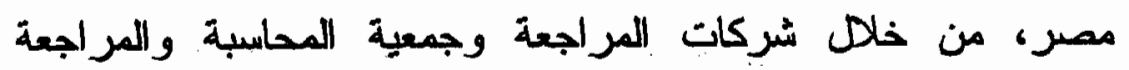

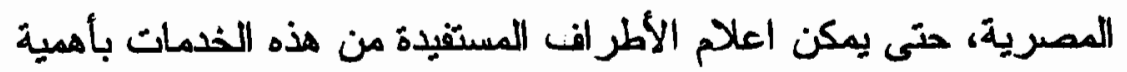
تطبيقها. هذا بالاضافة الى الاعداد و التريب الجيد للمر الجعين المصريين ليكونوا قادرين على تأية مثل هذه الخدمات، ويمكن أن تتظم جمعية

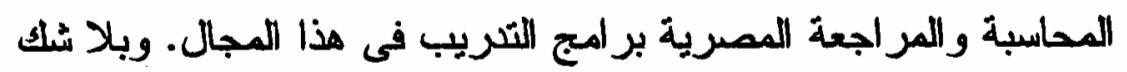

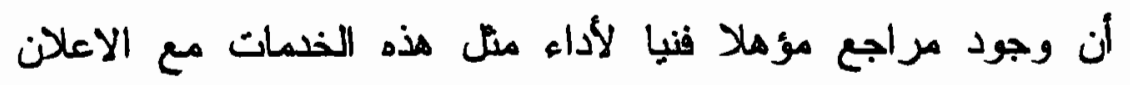

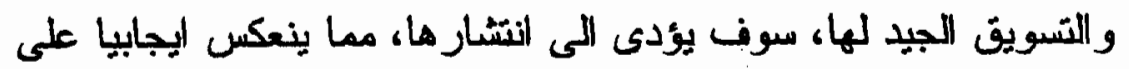

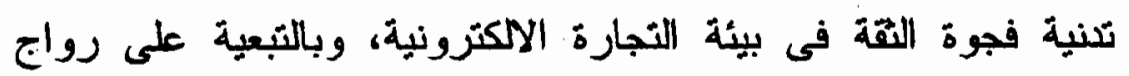
التجارة الالكترونية فى مصر .

9- أشارت نتائج الاستقصاء الى أن \& \& من مفردات عينة الدراسة

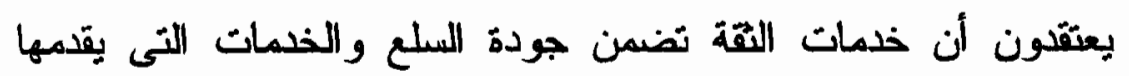

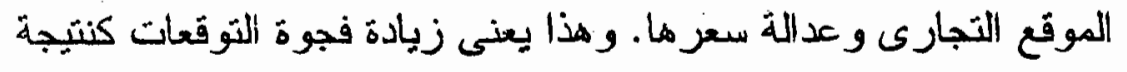

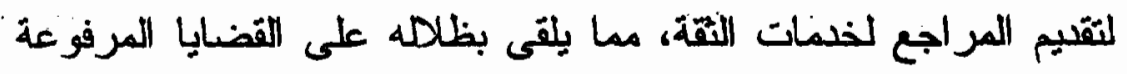

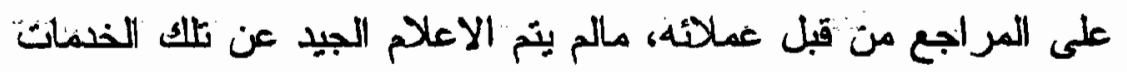
بأنها لا تضمن الجودة وعدالة السعر.

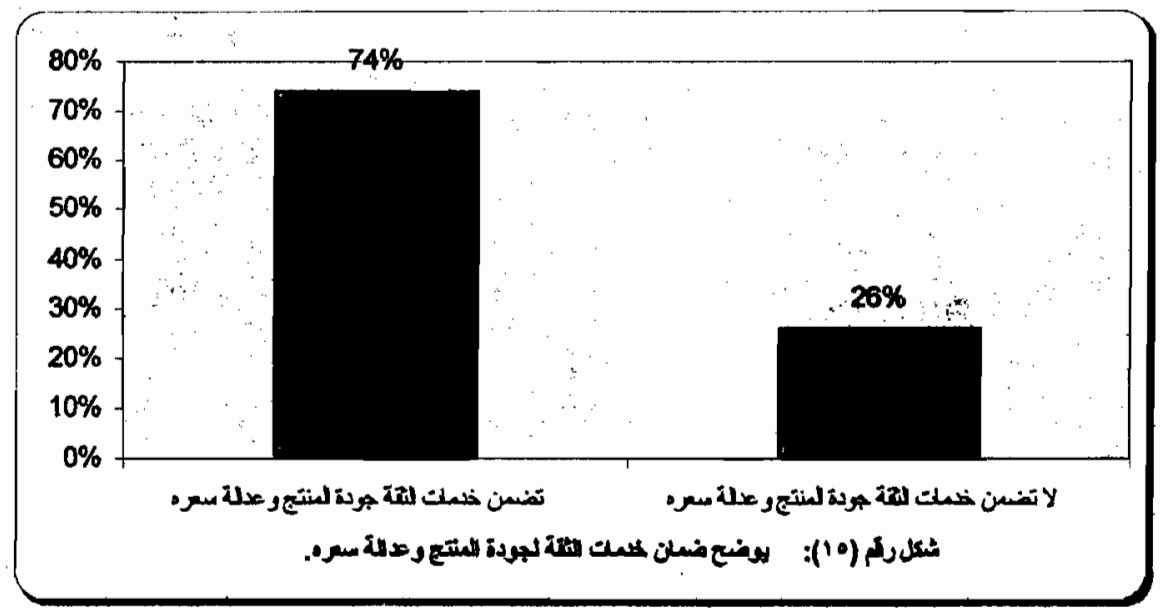




\section{؛ـ الخلاصة و النتائتج والتوصيات}

لقد أدى ظهور شبكة المطلومات الدولية والتوسع فى استخدامها

اللى ظهور التجارة الاككترونية، وعلى الرغم من مزاياها سواء من وجهة

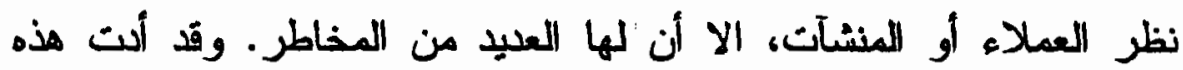

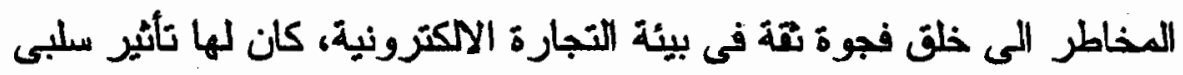
علىانثشار التجارة الاككترونية بالقدر الذى تستحقه. وقد فلعت فجوة الثقة العبد من المنشآت المتخصصة فى بناء وتأمين المواقع التجارية على شبكة

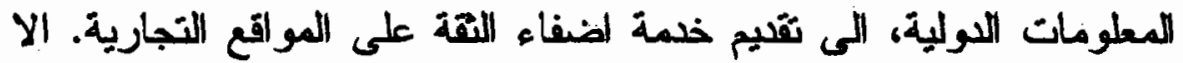

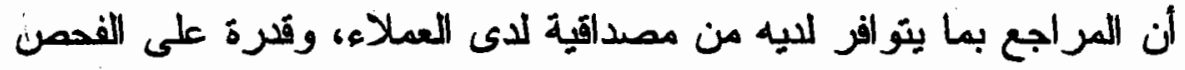

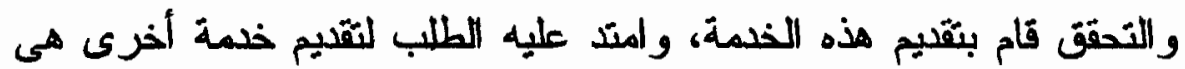
خدمة اضفاء اللقة على الأنظمة الأكترونية.

ونظرا للثقارب الكبير بين خدمتى اضفاء. الثقة على الأنظمة

الاككترونية والمواقع التجارية على شبكة المطلومات الدولية، قاما معهدى

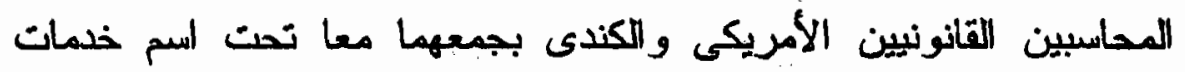
النقة، واصدار مجموعة من المبادىء والمعايير لتحكم المراجعين عند أدائهم لهذه الخمات. وتتمل مبادىء خدمات التقة فى: الأمن، الاتاحة، السرية،

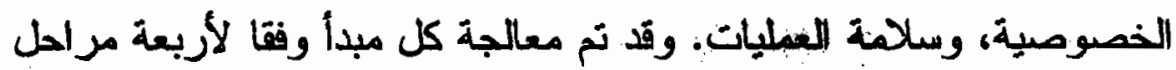

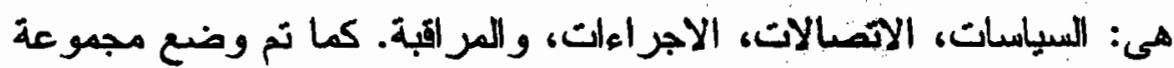
من المعايير وزعت على هذه المراحل بهدف تحقيق مبدأ معين.

ويهاف هذا للبهث الى التعريف بدور المراجع الخارجى فى التى

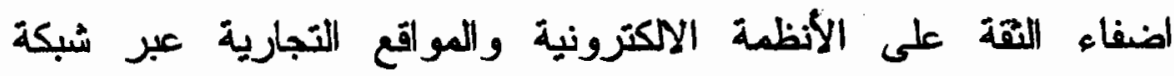
المعلومات الدولية فى ضوء المبادىء والمعايير التى أمدرها معهىى المحاسبين القانونيين الأمريكى و للكندى، ونلك كمساهمة منه في تكنية فجوة 
الثقة فى بيئة التجارة الاككترونية. ولتحقيق هذا الهلف تم اجراء دراسة استكثافية على ه01 مفردة. من طلبة الراسات العليا النين بمارسون التجارة

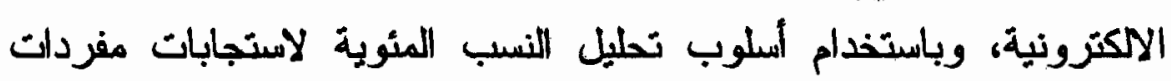
عينة الدراسة تم التوصل الى النتائج الآتية:

1- أن نسبة تتراوح بين 9 و 90\% من مفردات العينة تكرث أن

للتجارة الالكترونية مزاياها، وهى وفقا لترتيب مغردات العينة

$$
\text { كما يلى: }
$$

أ- عالمية الأسواق وتنوع السلع و الخدمات المعروضة.

ب-تخفيض تكلفة عملية الشراء.

تسرس عة تتفيذ عملية الشر اء.

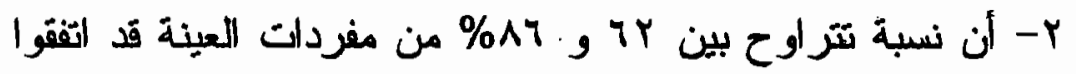

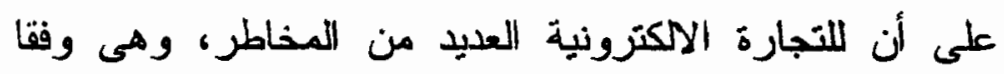

لترتيب مفردات العينة كما يلى:

أ- أ- مخاطر تثعلق بأمن البيانات.

ب-مخاطر تتعلق بخصوصنية البيانات.

ت-مخاطر تتعلق بسرية البيانات.

ث-مخاطر علم التزام الموقع بالجودة المطلوبة.

ج-مخاطر عدم التزام الموقع بالتفيذ.

ح-مخاطر انتشار الفيروسات.

r- أن . 9 \% من مفردات عينة الدراسة بمارسون التجارة الاكترونية بصورة جزئية، حيث يتم جمع المعلومات عن المنتج من خلال شبكة المعلومات الدولية على أن يتم الافع بطريقة

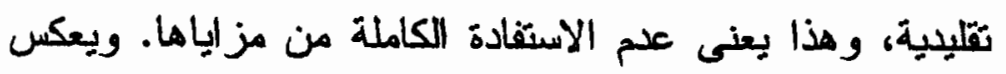


هذا نقص القةة في بيئة التجارة الاككترونية، وما يؤكد ذلك أن

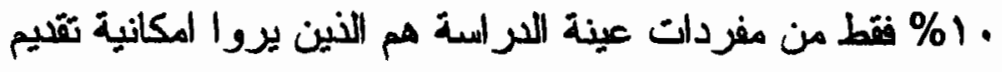
رقم بطاقة الاثتمان عند طلب الموقع لها، في حين أن نسبة مئة

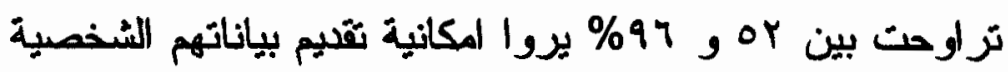

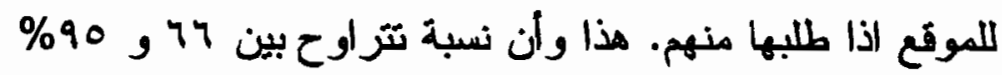

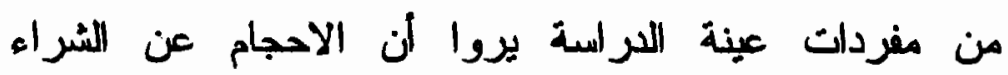

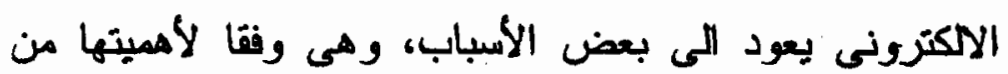
وجهة نظر هم كما يلمى:

أ- الخوف من سرقة الموقع للبيانات المالية. ب-الخوف من اختراق الموقع وسرقة البيانات الشخصية

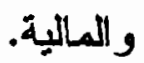

ت ت-الخوف من سوء استخدام البيانات الشخصية. ثأن الموقع لايفصح عن وسائل حماية بيانات العملاء.

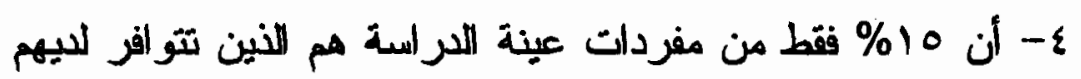

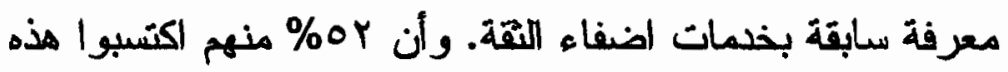

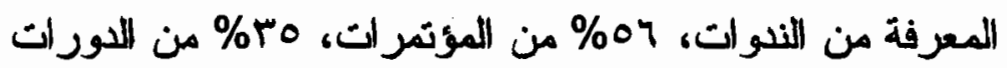

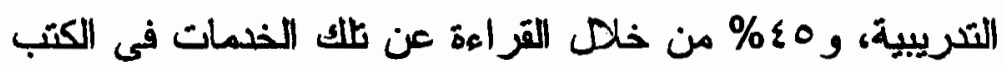
أو المجلات أو على شبكة المعلومات الدولية.

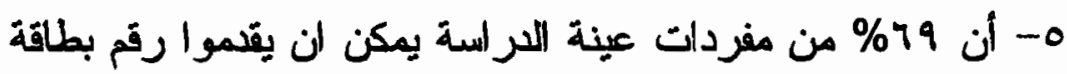

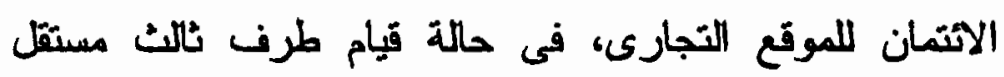

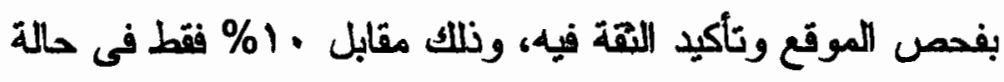

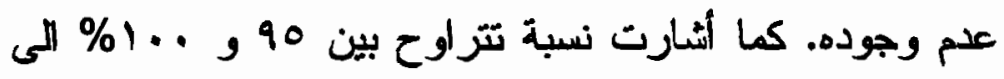

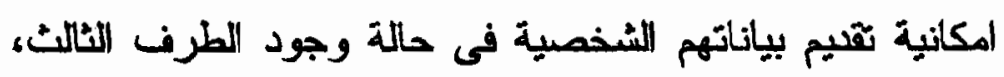

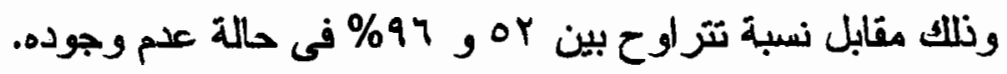

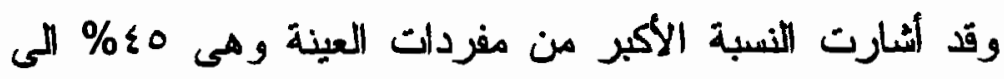


أنهم يفضلون أن يكون هذا الطرف الثالث مراجع خارجى مصرى أو عربى بالتعاون مع احدى الشركات الأجنبية لبناء

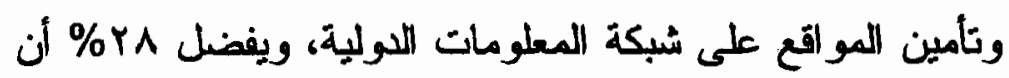

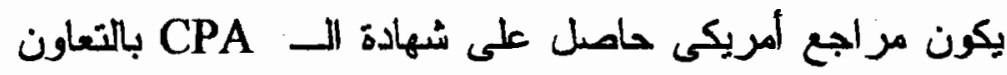

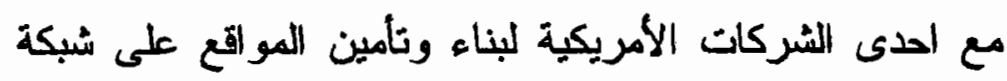

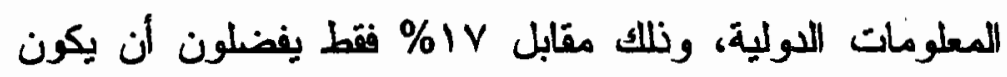

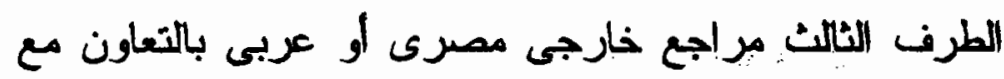

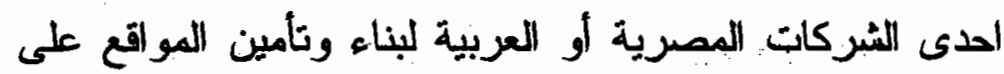
شبكة المعلوماتت الدولية. 7 - أهمية تحقيق كافة مبادىء خدمات اضفاء الثقة، لأغر اض زبيلدة نقة العملاء فى الشراء. المباشر من المواقع التجارية على شبكة

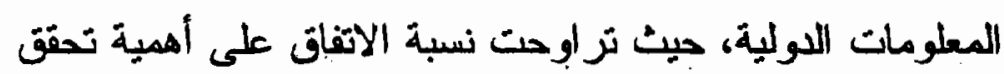

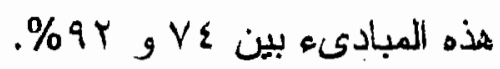

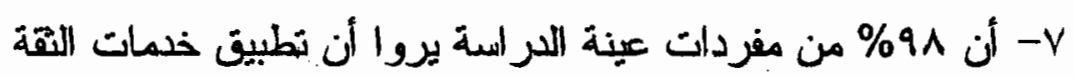

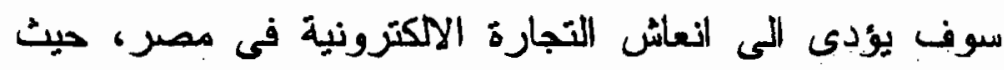

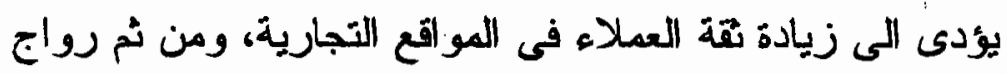

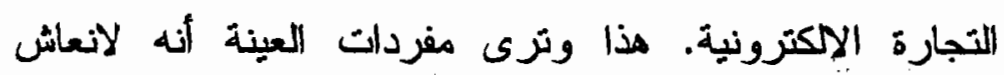

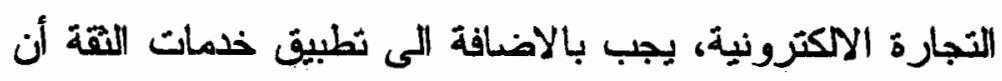
يتم تصسين البنية التحتية ونشر الثقافة الاكترونية. 1- ترى مفردات عينة الدراسة أن عدم انسّار خلمات الثقة فى ونى

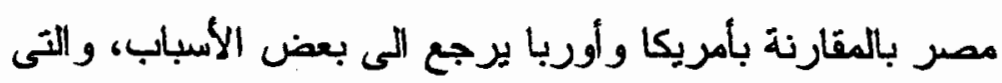

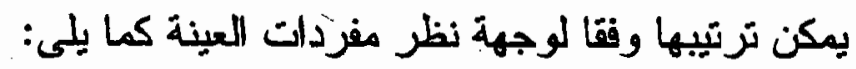
أ- عدم انتشار التجارة الالكترونية.

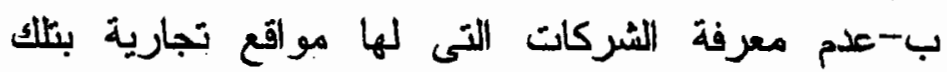


ت-عدم وجود الشخص المؤهل لأداء ثلك الخدمات.

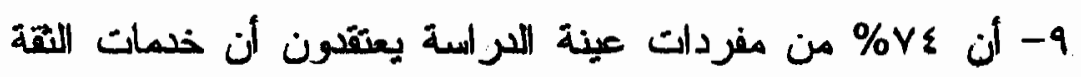
تضمن جودة السلع والخدمات التى يقمها الموقع التجارى

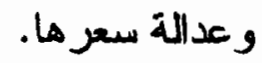

وعلى ضوء النتائج التى توصل اليها الباحث يوصى بالآتى:

ا- ضرورة تطوير التعليم الجامعى لمرطلة البكالريوس بكليات التجارة لطلبة المحاسبة، ليشّمل دراسة نظم شبكات الحاسبات، التجارة الالكترونية، اجراعات الرقابة الداخلية فى بيئة التجارة الاككترونية، وطرت فحص ومراجعة الأنظمة الالكترونية و المواقع التجارية على شبكة المعلومات الدولية.

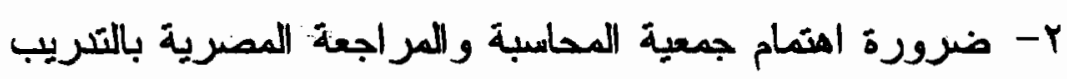
والتعليم المستَر للمراجعين، وبصفة خاضة غلى جلى أدوات وأساليب المراجعة فى ظل بيئة الحاسبات الاكترونية، مع وبهين المزيد من التركيز على فحص الأنظمة الاككترونية والمواقع فئ التجارية على شبكة المعلومات الدولية. r- ضرورة قيام المراجع الخارجى المصرى بتقديم خدمات الثقة، وذلك بالتعاون مع اخدى منشآت بناء وتامين المواقع التجارية على شبكة المعلومات الدولية وجمعية المحاسبة والمراجعة

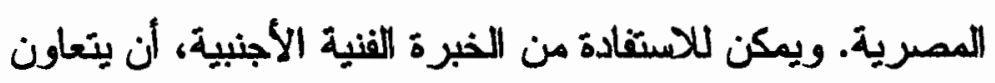

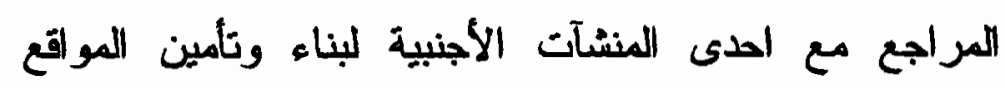
التجارية على شبكة المعلومات الدولية. ع- ضرورة قيام كل من: مكاتب المراجعة الخارجية وجمعية تَية

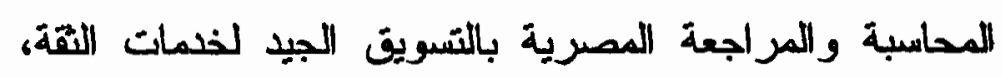


ونلك لاعلام كل من المنثآت التى لها مواقع تجارية على شبكة

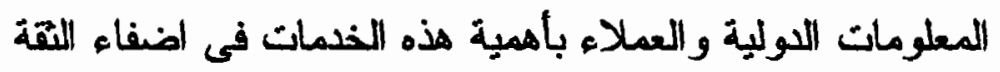

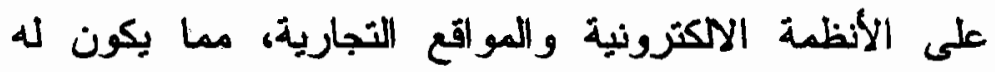
انعكاساته الإيجابية على الحد من خون العملاء، ومن ثم تثقلص فجوة الثقة وتزدهر التجارة الالكترونية لنكون عند المستوى الائه الذى تستحقه. 


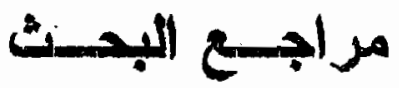

\section{أولا: المراجع العربية}

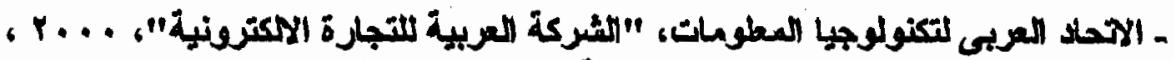

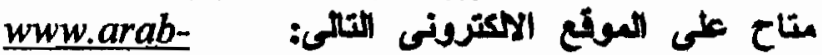
ita.org/itu company.asp. Accessed July 14

2005.

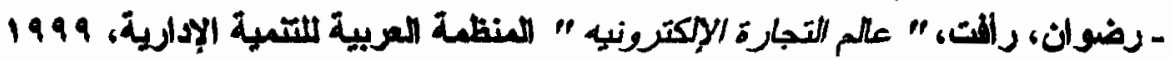

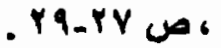

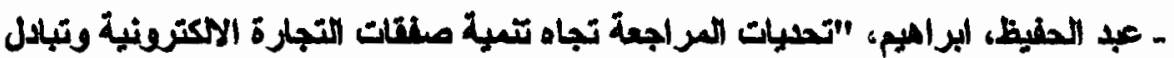

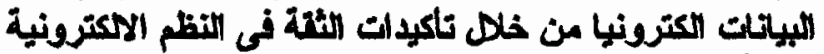

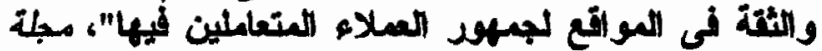

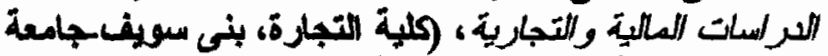

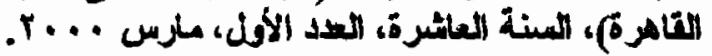

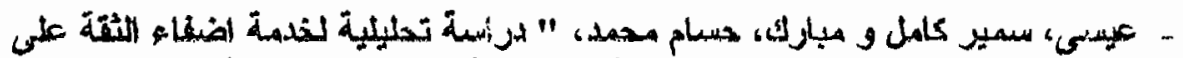

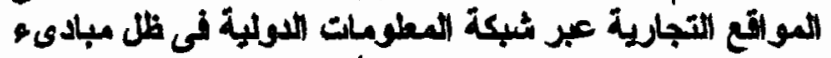

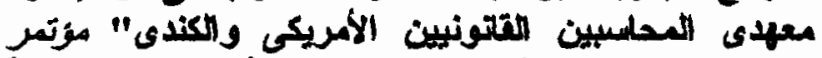

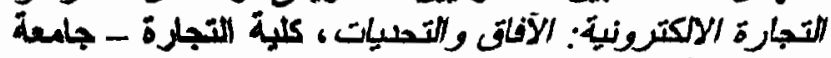

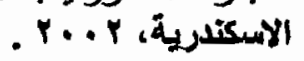

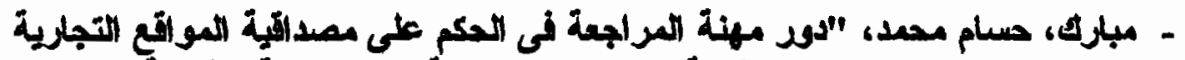

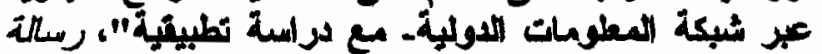

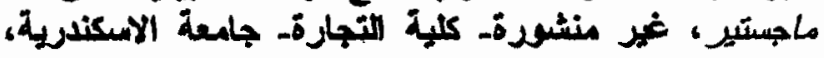

$$
\text { . } . . .0
$$

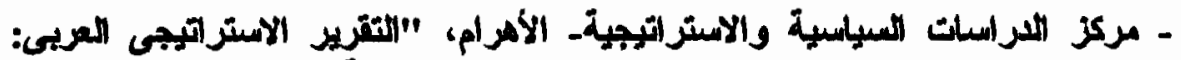

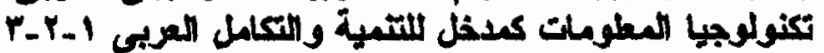

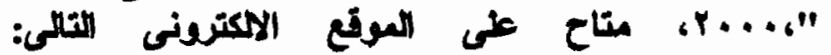
WWW.acpss.ahram.org.eg/index arabic.asp, Accessed July 142005. 

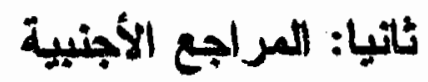

- AICPA / CICA, "Suitable Trust Services Criteria and Illustration for Security, Availability, Processing, Online Privacy, and Confidentiality (Including WebTrust and Systrust)", (April 2003), Available From: http://www.aicpa.org

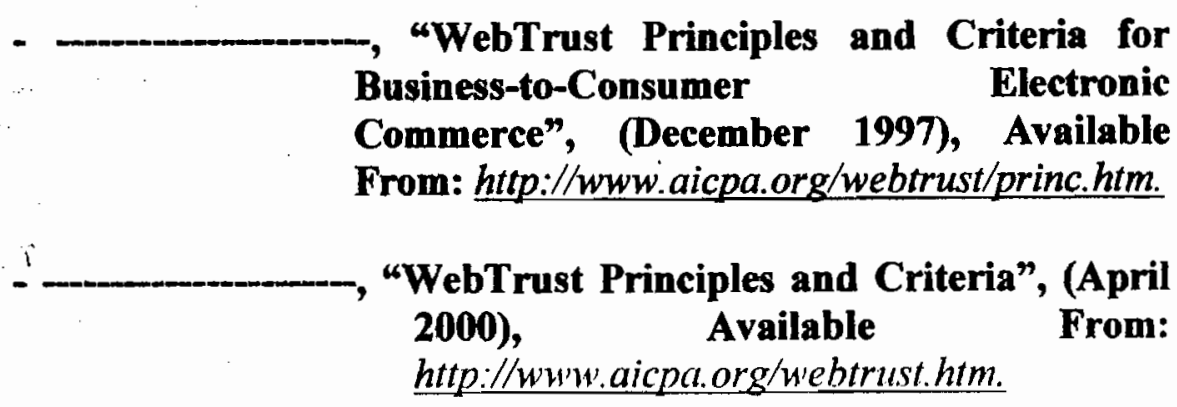

- AICPA, "What Skills Do I Need to Provide SysTrust Services", (2005), Available From:

https://www.cpa2biz.com/ResourceCenters/Inj ormation+Technology/SysTrust/None 00 aicp aorg_assurance Systrust skills what skill 09 917.htm.

- …_..., "What Skills Do I Need to Provide WebTrust Services", (2005), Available From: https://www.cpa2biz.com/ResourceCenters/Inf ormation+Technology/WebTrust/None 00 aic paorg assurance webtrust skills what skill 10057.htm.

- -----, "Why Should My Business Have a SysTrust/WebTrust Engagement?", (2004), Available From: http://www.webtrust.org/why have engageme nt.htm.

- Anderson, Alan W., "New Flash", The CPA Journal, (May 1999), Available From: http://www .nysscpa.org. 
- Cobn, Michael, “CPA Assurance Goes Online”, Accountant Media Group, (Feb 2001), Available From: http://www.electronicuccountant.com.

- Conviser, Becker, "Auditing 2004", Devry / Becker Educational Development Corp, (2004), PP. 52-53.

- Dialouge, C., "Security Fears Stop Women Buying Online", Reported by Nua Ltd, (January 2001), Available From: wwu:nua.ie/surveys.

- Elliott, R.K., "The Future of Assurance Services: Implication for Academia", Accounting Horizons, Vol.9, No.4, (December 1997), PP.119-127.

_- "Who Are We As A Profession- and What Must We Become", Journal of Accountancy, Vol.189, No.2, (February 2000), Available From:

htup://w'w'w.aicpa.org/pubs/jofalfeb200/elliott.htm.

- Fleming P., "Steering Course for The Future", Journal of Accountancy, Vol.188, No.5, (November 1999), PP.40-48.

- Gray, Glen L. and Debreceny, Roger, "The Electronic Frontier", Journal of Accountancy, Vol.185, No.5, (May 1998), PP.32-38.

- Hicks, J., "E-commerce and its Impact on the Accounting Profession", UNC Greensboro Journal of Student Research in Accounting, 2004, PP. 116.

- Houston, Richard W. and Taylor, Gray K., "Consumer Perceptions of CPA WebTrust Assurance: Evidence of an Expectations Gap", International journal of Auditing, (July 1999), Available

From:

http://www. ssrn.com. 
- International Federation of Accountants- Information Terhnology Committee, "Towards Competent Professional Accountants", (April 2003), Available From: http:// wuw ifac.org/Members/DownLoads/TowardsCompetent Profession.pdf.

- Koreto, Richard J., "In CPA We Trust", Journal of Accountancy, Vol.184, No.6, (December 1997), pp.62-68.

- Lanz, J., "The CPA and the Computer", The CPA Journal, (April 2002), Available From: http://www aicpa.org

- Milloy, M., Fink, D. and Morris, R., "Modeling Online Security and Privacy to Increase Consumer Purchasing Intent "Edith Cowan University, (2002).

- Odom, M., Kumar, A. and Saunders, L., "Web Assurance Seals: How and Why They Influence Consumer's Decisions", Journal of Information Systems, Vol.16, No. 2 (Fall 2002), PP. 231-250.

- Pacini, Carl and Sinason D., "Auditor Liability for Electronic Commerce Transaction Assurance: The CPA/CA WebTrust", American Business Law Journal, Vol.36, No.3, (Spring 1999), pp.479-505.

- Pitkow, J. and Kehoe, C., "(1997) $7^{\text {th }}$ WWW User Survey" Georgia Tech Research Corp., (June 1997), Availäble From: www.gvu.gatech.edu /user surveys.

- Portz, Kris, Joel M.Strong , Bruce Busta and Ken Schneider , “ Do Consumer Understand What WebTrust Means? ", The CPA Journal, Vol.70, No.10, (Oct 2000), PP.46-51. 
- Primoff, Walter M., "Electronic Commerce and WebTrust", The CPA Journal, (November 1998), PP.14-22, Available From: http://www.nusscpa.org.

- Pugliese, Anthony and Halse, Ronald "SysTrust and WebTrust Technology Assurance Opportunities", The CPA Journal, 2000, available from: www.nysscpa.org/cpaiournal/2000/1100/feature s/f112800a.htm.

- Richardson, W.T., "Benefits and Limitations of E-Business", University of Michigan Transportation Research Institute, (May 2004), Available from: www.witiger.com/ecommerce/benefitslimitions.htm.

- Salterio, S., “Expanding Assurance Services: An Update from The Assurance Services Executive Committee", American . Accounting Association-The Auditor Report, Vol.23, No.3, (Summer 2000), Available from: hitp://www.aaahq.org/audit/Pubs/Audrep/00su mmer/item03.htm.

- Schmidt, Walter, “Assurance Services”, The CPA Journal, Vol.68, No.5, (May 1998), PP.70-74.

- Sivasailam, N., Kim, D. and Rao, R., "What Companies are (n't) Doing about Web Site Assurance", 2002, Available from: $h t t p / / w w w . E$-commerce.com.

- Tribunella, T., "Twenty Questions on E-commerce Security", (January 2002), Available from: www.nysscpa.org/cpajournal/2002/0102/dept/d $016002 . \mathrm{htm}$. 


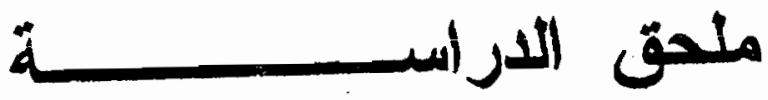




\section{الو : الاستخمساء}

فيعا بلى بعض الأسئلة التى تقيس مدى الالمام بالتجلرة الاكترونية ومدى فعلية خدمات اضفاء

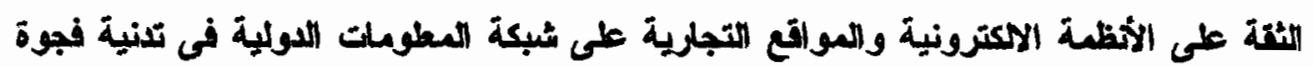

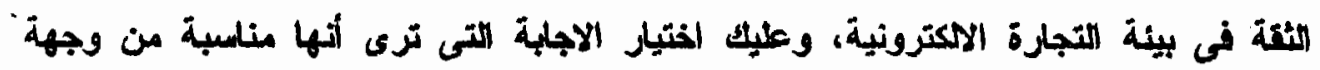

\begin{tabular}{|c|c|c|c|c|c|c|}
\hline \multirow[t]{5}{*}{ 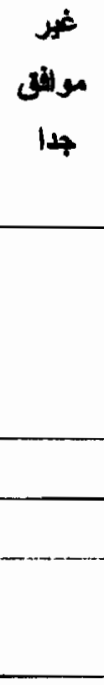 } & مواشق & مراثقد & لألى حو & ال & أواتث & \\
\hline & & & & & & 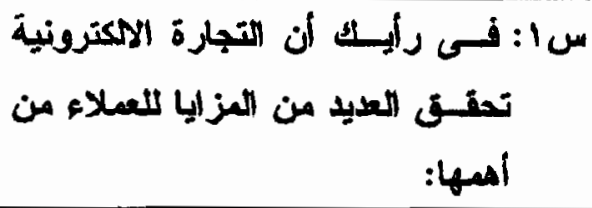 \\
\hline & & & & & & 1- تخفيض تكلقة علية لششراء. \\
\hline & & & & & & r- سرعة تلميذ علية الثقراء. \\
\hline & & & & & & 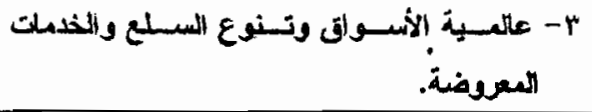 \\
\hline & & & & & & أ- مزايا أخرى (برجاء نكرما) \\
\hline
\end{tabular}

\begin{tabular}{|c|c|c|c|c|c|c|}
\hline \multirow[t]{8}{*}{ موالمير } & مغالمر & لمانى & المى حـ & أو & أجأli & \\
\hline & & & & & & سبץ: فسى رأيسك أن للتجارة الاكترونية \\
\hline & & & & & & 1- مخلطر اتتطلر الفيروسطت. \\
\hline & & & & & & r- مخلطر تتعلى بلمن البيركت. \\
\hline & & & & & & r- مخلطر تتعلى بخصوصية الميلاتت. \\
\hline & & & & & & | - مخاطر تتعلى بسرية البريتات. \\
\hline & & & & & & ه- مخلطر عدم التزام السوكع بلتثنيذ. \\
\hline & & & & & & و- مخاطر عمم التزام العوقع بلاجودة العطلوبة. \\
\hline
\end{tabular}




\begin{tabular}{|c|c|c|c|c|c|c|}
\hline موالثير & مراثقي & غير & 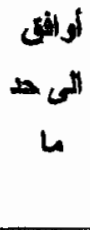 & أوالقى & الوالث & \\
\hline & & & & & & سلبك: عـند مسرستك للتجارة الاكترونية \\
\hline & & & & & & 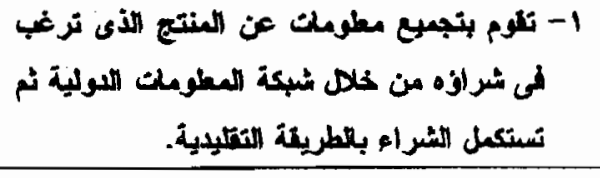 \\
\hline & & & & & & 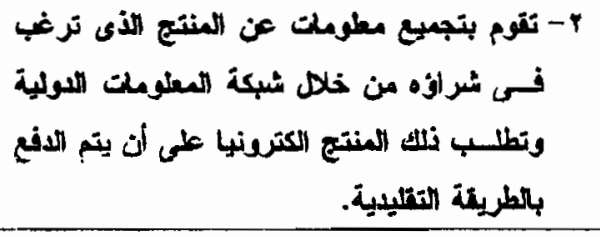 \\
\hline & & & & & & 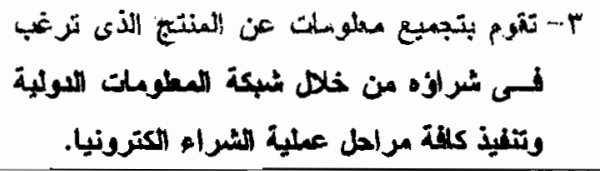 \\
\hline
\end{tabular}

\begin{tabular}{|c|c|c|c|c|c|c|}
\hline غولثير & غوانير & 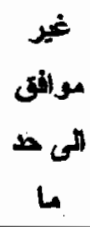 & 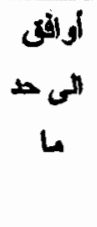 & أوانق & اولثا & \\
\hline & & & & & & 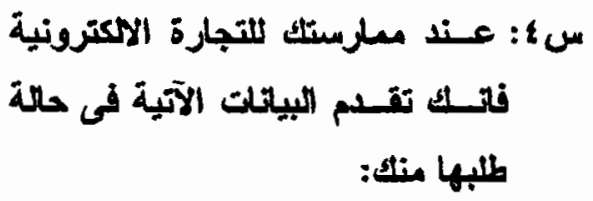 \\
\hline & & & & & & 1-1 الاسمب. \\
\hline & & & & & & ץ- رلم الهاتف. \\
\hline & & & & & & ז- البردا الاكترعنى. \\
\hline & & & & & & ع - العنوان. \\
\hline & & & & & & ه- رقم بطاقة الأنتسن. \\
\hline
\end{tabular}




\begin{tabular}{|c|c|c|c|c|c|c|}
\hline \multirow[t]{6}{*}{ موالمئ } & موآلقير & 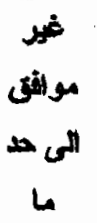 & 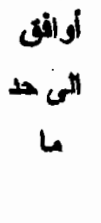 & (ail) & جأli & \\
\hline & & & & & & 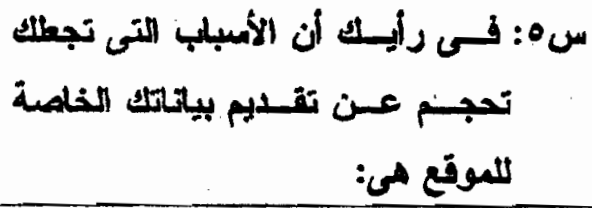 \\
\hline & & & & & & 1 - الخوف من سوء الستخدام لليوتات الثخصبة. \\
\hline & & & & & & 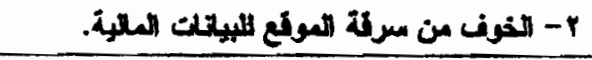 \\
\hline & & & & & & 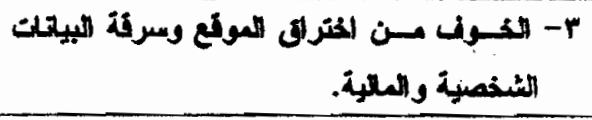 \\
\hline & & & & & & 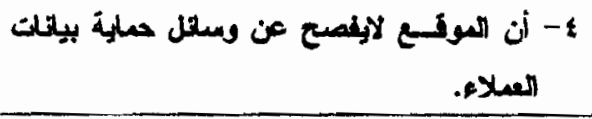 \\
\hline \multicolumn{7}{|r|}{ ه- لمبلب أخرى (يرجاء نكرها): } \\
\hline \multirow[t]{7}{*}{ مونمير } & موالثيز & غواتِّر & الم حأفقى & أوافق & جئ أوانق & - \\
\hline & & & & & & 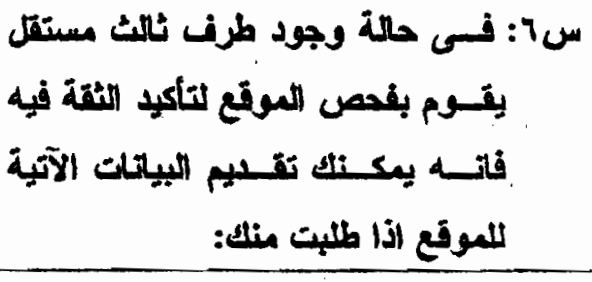 \\
\hline & & & & & & 1 الاسم. \\
\hline & & & & & & r- رقم الهلتف. \\
\hline & & & & & & r- البريد الاكترونتى. \\
\hline & & & & & & 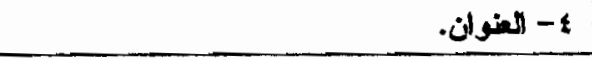 \\
\hline & & & & & & 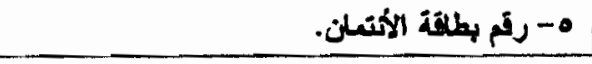 \\
\hline
\end{tabular}




\begin{tabular}{|c|c|c|}
\hline$y$ & \\
& & \\
\hline & & (Trust Services) \\
\hline
\end{tabular}

\begin{tabular}{|c|c|c|c|c|c|c|}
\hline موالقي & ميلير & 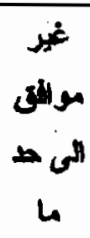 & $\begin{array}{r}\text { (1) } \\
\text { - } 4 \\
4\end{array}$ & الو & لو لوالقى & \\
\hline & ' & - & & & & 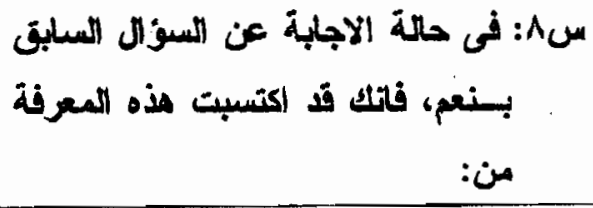 \\
\hline & & & & & & 1 ا ندوة. \\
\hline & & & & & & با - مؤتمر . \\
\hline . & & & & & & 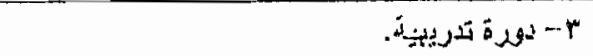 \\
\hline & & & .. & & & 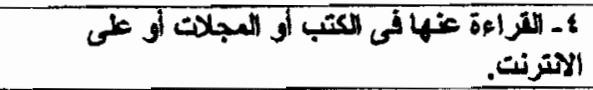 \\
\hline & & & & & & هـ مصلكر أفرى (برجاء ذيكرها): \\
\hline
\end{tabular}

\begin{tabular}{|c|c|c|c|c|c|c|}
\hline هالقيل & مغالقير & 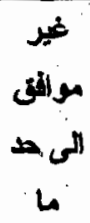 & 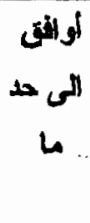 & أfill & جدالق & \\
\hline & & & & & & 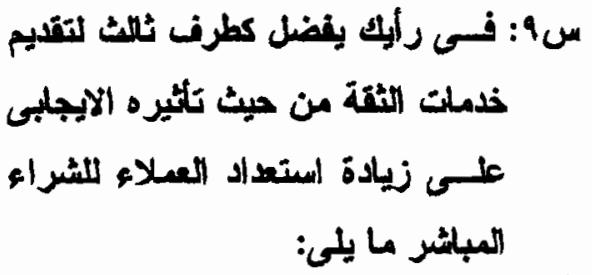 \\
\hline & & & & & & 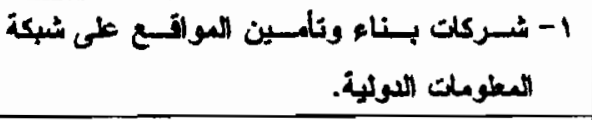 \\
\hline & & & & & & ب- مسراجع خارجى مصرى أو عربى بلتعالون مي \\
\hline
\end{tabular}




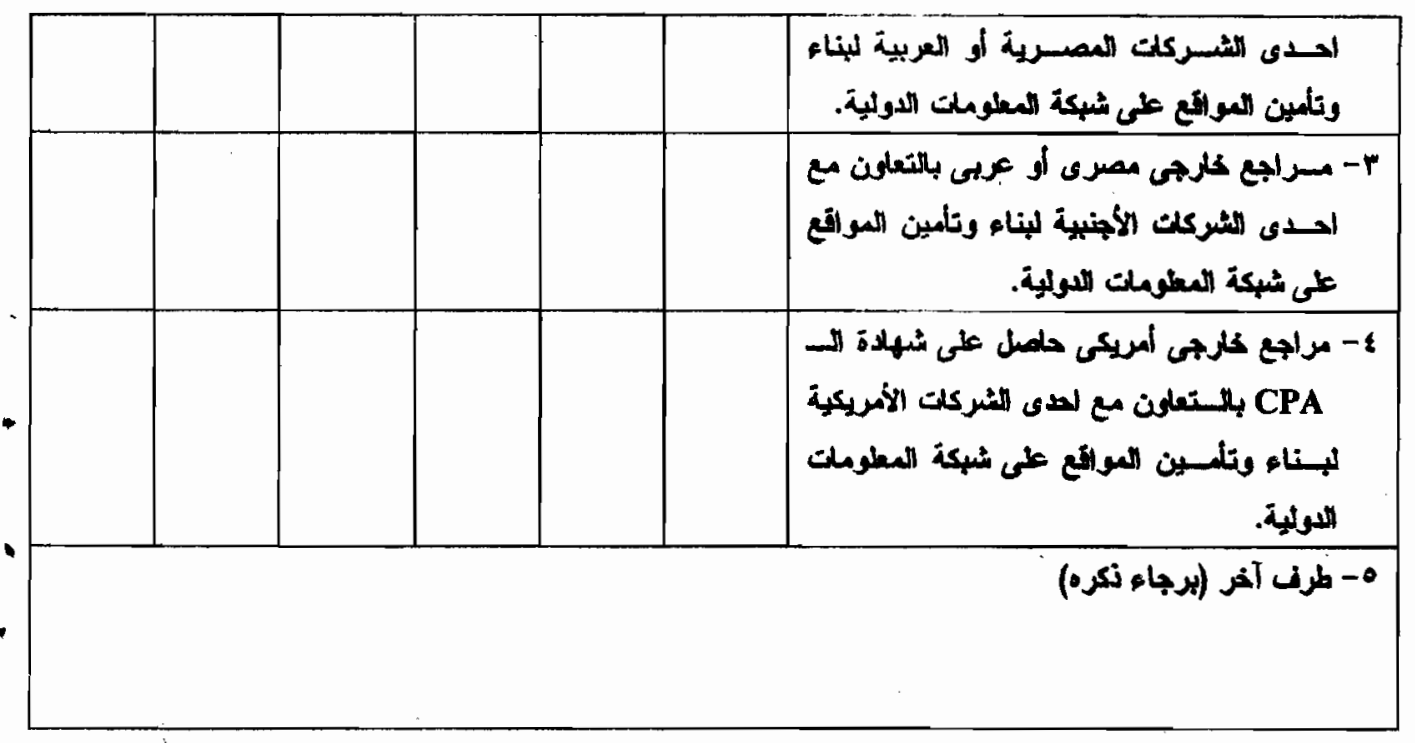

\begin{tabular}{|c|c|c|c|c|c|c|}
\hline مير ميلم & موالثير & مالقير & 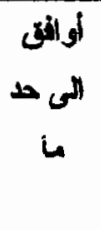 & أولنق & أوالما & \\
\hline & & & & & & س ، ا: فــى رأيك أى من العبادىء الآنية \\
\hline & & & & & & 1) الأمن (Security) -1). \\
\hline & & & & & & r- الخصوصبخ (Specialty). \\
\hline & & & & & & r (Confidentiality) (لسرية). \\
\hline & & & & & & (Availability) \\
\hline & & & & & & ه - سلكاة العلعيك (Transactions Integrity). \\
\hline & & & & & & ا - مبلدى أفرى (يرجاء نكرسا): \\
\hline
\end{tabular}



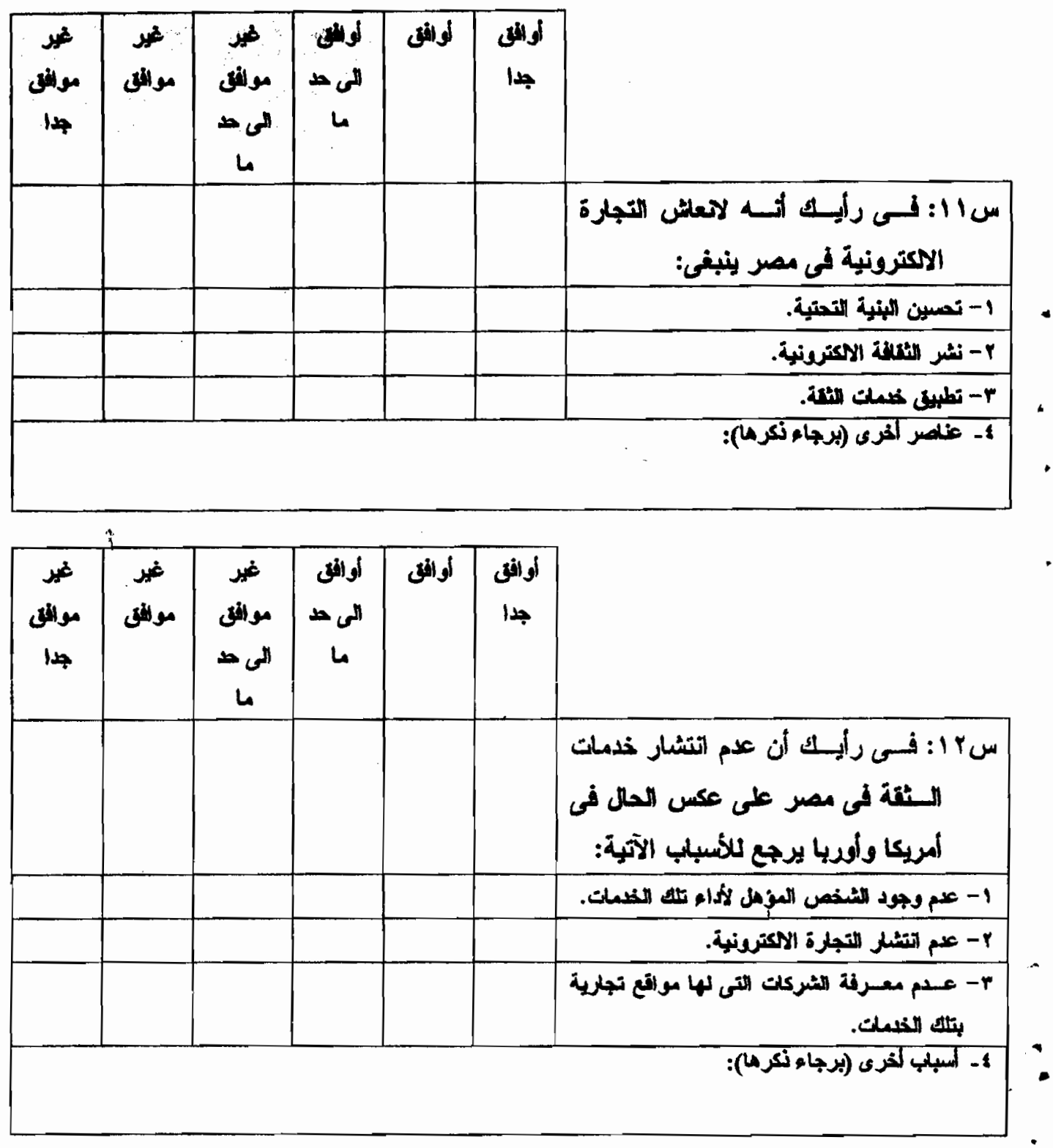

\begin{tabular}{|c|c|c|c|c|c|c|}
\hline $\begin{array}{l}y \\
\text { is }\end{array}$ & ysiel & 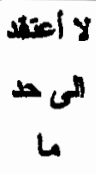 & 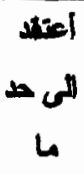 & أ أعits & أجنا & \\
\hline & & & & & & 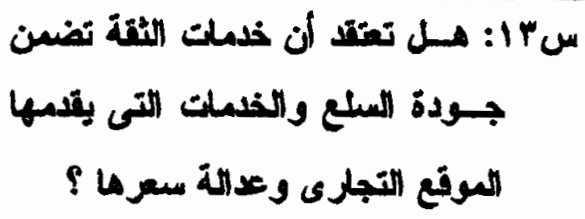 \\
\hline
\end{tabular}




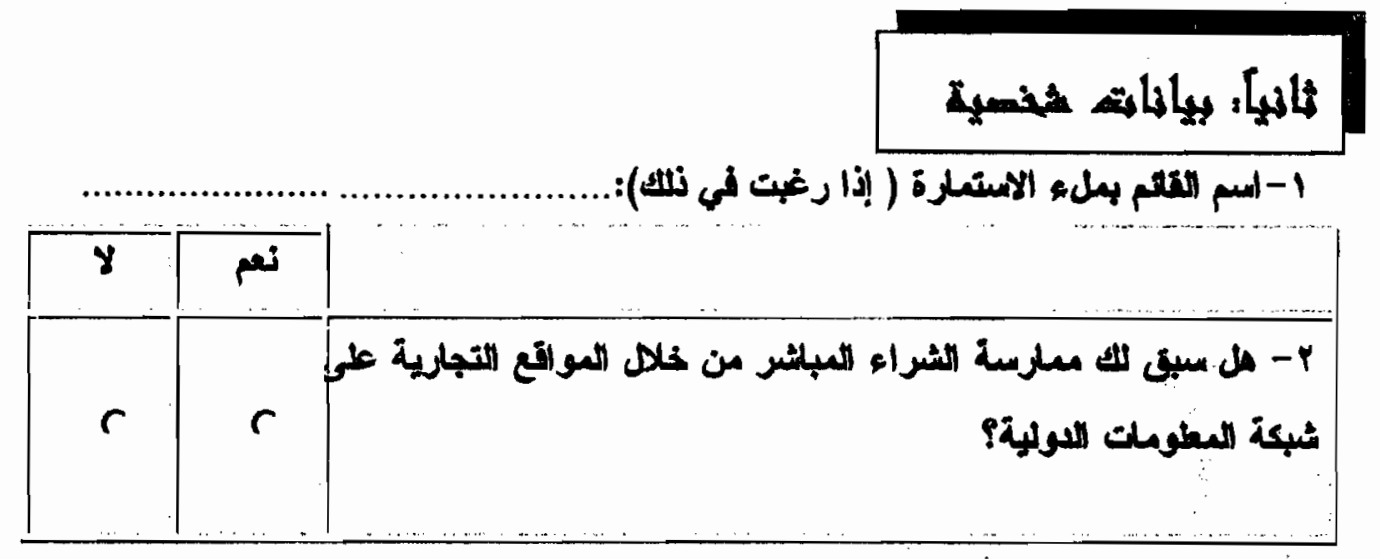

